\title{
Remembrance of things past : the cognitive psychology of remembering and forgetting trauma
}

Citation for published version (APA):

Geraerts, E. G. (2006). Remembrance of things past : the cognitive psychology of remembering and forgetting trauma. [Doctoral Thesis, Maastricht University]. Datawyse / Universitaire Pers Maastricht. https://doi.org/10.26481/dis.20060616eg

Document status and date:

Published: 01/01/2006

DOI:

10.26481/dis.20060616eg

Document Version:

Publisher's PDF, also known as Version of record

\section{Please check the document version of this publication:}

- A submitted manuscript is the version of the article upon submission and before peer-review. There can be important differences between the submitted version and the official published version of record.

People interested in the research are advised to contact the author for the final version of the publication, or visit the DOI to the publisher's website.

- The final author version and the galley proof are versions of the publication after peer review.

- The final published version features the final layout of the paper including the volume, issue and page numbers.

Link to publication

\footnotetext{
General rights rights.

- You may freely distribute the URL identifying the publication in the public portal. please follow below link for the End User Agreement:

www.umlib.nl/taverne-license

Take down policy

If you believe that this document breaches copyright please contact us at:

repository@maastrichtuniversity.nl

providing details and we will investigate your claim.
}

Copyright and moral rights for the publications made accessible in the public portal are retained by the authors and/or other copyright owners and it is a condition of accessing publications that users recognise and abide by the legal requirements associated with these

- Users may download and print one copy of any publication from the public portal for the purpose of private study or research.

- You may not further distribute the material or use it for any profit-making activity or commercial gain

If the publication is distributed under the terms of Article $25 \mathrm{fa}$ of the Dutch Copyright Act, indicated by the "Taverne" license above, 
REMEMBRANCE OF THINGS PAST:

The Cognitive Psychology of

Remembering and Forgetting Trauma 


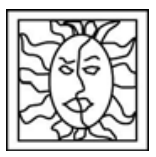

(C) E Geraerts, TONGEREN 2006

OMSLAGONTWERP \& LAYOUT: designocima ${ }^{\circledR}$, www.designocima.com

COVER ILLUSTRATION: Proust remembers (Proust Series). Painting reproduced with permission of Ann Baldwin

DRUK: Datawyse

ISBN-10: 9080771562

ISBN-13: 9789080771567 


\section{REMEMBRANCE OF THINGS PAST: The Cognitive Psychology of Remembering and Forgetting Trauma}

\section{PROEFSCHRIFT}

ter verkrijging van de graad van doctor aan de Universiteit Maastricht, op gezag van de Rector Magnificus, Prof. mr. G.P.M.F. Mols, volgens het besluit van het College van Decanen, in het openbaar te verdedigen op vrijdag 16 juni 2006 om 14:00 uur

door

Elke Ghislaine Geraerts 


\section{PROMOTORES}

Prof. dr. H. L. G. J. Merckelbach

Prof. dr. J. van Heerden

\section{COPROMOTOR}

Dr. M. Jelicic

\section{BEOORDELINGSCOMMISSIE}

Prof. dr. C. de Ruiter (voorzitter)

Prof. dr. A. Arntz

Prof. dr. T. Brennen (University of Oslo, Norway)

Dr. B. M. Jansma

Prof. dr. R. J. McNally (Harvard University, United States) 
"Il y avait déjà bien des années que, de Combray, tout ce qui n'était pas le théâtre et le drame de mon coucher, n'existait plus pour moi".

Marcel Proust, 1913, p. 58; A la Recherche du Temps Perdu. Volume 1 : Du côté de chez Swann.

"Many years had elapsed during which nothing of Combray, save what was compromised in the theatre and the drama of my going to bed there, had any existence for me".

Marcel Proust, 1923, p. 58; Remembrance of Things Past. Volume 1: Swann's Way. 



\section{CONTENTS}

Acknowledgments $\quad 9$

$\begin{array}{ll}\text { Cases of Recovered Memories } & 13\end{array}$

$\begin{array}{lll}\text { CHAPTER I } & 17\end{array}$

PART $1 \quad$ AMNESIA AND TRAUMA

CHAPTER 2 Traumatic Memories in War Veterans:

Not So Special After All $\quad 35$

CHAPTER 3 Retrieval Inhibition of Trauma-Related

Words in Women Reporting Repressed or

Recovered Memories of Childhood

Sexual Abuse $\quad 49$

PART 2 FALSE AND RECOVERED MEMORIES

CHAPTER 4 Fantasy Proneness, but not Self-Reported Trauma is Related to DRM Performance of Women Reporting Recovered Memories of Childhood Sexual Abuse

CHAPTER 5 Dissociative Symptoms and How They Relate to Fantasy Proneness in Women Reporting Repressed or Recovered Memories 


\section{CONTENTS}

PART 3

CHAPTER 6

PART 4

CHAPTER 7

PART 5

CHAPTER 8

CHAPTER 9

CHAPTER 10
OVERREPORTING AND TRAUMA

Symptom Overreporting and Recovered

Memories of Childhood Sexual Abuse

ASSESSING PRIOR REMEMBERING

Forgetting of Prior Remembering in Persons

Reporting Recovered Memories of Childhood

Sexual Abuse

REPRESSIVE COPING AND MEMORY

Long Term Consequences of Suppression of Intrusive Thoughts and Repressive Coping

Suppression of Intrusive Thoughts and Working Memory Capacity in Repressive Coping

General Discussion

153

Notes

Summary

Samenvatting

179

Works Cited

Author Affiliations

Curriculum Vitae

List of Publications 


\section{ACKNOWLEDGMENTS}

Finally! The opportunity to thank everyone who has been involved in my $\mathrm{PhD}$ project!

First of all, I would like to thank the team who stood behind me during my PhD project: Jaap van Heerden, Marko Jelicic, and Harald Merckelbach (in order of appearance). Jaap, I cannot top your description of our conversations as being non-worldly. Although not frequent, I really loved them. I haven't met many people in my life who are as kind and erudite as you are. I am pleased that you let me go my way and do the things I liked to do. I owe a lot of my success as a researcher to Marko Jelicic. Marko, already as an undergraduate student, you taught me a lot about how to conduct research and write articles. As a PhDstudent, I was very grateful that you instantly agreed to become my copromotor. This stimulated me to carry on and conduct the research I really liked to do. Thanks a lot! Harald, thank you for lots of inspiration. I am really happy that I could work with you and learn from so many of your enlightening ideas. Although you have always claimed that your contribution to this thesis was small, the contrary is true!! Many of the studies reported in this thesis were realized because of your instantaneously generated thoughts. Thank you so much for this! Marko and Harald, I also really appreciate that both of you were always willing to support my research and conference trips (mentally and financially).

Richard McNally and Susan Clancy, your innovating research with people reporting repressed and recovered memories inspired me to conduct similar studies. Rich, thanks so much for being here today, as it means a lot to me. I am looking forward to visiting Harvard University and learning from your experience.

Dragica Kozarić-Kovačić, I really enjoyed my visits to the National Psychotrauma Centre in Zagreb (and of course the NATO conference in Dubrovnik). I am really thankful that you were willing to participate in the studies with all of the war veterans. Also many thanks to the whole staff of the Centre who have spend so much time on this project. I am really looking forward to continuing our nice projects. 
Jonathan Schooler, it's great working with you. I really benefited from our brainstorms about recovered (please read: discovered) memories and I am pleased that your ideas instigated me to seek the middle ground as well.

Steve Lindsay and Michelle Arnold, working with you was so great. Steve, I really liked our sharp e-conversations and I can't wait for our beautiful symposium in Sydney in a few weeks. I am grateful that I can work with such a brilliant researcher as you are. Michelle, I knew it all along that you are a great researcher and I loved our brainstorms about the FIA effect.

So, Tim Brennen, it looks like you are becoming a part of the Maastricht scenery... dearie me! Besides discussions about wegom/egging, Softit, tuna guides, Roger Daltrey, and Shakespeare, I really liked the "riveting" conversations about our related studies and teaching!

Bettina Sorger, Petra Habets, and Rainer Goebel, your knowledge about fMRI combined with our experience on recovered memories looks very promising. Thanks for all the time you are investing in this project.

I also want to thank my colleagues at the Department of Neurocognition and the Department of Experimental Psychology. I had the good fortune of being a "mixed product" of both departments and I loved getting to know so many people.

Also many thanks to all the members of the "Interfacultary Psychology \& Law" (IRP) group: our retreats in the Belgian "mountains" were really pleasant and inspiring. My colleagues in the PsyLaw group, Beatrijs, Corine, Ewout, Harald, Ingrid, Kim, Maarten, Marko, Robert, Saskia, Timo and Tom: thanks for the nice coffee breaks and collegiality. Also a special thanks to Corine de Ruiter for being such a good chair of the assessment committee of my thesis.

Ingrid Candel and Bettina Sorger, thanks for being my paranimfs. Ingrid, it's great that we can share all our thoughts about so many things. I am looking forward to working with you in the years to come! Bettina, your huge knowledge on fMRI, as well as your cheerfulness make it great to work with you! I am glad you are standing next to me today.

I want to thank my parents for the love and support they gave me throughout all of these years. Christophe, thanks a lot for your understanding that I wasn't around much lately. It's so great that you are supporting all the things I do. And thanks for so much more...

Last, but so not least: the research described in this thesis wouldn't have existed without the help from all of the people who were willing to 


\section{ACKNOWLEDGMENTS}

participate and all the students who helped me with testing the participants. It really encouraged me that participants were sending me e-mails to tell me how much they liked being part of the studies. Clearly, an encouragement to go on with this kind of research! 



\section{CASES OF RECOVERED MEMORIES}

\section{CASE 1}

Elizabeth Janssen, a 53-year old woman, came into my office with one of the brightest smiles I had ever seen. With gray short-cut hair and her colourful clothes, she immediately made a very self-confident and attractive impression. She started talking incessantly. She had been a successful business woman for many years and had been travelling all around the world for her work. New York, Paris, Shanghai, Sydney, just name it: she had been there. Elizabeth and her husband Carl had a good life, and together with their two daughters, they formed a happy family. However, it had not always been like this. Nine years ago, Elizabeth became very depressed. Her marriage was falling apart and she even quit her job for a while. Elizabeth and Carl went to a marriage counsellor to solve their problems. After several sessions, the therapist referred them to a colleague of hers because she could not figure out why they stopped caring for each other and why their sex life was unsatisfactory. Elizabeth and Carl then started individual therapy with this psychiatrist. Almost immediately, Elizabeth was diagnosed with a major depressive disorder. She was told that she had to uncover her repressed memories of early childhood abuse, as this was the underlying cause of her disorder. At first, Elizabeth vehemently denied having been abused, and certainly not by her beloved father, like her psychiatrist insinuated. Her psychiatrist, however, insisted that a childhood trauma must have happened to her; he had seen the same symptoms in so many patients and she was no exception to this. He started using guided imagery in a suggestive manner, with Elizabeth being instructed to imagine scenes of the supposed abuse even though Elizabeth continued to deny, although less fervently, that she had such memories. Because no abuse memories were surfacing yet, Elizabeth was given books about child abuse survivors to read; she was told that if something felt uncomfortable to her while reading these books, this would indicate that similar things had happened to her. Moreover, in order to help Elizabeth remember the 
childhood abuse, hypnosis was used during her therapeutic sessions. After about two months of intense therapy, Elizabeth had gradually recovered clear and vivid images of being abused by her father. She told me that she can still see herself lying in bed as her father came into her room at night. While she was very anxious, he performed terrible and painful sexual acts on her. "Yes, even penetration". These traumatic events allegedly had continued until she went to boarding school when she was 12 .

Meanwhile, Elizabeth's husband Carl had been in therapy as well. He saw the same psychiatrist. He was told that not only his wife showed depressive symptoms, but that he also suffered from depression. After several weeks, Carl had recovered being sexually abused by several priests while being at boarding school. "No, Carl doesn't want to participate in this study, as he still isn't able to talk about it with others, except for me", Elizabeth said.

When I asked her how she had felt after recovering these abuse memories, Elizabeth told me that she had never felt such a relief. It turned out that not she, but her father was responsible for her depression. The consequence of these recovered memories was that she broke off all contact with her parents. The contact with her sister and brother also became very infrequent since they still did not believe her story at all. Elizabeth told me that, even though all these horrible events had happened to her, she was very happy that she had found a reason for her depressive episodes. I assume that she is happy now; after all, she has one of the brightest smiles I had ever seen.

\section{CASE 2}

Mary de Vries was a good-looking young woman, aged thirty-five. Although she was shy at first, she became talkative after a while. For several years, she had been working in the hospital in Maastricht as a paediatric nurse. She had a happy marriage and a 3-year old daughter. She had been very happy, that after several years of trying, she had finally become pregnant. However, the birth of her daughter Lynn also elicited some serious problems. When Mary came back home with Lynn from the hospital, she felt very uncomfortable when her husband was taking care of their baby. Moreover, she almost never left him alone with their daughter; she always wanted to be there when he was washing her or changing her nappies. She really could not stand the thought of her husband doing something bad to Lynn. Frequently, her mistrust towards him had resulted in 
heavy arguments between the couple. Mary wished she could explain her feelings to her husband, but even she did not know why she mistrusted him that much.

Almost at the same time, her mother fell ill. Her mother had been living alone in her large villa on the Belgian coast since her second husband, Mary's stepfather, had left her several years ago. Mary reassured her mother and told her that she would come over for a couple of days with her baby Lynn and would help her with the housekeeping.

While she was cleaning her mother's house, she also entered her former bedroom. Mary told me that she suddenly had a complete recollective experience in which "a whole series of pictures were running through my head". It was a cascade of memories, very much like the flow of memories that Proust describes in his novel Swann's Way (1923). She was horrified, shocked, overwhelmed, surprised, and entirely baffled at the same time. Suddenly she remembered vulgar events that had happened to her in that room. She remembered that her stepfather had approached her several times while she was playing there. He had fondled her genitals several times. It took Mary more than an hour before she was able to go back to her mother who was resting in the living room. She just could not talk about these horrible memories that had come back to surface just an hour ago. She did not want to upset her mother because she was already in such a bad condition. A few days later, when Mary got back home, she called her sister who lived in Prague. Her sister immediately noticed that something was wrong. That was why Mary told her what had happened at their mother's place. First, her sister said nothing at all. After a couple of minutes, she told Mary that she had always vividly remembered that she had been molested by their stepfather as well. 

CHAPTER 1

General Introduction 


\section{FROM FREUD TO THE MEMORY WARS}

Are individuals like Elizabeth and Mary able to forget a traumatic experience such as being sexually abused? This question pertains to one of the most contentious controversies in psychology and psychiatry. The idea of repression was propagated by Freud (1915/1957) - a notion which Freud had borrowed from Herbart's analysis of unconscious percepts (Herbart, 1816/1881). Freud employed in different publications radically different definitions of repression. In some of his monographs, he considered repression to be an automatic defense mechanism banning aversive memories or experiences from consciousness, while in other books, he thought of repression as a conscious, deliberate process, including active avoidance (see also Erdelyi, 1990, in press). According to Freud, repressed memories of sexual abuse in early childhood caused hysteria. Later, however, he abandoned this theory, concluding instead that his patients had only imagined their abuse, and that only few of them had actually been maltreated.

Over the past 15 years, Freud's essential ideas have been revived by proponents of the view that unconscious memories of a trauma like childhood sexual abuse (CSA) underlie many forms of adult maladjustment and psychopathology (see, for example, Bass \& Davis, 1988; Frederickson, 1992; Herman, 1992; Terr, 1994). The concept of repressed memories is controversial and has led to, what is sometimes dubbed, "the memory wars" (Crews, 1995; Schacter, 1996). On the one hand, pursuing Freud's legacy, several clinical theorists hold that the mind can protect itself by expelling the most terrifying experiences from awareness. As Brown, Scheflin, and Hammond (1998, p. 97) argued, "when emotional material reaches the point of being traumatic in intensity - something that cannot be replicated in artificial laboratories - in a certain subpopulation of individuals, material that is too intense may not be able to be consciously processed and so may become unconscious and amnesic". Conversely, many psychologists hold that abuse, combat, and other overwhelmingly horrifying events are ostensibly imprinted in memory and are hardly ever, if ever, truly forgotten (e.g., Kihlstrom, 2004; McNally, 2003a, 2005a; Pope, Oliva, \& Hudson, 1999).

For example, Roediger and Bergman (1998, p. 1095) argued that it is "mysterious how painful events, banished to an unconscious state for years through mechanisms of dissociation or repression could be brought back to consciousness and recollected with great fidelity". Likewise, McNally (2004) noted 
that clinical theorists who endorse the hypothesis that experiences are so overwhelmingly traumatic that many victims dissociate their memory for the experience often exhibit confusion about the very studies they cite in support of it. For example, they often misinterpret all kinds of memory problems (e.g., everyday forgetfulness) with an inability to remember the trauma itself. Also, not thinking about something (e.g., sexual abuse) for a long period of time should be insufficient evidence that it has been blocked from awareness by some defensive mechanism like repression or dissociation.

Additionally, skeptics have warned that memories may be susceptible to distortions (Schacter, 1999) and that therapeutic interventions such as hypnosis, dream interpretation, and imagination - intended to recover memories of CSA may unintentionally foster pseudo-memories of CSA (Lindsay \& Read, 1994; Loftus, 1993, 2003). Thus, McNally (2005b, p. 815) argued that "the movement to help survivors recall these allegedly repressed memories resulted in the worst catastrophe to befall the mental health field since the lobotomy era".

A salient case in point of this controversy is that the American Psychological Association brought together a special 'Working Group on Investigation of Memories of Childhood Abuse'. This working group, consisting of three clinical practitioners and three research scientists, was unable to agree on several aspects. Consequently, their final report took the shape of a debate (for publications on this issue, see Alpert, Brown, \& Courtois, 1998a, 1998b, 1998c; Ornstein, Ceci, \& Loftus, 1998a, 1998b, 1998c).

It should be emphasized however, that, besides these two conflicting positions, some authors have emphasized that neither position is mutually exclusive, and hence that emotion sometimes has a facilitative effect while sometimes it can be detrimental to memory (e.g., Candel, 2003; Christianson, 1992). For example, Christianson and Lindholm (1998) claimed that the various studies in the field of emotion and memory have yielded different answers concerning the direction of emotional stress on memory, that is whether emotional events are poorly or well maintained. A major finding obtained ... is that traumatic memories tend to be accurate and persistent with respect to the traumatic event itself and the central, critical detail information ... that elicits the emotional reaction. This is not to say that traumatic memories are always fully accurate. It is often found that emotional events are less accurately recalled with respect to 
peripheral or more irrelevant details within an emotional scenario or information preceding and following traumatic events. (p. 762)

The claim that repression exists has not been restricted to the domain of trauma and memory research. Even in philosophy one easily speaks of repression as a cause, a mechanism that yields certain effects. For example, Searle (1992) puts the mechanism of repression on a par with brain damage as to its causal effectiveness. It seems to be something that autonomously can occur. Similarly, the neurologist Ramachandran (1995) claims that the existence of repression is demonstrated in his anosognosia patients who suffered from a stroke in their right hemisphere: "This is about as close as one can get to Freudian repression" (Ramachandran \& Blakeslee, 1998, p. 149; for a critical review, see Geraerts \& van Heerden, 2004; Geraerts, Elbers, \& van Heerden, 2005). Likewise, in developmental psychology, the concept of repression has been put forward, with Piaget (1973) postulating age-dependent cognitive repression, meaning that, children, to circumvent conflicts of ideas, avoid a conscious awareness of certain schemas.

\section{REMEMBERING AND FORGETTING TRAUMA}

According to advocates of the Freudian legacy, repression is a causal mechanism and one of its distinct effects is abnormal memory loss, i.e., amnesia. Alternatively, Bernstein and Putnam (1986, p. 727) define dissociation "as the lack of normal integration of thoughts, feelings, and experiences into the stream of consciousness and memory" (see for recent studies on dissociation, Giesbrecht, 2006; for a critical review, see Merckelbach \& Muris, 2001). It should be stressed that repression as well as dissociation are considered mechanisms, which can result in dissociative amnesia. Kihlstrom and Schacter (2000; p. 410) describe dissociative amnesia as entailing "memory loss for specific, often traumatic events in the individual's personal history. The patient has forgotten what he or she did, or what happened to him or her, during a relatively constricted period of time".

Since the onset of the memory wars, a multitude of studies examining dissociative amnesia have been conducted. A number of retrospective and prospective studies of CSA have found a non-trivial proportion of victims saying that they at some point in their life had not remembered their abuse. For 
example, in one of the most widely cited retrospective studies, Briere and Conte (1993, p. 24) asked 450 patients in treatment for CSA the following question: "During the period of time between when the first forced sexual experience happened and your eighteenth birthday, was there a time when you could not remember the forced sexual experience?" Fifty-nine percent of the patients answered that there had been such a time. Accordingly, Briere and Conte concluded that nearly 60 percent of survivors experience "sexual abuse-related repression" of their traumatic memories prior to recovering the memories later in life (p. 26).

However, due to methodological limitations, this study cannot be adduced as support for massive repression. First, participants in the study were patients possibly exposed to therapeutic techniques likely to foster memories of abuse (Poole, Lindsay, Memon, \& Bull, 1995). Also, as in many studies in this domain, it was not established whether the recalled abuse had actually happened. Moreover, the duration of amnesia for trauma was unspecified. Perhaps the most important issue concerns the question that respondents were given. In a way, this question was formulated in an ambiguous way. Thus, McNally and colleagues pointed out that participants were more likely answering a different question: "Was there ever a time that you did not think about having been abused?" (McNally, Clancy, \& Barrett, 2004a, p. 131). That's why an affirmative answer to this question does not necessarily provide solid evidence for the type of massive repression put forward by CSA researchers. Instead, such a positive reaction might simply mean that those who experienced CSA can sometimes manage not to think about the abuse. These and other critical points have also been made with regard to similar retrospective studies published in the last 15 years (for an overview, see Wessel, 1997).

A much smaller number of studies have used a prospective methodology to assess whether traumatic events can be forgotten. In an influential study by Williams (1994), 129 women with previously documented histories of CSA were interviewed. Of these, 38 percent failed to report the index event of abuse for which Williams had a record. Some authors have interpreted these data as showing that massive forgetting of trauma is not only possible, but even very common. Nevertheless, there are several other, more likely explanations for this nonresponse rate of 38 percent. Sixty-eight percent of those who forgot the index event of abuse did report other abuse events, suggesting that the index event may have merely been less traumatic or less important to them than other 
instances of CSA. Given that several women had been abused when they were younger than five, not remembering the abuse might be the result of childhood amnesia. Moreover, one can argue that the younger the child at the time of the index event, the more likely she is to fail to understand the abuse as sexual at the time. Also, other women may not have wanted to label themselves as abused and/or disclose such personal matters to the interviewer. Thus, a failure to disclose cannot be regarded as evidence of repression (Loftus, Garry, \& Feldman, 1994).

A study by Goodman and colleagues (Goodman, Ghetti, Quas, Edelstein, Alexander et al., 2003) provides further data on failure to disclose abuse. They assessed 168 persons who had been involved in legal proceedings concerning sexual abuse. These proceedings occurred when the persons were approximately nine years old. A survey was administered 13 years after the persons had been involved in the legal proceedings. Questions about sexual abuse were inserted in a longer survey concerning legal attitudes and experiences. Results revealed that $15.5 \%$ failed to report the target incident during a telephone interview conducted approximately 13 years after the events in question. Nondisclosure dropped to 8.3\% after follow-up by a mailed questionnaire and a telephone interview. Moreover, providing an in-depth analysis, Goodman and Paz-Alonso (in press) furnished a reduced estimate of $3.6 \%$ for the incidence of traumatic amnesia.

As these studies indicate, claims of widespread repression and recovery of childhood abuse have been exaggerated. Accordingly, Goodman et al. (2003) concluded that "these findings do not support the existence of special memory mechanisms unique to traumatic events, but instead imply that normal cognitive operations underlie long-term memory for CSA."

\section{Inhibition}

Certainly, in experimental psychology, repression has been an intricate theme almost from the beginning. Researchers looking for repression in the laboratory have rarely found it, and even the few apparently positive findings are beset by several methodological problems (Holmes, 1990). Recently, clinical psychologists have increasingly employed experimental paradigms to study repression in the laboratory. One of them is directed forgetting (Cloitre, 1998). Some authors have suggested that this paradigm may be used to study individual differences in the ability to put disturbing material out of consciousness (e.g., Bjork, 1989; Brewin $\&$ Andrews, 1998). In the typical experiment, participants are presented with 
words and they are instructed either to remember or forget these words. Contrary to forget instructions, however, memory for both to-be-remembered and to-beforgotten words is tested. The basic directed forgetting effect consists of a decrease in memory performance for to-be-forgotten words, combined with a recall advantage for to-be-remembered words. A retrieval inhibition mechanism has been proposed to account for certain variants of this directed forgetting effect (Bjork, Bjork, \& Anderson, 1998). Moreover, it has been suggested that, due to such a retrieval inhibition mechanism, abuse survivors are turned into skilled forgetters of traumatic events (Cloitre, 1998). On the other hand, some research shows that the more emotional material is, the harder it becomes to turn it to a target for successful directed forgetting (Wessel \& Merckelbach, 2006).

Similarly, other paradigms tapping inhibition (e.g., retrieval-induced forgetting; Anderson, Bjork, \& Bjork, 1994; think-no-think procedure; Anderson \& Green, 2001; Anderson, Ochsner, Kuhl, Cooper, Robertson, et al., 2004) have been linked to theories about the forgetting of traumatic experiences. Anderson argues that the suppression of traumatic memories results in a lowered accessibility of these memories (Anderson \& Levy, 2002; see also Conway, 2001). Anderson and co-workers concluded that these recent paradigms demonstrate the existence of Freudian repression. Accordingly, Anderson's sweeping speculations have raised considerable disagreement. As Kihlstrom (2002, p. 502) stated: "The repression (or suppression) of trauma appears to be a clinical myth in search of scientific support. It is unfortunate that Levy and Anderson apparently feel the need to supply it".

\section{REPRESSIVE COPING}

Up till now in this thesis, repression has been regarded as an incidental reactive mechanism, occurring when an overwhelmingly terrifying event like combat or rape takes place. Some authors, however, view repression as a chronic tendency. In their opinion, repression should be regarded as a trait, reflecting an avoidant processing style for coping with aversive events (Myers, 2000a). This repressive coping style has been operationalized by Weinberger and his co-workers (Weinberger, 1990; Weinberger, Schwartz, \& Davidson, 1979), and has been particularly well-studied in recent years. Repressors engage in a variety of selfdeceptive maneuvers to avoid awareness of threat and negative affect. As 
Weinberger argues (1990, p. 338): "repressors are people who fail to recognize their own affective responses ... repressors as a group seem actively engaged in keeping themselves, rather than just other people, convinced that they are not prone to negative affect". Accordingly, studies have indicated that repressors have limited access to their childhood memories, but also to their more recent negative autobiographical memories (Myers \& Brewin, 1994; Myers \& Derakshan, 2004a). Curiously enough, they are also more likely to report childhood adversity (Myers \& Brewin, 1994). Strikingly, there has been no research linking repressive coping to repression of terrifying events like rape or combat. Repressive coping has received very little attention in clinical samples, particularly in reference to how certain types of coping are employed after a traumatic event.

One could speculate that some avoidance of negative or even traumarelated thoughts may be adaptive. By this view, a repressive coping style may be regarded as an adaptive mechanism to deal with emotionally negative, possibly traumatic, events. In fact, there are data indicating long term stress-buffering benefit associated with repressive coping (Ginzburg, Solomon, \& Bleich, 2002; for a review, see Bonanno, 2004). Conversely, there is some evidence that avoidance of negative and trauma-related thoughts and emotions may lead to intrusive thoughts. In their dual presentation theory of posttraumatic stress disorder (PTSD; American Psychiatric Association [APA], 1994), Brewin, Dalgleish, and Joseph (1996) argued that individuals who prematurely inhibit the processing of an upsetting event have a tendency to display a repressive coping style. This style would promote PTSD, a condition that is far from adaptive. Yet, no study has looked at the long term cognitive effects of repressive coping. This issue clearly warrants further study.

\section{REPRESSED AND RECOVERED MEMORIES IN THE LAB}

It is also remarkably that, until recently, no studies have been conducted on the cognitive functioning of people in the center of this recovered-memory debate: those who report repressed and recovered CSA memories. This state of affairs could be due to the fact that few clinicians have expertise in laboratory research and few cognitive psychologists have access to trauma populations (McNally et al., 2004a). In fact, Richard McNally and Susan Clancy of Harvard University were the first to apply experimental methods to investigate memory functioning in 
people reporting repressed and recovered memories of CSA. By doing so, their studies have tested hypotheses relevant to mechanisms implicated in the ability to repress and recover traumatic memories, as well as mechanisms relevant to forming pseudo-memories of trauma (McNally, 2003a). Several of these studies will be described in the chapters that follow.

\section{AN IMPRESSION OF REPRESSION}

The present thesis is inspired by the research line of McNally and colleagues and will investigate hypotheses relevant to the repressed/recovered memory debate. This dissertation will examine whether reports of amnesia exist on a non-trivial scale in samples of victims, and if so, whether repression provides a good account of such memory loss. To address this question, studies reported in this thesis will use methods of cognitive psychology to examine remembering and forgetting of people who report having experienced traumatic events. As Loftus and colleagues (Loftus, Joslyn, \& Polage, 1998, p. 790) argued that "memory distortions other than repression may well lead to the impression that traumatic memories are often repressed", four possibilities will be considered that may render an impression of repression?.

The first possibility is that reports about traumatic events in individuals with recovered memories are essentially correct. Thus, the idea here is that traumatic events can be forgotten and subsequently recovered. A second possibility is that reports about traumatic experiences are incorrect and are the result of suggestive therapeutic techniques. Yet, the victim is bona fide in his/her belief that the reports are accurate. Here, reports are what may be termed pseudo-memories (Loftus, 2003). Perhaps the case of Elizabeth Janssen (Case 7) is an example of this scenario. A third possibility is that reports of traumatic experiences are a form of overreporting. In that case, the person may be intentionally overreporting symptoms and possibly fabricating trauma stories (Cunnien, 1997). Finally, a fourth possibility is that reports about traumatic events are essentially correct, but although they have always been accessible to the victim, the victim firmly believes that he/she has repressed these memories for some time (e.g., Schooler, 1994). This scenario might be highly relevant for understanding a case such as that of Mary de Vries (Case 2). These four possibilities will be elaborated below. 


\section{Amnesia and trauma}

Can memories of a trauma be forgotten and/or subsequently recovered? According to one popular view known as the trauma-memory argument, memories of traumatic events have special properties that distinguish them from ordinary memories (for a critical discussion, see Kihlstrom, 1996). By this view, traumatic memories are qualitatively different (i.e., processed and stored differently) from other types of memories, thereby involving mechanisms different from those associated with general memory functioning (van der Kolk, 1996). This view asserts that many survivors of a trauma invoke mechanisms such as repression and dissociation which result in dissociative amnesia for the stressful event itself. Moreover, it is contended that survivors of a trauma suffer from intrusions with strong sensory qualities.

However, as already mentioned, research testing these assumptions has revealed a diversity of percentages concerning the forgetting of traumatic events like war atrocities or childhood abuse (e.g., Briere \& Conte, 1993; Goodman et al., 2003). Given the mixed results in this domain and the popularity of the traumamemory argument, there is a clear need for more empirical data.

Besides special memory mechanisms for traumatic events, some authors have focused on individual differences in the ability to put aversive experiences out of mind (Bjork, 1989; Cloitre, 1998). As already mentioned, mechanisms like retrieval inhibition have been proposed to explain that some people manage not to think about their traumatic experiences. However, hardly any studies examining retrieval inhibition have been conducted in people reporting repressed memories of a trauma. Obviously, this issue warrants further study on inhibition in these people.

\section{False and recovered memories}

A second possibility for the impression that one has harboured repressed memories is that a failure to remember traumatic events took place because such events did not actually occur in the first place (Loftus et al., 1998). At first sight, the idea that someone might remember having experienced a trauma that never took place, seems an unlikely account for repression. Yet, people have recollected atrocities that never happened and have been experiencing the emotional pain paralleled with their belief in the authenticity of their memories. Some of the inconceivable traumatic events for which people claim to have recovered memories in recent years involve satanic ritual abuse (Scott, 2001) and abduction 
by space aliens (Clancy, 2005; Mack, 1994), memories which are often 'recovered' during psychotherapy. In reviewing the influence of psychotherapy, Lindsay and Read (1994, p. 304; see also Lindsay, 1994; Lindsay \& Read, 1995) concluded that "there are good reasons to believe that: (1) some recollections produced by intensive memory recovery may be false; and (2) when such techniques are used it is very difficult to discriminate between clients who are remembering accurately and clients who believe they are remembering accurately but are not."

Consider the story of Binjamin Wilkomirski, portrayed in his award winning autobiographical memoir Fragments (1996). In this sensational memoir, Wilkomirski described vivid recollections of his childhood experiences in a Nazi concentration camp. Unaware of these childhood traumatic memories during his adult life, he came to terms with them only in therapy. Because his story inspired many others, Wilkomirski became a hero to Holocaust survivors. In 1998, however, the story began to unravel when Daniel Ganzfried, a Swiss journalist and the son of a Holocaust survivor, published an astonishing article in a Swiss newspaper. Ganzfried revealed that Wilkomirski is actually Bruno Dossekker, who had spent all of the war years with his foster parents, the Dossekkers, in Zurich. Wilkomirski, however, still intensely believes that his recollections are real (see for a detailed investigation, Maechler, 2001).

The fact that a growing number of former patients have retracted their claims of CSA also suggests that false CSA memories can be induced by therapists. Most retractor cases involve adults who had sought psychotherapy for depression or related complaints. During therapy, memories of CSA were recovered. However, later patients come to believe that the 'recovered memories' were only products of therapeutic suggestion (Goldstein \& Farmer, 1993; Lief \& Fetkewicz, 1995; Loftus, 1997a; Öst, Costall, \& Bull, 2001, 2002).

In the 1990s, the experimental research community responded in earnest to these frequent memory reports by patients claiming their experiences have been previously repressed. If these memories were not authentic, where could they have come from? If they were false, how could they develop? With this question in mind, several lines of research on the development of false beliefs and memories began to flourish (see for recent reviews, Horselenberg, 2005; Laney \& Loftus, 2005; Smeets, Merckelbach, Horselenberg, \& Jelicic, 2005). One of the most well-know paradigms that has been strikingly successful in creating pseudo-memories in the laboratory is the Deese-Roediger-McDermott (DRM) 
paradigm (Deese, 1959; Roediger \& McDermott, 1995). In this task, participants often falsely recall and recognize a nonpresented word, the critical lure, following presentation of its strongest associates.

The DRM paradigm relies on semantic material. Yet, apart from semantic material, research has demonstrated that techniques such as imagination inflation (Garry, Manning, Loftus, \& Sherman, 1996; Horselenberg, Merckelbach, Muris, Rassin, Sijsenaar, \& Spaan), dream interpretation (Mazzoni, Loftus, Seitz, \& Lynn, 1999), and suggestions containing incorrect feedback (Crombag, Wagenaar, \& van Koppen, 1996; Hyman \& Billings, 1998; Jelicic, Smeets, Peters, Candel, Horselenberg, \& Merckelbach, in press; Smeets, Jelicic, Peters, Candel, Horselenberg, \& Merckelbach, in press) may create false beliefs, and pseudo-memories. Moreover, recent studies have successfully employed doctored photographs (e.g., a child in a hot air balloon; a child in the hospital with a broken arm) suggesting childhood events that never happened to the child or adult participants (Candel, Geraerts, Wade, \& Raymaekers, 2006; Wade, Garry, Read, \& Lindsay, 2002). Additionally, studies have shown that experimental manipulations intended to implant pseudo-memories may have overt behavioural consequences (Bernstein, Laney, Morris, \& Loftus, 2005a, 2005b).

\section{Symptom overreporting}

A third possibility is the issue of feigning trauma-related memories and symptoms. Most authors in this domain have focused on veterans overreporting their symptoms or even fabricating whole combat histories to acquire serviceconnected disability payments (Rosen, 2004, in press). For example, in their award-winning book Stolen Valor, Burkett and Whitley (1998) pointed out how widespread this problem was among Vietnam veterans by describing many cases falsifying entire combat histories that had never occurred. The problem of simulating trauma-related memories and symptoms is, however, not unique to veterans seeking compensation on the basis of their posttraumatic stress disorder symptoms (see also Cima, 2003). There is reason to believe that some patients exaggerate or even fabricate psychiatric CSA-related symptoms (Cunnien, 1997). They may overreport their symptoms because of external incentives such as financial compensation or because of internal motives like the wish to adopt the patient role. There are case descriptions of patients who recovered memories of traumatic events that never actually occurred (e.g., alien abduction; Clancy, 2005). Hence, it seems plausible, at first sight, to assume that 
symptom overreporting might be especially pronounced in people with recovered CSA memories, relative to people having always remembered being abused.

\section{Assessing prior remembering}

A fourth possibility that may produce an impression of repression is that individuals who report having recovered previously repressed memories of CSA overestimate their prior forgetting of the abuse (e.g., Schooler, Ambadar, \& Bendiksen, 1997a). In such situations, the memory of the event may be quite valid. It is rather the memory for the period of forgetting, that is incorrect. The person falsely believes that there was an extended period in the past when he/she could not remember the event. Good examples of this are provided by the case studies reported by Schooler and his co-workers (Schooler, 1999; Schooler, Bendiksen, \& Ambadar, 1997b; but see Wagenaar \& Crombag, 2005, for a critical analysis). They showed that some people who believe they have not thought about their traumatic experiences for many years are surprised to learn that they had, in fact, talked about the abuse with family members during the period when they thought the memories never came to mind. Thus, a person can forget having remembered a traumatic event, producing an "illusion of amnesia". A person might be especially likely to forget a previous instance of recalling abuse if the recollection was not accompanied by strong emotions. Schooler and colleagues (Schooler et al., 1997a) proposed that such cases are instances of a "forgot-itall-along" (FIA) phenomenon, leading to the underestimation of prior recollections of past events.

\section{OUTLINE AND RESEARCH OBJECTIVES OF THIS THESIS}

Besides a General Introduction and a General Discussion, the present thesis consists of five main parts. These five parts implement methods of cognitive psychology to investigate the remembering and forgetting of trauma. The first four parts each focus on a different aspect rendering an impression of repression. The fifth part of the thesis focuses on memory functioning of repressors.

Part $l$ of this thesis focuses on the possibility that reports about traumatic events in individuals with recovered memories are essentially correct. Can traumatic events be forgotten and subsequently recovered? Chapter 2 
describes a study conducted with Croatian war veterans reporting combat experiences during the Balkan wars in the early 1990s. The aim of this study was to test assumptions underlying the trauma-memory argument in this sample of war veterans. Also in Part 1, the concept of retrieval inhibition is examined. According to some theorists, traumatized people would possess a superior retrieval inhibition mechanism and as a consequence would be better in forgetting trauma-related material (Cloitre, 1998). In Chapter 3, we made an attempt to tests predictions flowing from these assumptions. By using a list-wise directed forgetting test, we explored whether women reporting repressed or recovered CSA memories display a superior ability to inhibit retrieval of traumarelated material. If these individuals possess a skill for repressing genuine memories of trauma, one would predict that this ability should easily be brought into play in the lab when they are asked to forget words linked to abuse, which can be considered mere weak proxies of traumatic events.

Chapters in Part 2 describe studies that are relevant to the formation of pseudo-memories. A number of researchers have argued that at least some reports of recovered traumatic experiences are incorrect and hence represent pseudo-memories. With this in mind, the study presented in Chapter 4 explored whether people reporting recovered CSA memories are especially vulnerable to false memory effects. To investigate this matter in the laboratory, we employed a variant of the Deese/Roediger-McDermott paradigm, relying on neutral as well as trauma-related word lists. Related to this, the research described in Chapter 5 examined whether people reporting recovered and repressed CSA memories show heightened scores on measures that have been found to be associated with false memory phenomena. More specifically, we explored whether people with repressed or recovered CSA memories score higher on measures tapping dissociative symptoms and fantasy proneness, relative to people reporting continuous CSA memories or controls reporting no history of abuse. In this way, this study tested specific hypotheses arising from the recovered memory controversy. For example, if dissociative symptoms are a manifestation of the ability to keep distressing recollections at bay, individuals reporting repressed and recovered CSA memories should score higher on a measure tapping these symptoms. Conversely, if people reporting repressed or recovered CSA memories have a pronounced tendency to fabricate stories about their abuse background, then one would predict that they score higher on a measure of fantasy proneness relative to the continuous memory group. 
Part 3 of this thesis relates recovered CSA memories to symptom overreporting. Therefore, the study in Chapter 6 examined whether people reporting recovered CSA memories have a stronger tendency to overreport symptoms relative to people with continuous CSA memories and controls. To this end, we administered to these three subgroups instruments tapping the tendency to endorse bizarre, implausible and/or low frequency symptoms.

Part 4 of this dissertation examines whether the impression of repression can be brought about by the overestimation of prior forgetting in individuals reporting recovered CSA memories. In other words, a person can forget having remembered a traumatic event, producing an "illusion of amnesia". Chapter 7 describes two studies exploring this forgot-it-all-along phenomenon in people reporting recovered CSA memories. By using semantic as well as autobiographical material, we examined whether people with recovered CSA memories are more prone to this phenomenon than people with continuous CSA memories and controls reporting no history of abuse.

Part 5 relates repressive coping to memory functioning. Although social psychologists have focused on several aspects of a repressive coping style (e.g., Bonanno, Noll, Putnam, O'Neill, \& Trickett, 2003), few studies have been conducted examining the memory functioning of repressors. Moreover, no consensus has been reached as to the possibly adaptive or harmful function of repressive coping. Therefore, the study described in Chapter 8 aimed at investigating both short and long term effects of repressive coping on the frequency of thoughts about negative autobiographical events. Related to this, Chapter 9 describes a study that sought to examine whether repressors' ability to suppress intrusive thoughts is related to their working memory capacity.

The thesis ends with a General Discussion (Chapter 10). Main results will be summarized and discussed. Findings from recently completed studies will be introduced, which will be integrated with some findings reported in this thesis. Implications of the presented studies and suggestions for future research will be addressed. 

PART 1

AMNESIA AND TRAUMA 



\section{CHAPTER 2}

Traumatic Memories in War Veterans: Not So Special After All

This chapter is in press as: Geraerts, E., Kozarić-Kovačić, D., Merckelbach, H., Peraica, T., Jelicic, M., \& Candel, I. (in press). Traumatic memories in war veterans: Not so special after all. Consciousness and Cognition. 


\begin{abstract}
Several authors have argued that traumatic experiences are processed and remembered in a qualitatively different way from neutral events. To investigate this issue, we interviewed 121 Croatian war veterans diagnosed with posttraumatic stress disorder (PTSD) about amnesia, intrusions (i.e., flashbacks and nightmares), and the sensory qualities of their most horrific war memories. Additionally, they completed a self-report scale measuring dissociative experiences. In contrast to what one would expect on the basis of theories emphasizing the special status of traumatic memories, amnesia and high frequency intrusions were not particularly typical for our sample of traumatized individuals. Moreover, traumatic memories were not qualitatively different from neutral memories with respect to their stability and sensory qualities. The severity of PTSD symptoms was not significantly correlated with dissociative experiences. Our findings do not support the existence of special memory mechanisms that are unique to experiencing traumatic events.
\end{abstract}

\title{
INTRODUCTION
}

In clinical literature, there is little consensus about how victims remember traumatic experiences (e.g., Kihlstrom, 2004; Loftus, 1997b; McNally, 2003a). According to one popular view, memories of traumatic events have special properties that distinguish them from ordinary memories. Thus, many authors have argued that traumatic memories are qualitatively different from other types of memories, involving unique mechanisms not related to general memory functioning (e.g., van der Kolk, 1996, 1997; for a review, see Zoellner \& Bittenger, 2004). For example, these authors assume that traumatic events are processed in a predominantly perceptual fashion, leaving survivors with traumatic memories that are not readily accessible (i.e., dissociative or psychogenic amnesia) and/or flashbacks that possess strong sensory qualities. This dissociative style of processing would also create a substantial overlap between dissociative and posttraumatic stress disorder (PTSD) symptoms. There are several versions of this theoretical stance (Brewin, Dalgleish \& Joseph, 1996; Ehlers \& Clark, 2000), but the core assumption they have in common is that trauma has a special impact on the way in which memories of the traumatic event are organized. For that reason, this position has been dubbed the trauma- 
memory argument (for a balanced discussion, see Kihlstrom, 1996, in press; Shobe \& Kihlstrom, 1997; for a reply, see Nadel \& Jacobs, 1998).

Although the trauma-memory argument has gained popularity among many clinicians, some findings argue against this view. As Pendergrast (1998) has pointed out, classic monographs like those of Spiegel and colleagues (Grinker \& Spiegel, 1943/1945; Kardiner \& Spiegel, 1941/1947) include only isolated case reports of soldiers suffering from amnesia (see also Lilienfeld \& Loftus, 1998). Moreover, more systematic studies suggest that only a small minority of war victims report dissociative amnesia. For example, Kuch and Cox (1992) studied 124 holocaust survivors and found that dissociative amnesia, with an estimated lifetime prevalence rate of $3.2 \%$, was quite rare in this group. Likewise, Merckelbach and colleagues (Merckelbach, Dekkers, Wessel, \& Roefs, 2003a, $2003 \mathrm{~b}$ ) found in a group of 29 Dutch concentration camp survivors only one survivor reporting mnemonic experiences that might be taken as evidence for dissociative amnesia'. Goodman and co-workers found that $15.5 \%$ of victims of documented childhood sexual abuse (CSA) failed to report the target incident during a telephone interview conducted approximately 13 years after the pertinent events (Goodman, Ghetti, Quas, Edelstein, Alexander et al., 2003; Goodman \& Paz-Alonso, in press). However, nondisclosure dropped to $8.3 \%$ after follow-up by a mailed questionnaire and a telephone interview ${ }^{2}$. Both rates of reporting failure are clearly lower than those found in earlier, less meticulous studies of CSA victims (e.g., Williams, 1994). Even when one accepts these lower rates of non-reporting, the question arises to what extent they do reflect genuine dissociative amnesia. People might not report the traumatic events for other reasons than amnesia (e.g., shame, ordinary forgetting; see McNally, 2003a). Recent literature is also critical about the idea that traumatic memories invariantly produce flashbacks. For example, using patient archives, Jones and colleagues showed that flashbacks were an uncommon symptom in generations of British war veterans before the 1980's Jones, Vermaas, McCartney, Beech, Palmer et al., 2003).

So far, empirical support for the trauma-memory argument is not very compelling. On the other hand, the studies cited above suffer from various shortcomings and thus, one could argue that they provide only suboptimal tests of the trauma-memory argument. One shortcoming is that it is not always clear whether the events (e.g., war experiences) were really traumatic to the participants (Jones et al., 2003). Another limitation is that the traumatic events 
often happened decades ago (Kuch \& Cox, 1992; Merckelbach et al., 2003a, $2003 \mathrm{~b})$. That recency of the traumatic event might be an important issue is suggested by a survey among earthquake survivors several months after the 1999 earthquake in Turkey (Basoglu, Salcloglu, \& Livanou, 2002). In that study, the authors noted that $54 \%$ of the survivors said to experience flashbacks, while $23 \%$ said to experience dissociative amnesia. These results seem to support the trauma-memory argument, but one weakness of this study is that it remains unclear with what type of questions precisely the survivors were interviewed. Given the mixed results in this domain and the popularity of the trauma-memory argument, there is an urgent need for more empirical data.

With this in mind, the current study was conducted. It relied on Croatian war veterans who had been confronted with extremely aversive events. More specifically, our sample consisted of Croatian war veterans with combat experiences during the Balkan wars in the early 1990s. All veterans had been exposed to conditions meeting the criteria of traumatic events according to the fourth edition of the Diagnostic and Statistical Manual of Mental Disorders (DSMIV; APA, 1994, p. 27). That is, all had experienced or observed "an event or events that involved actual or threatened death or serious injury, or a threat to the physical integrity of self or others". Accordingly, self-reports of these war veterans about their traumatic memories offer an opportunity to assess the virtues of the trauma-memory argument. Compared to PTSD patients who survived the atrocities of World War II, our patients were relatively young people. Given that the quality of memory self-reports may be affected by cognitive aging (Schwarz, Park, Knäuper, \& Sudman, 1998), studying memory characteristics in young or middle-aged PTSD patients would probably yield more valid results than interviewing older patients.

The aim of our study was to test the assumptions underlying the trauma-memory argument in this sample of war veterans. We interviewed these veterans about the presence of flashbacks and about the accessibility and sensory qualities of their traumatic memories. We also examined whether there was in this sample - as the trauma-memory argument would predict- a substantial overlap between dissociative experiences and PTSD symptoms. 


\section{METHOD}

\section{Participants}

The study included 121 Croatian war veterans ( 2 women) with a mean age of 40.3 years ( $S D=6.3$; range: $30-55$ years). The mean duration of their combat activity was 2.7 years $(S D=1.7$; range: $1-5$ years). An average of 12.7 years $(S D=3.4$; range: 10-14 years) had elapsed since they had experienced combat trauma. Their military and medical records suggested that many of them had been exposed to multiple traumas (e.g., combat, imprisonment in detention camps, deportation, confrontation with killed family members or missing family members). Given these records and given the large scale on which war atrocities occurred during the Balkan wars, we assume that most veterans had, indeed, been exposed to traumatic events they claimed to have experienced. Still, we were not able to validate their traumatic war experiences. Similarly, we cannot rule out that some veterans exaggerated their post-traumatic symptoms. Veterans were invited to participate in the current study while seeking medical services in the Referral Centre for Stress-related Disorders in the Dubrava University Hospital in Zagreb, Croatia. The diagnosis of current and chronic PTSD was made on the basis of the Structured Clinical Interview (SCID) for DSM-IV (First, Spitzer, Gibbon, \& Williams, 1996) and the Clinician-Administered PTSD Scale (CAPS; Blake, Weathers, Nagy, Kaloupek, Gusman et al., 1995). Eighty-three participants (68.6\%) were diagnosed with PTSD of whom 41 (33.9\%) had a comorbid diagnosis of major depressive disorder (MDD), while 38 participants (31.4\%) were diagnosed with a trauma-related anxiety disorder other than PTSD.

\section{Historical background of the war in Croatia}

Until 1990 Croatia was one of the regions constituting the Socialistic Federal Republic Yugoslavia. According to the Central Department of Statistics (Državni zavod za statistku, 1991), Croatia had at that point in time a population of five million people. In 1990, Serb forces together with the federal Yugoslav Army began a war in Slovenia which spreaded to Croatia and lasted until June 30, 1996 (Sabor Republike Hrvatske, 1997). More than 250.000 Croatians were forced to flee their homes and live with host families (around 80\%) or in camps (around 20\%). The war in Bosnia and Herzegovina made the problem even larger. By the end of 1993, many people of non-Serb nationality were forced to leave from Bosnia and Herzegovina and temporarily settled in Croatia, mostly in Zagreb. The 
majority of them were children and women, of whom some had been raped or had experienced other psychological traumas (Kozarić-Kovačić, FolnegovicSmalc, Skrinjaric, 1993; Kozarić-Kovačić, Folnegovic-Smalc, Skrinjaric, Szajnberg, Marusic, 1995). Over one million people or more than $20 \%$ of the total population of Croatia had to leave their homes, either as refugees or displaced persons.

According to the data by the Office for the Imprisoned and Missing Persons, the total number of prisoners of war (POW) in Serbian camps was 7.666 (932 women). Besides the official camps, there were many informal camps, among which transit camps. It is estimated that about 10.000 people have been hold in detention in Serb POW camps. The need for psychological and psychiatric help and social support was and still is substantial among war victims (KozarićKovačić, Kocijan-Hercigonja, \& Jambrosic, 2001).

\section{Interview}

Trained clinicians conducted the structured interview, consisting of a series of open-ended questions. Interview questions were based on a protocol used in a previous study on Dutch survivors of WO II concentration camps (Merckelbach et al., 2003a, 2003b). Each participant was interviewed individually. The interview started with the interviewer asking the war veteran to pinpoint his/her most upsetting war experience. Veterans were also instructed to select one relatively neutral event that happened to them during the war. Veterans were encouraged to select neutral events that in terms of location, the people involved, and activities were comparable to the upsetting war experience. The events veterans chose pertained to experiences like, for example, "going to the market on a Friday morning", "picking up my daughter from school on Easter", and "going to the church in Zagreb". After participants had selected a traumatic and a more neutral topic, they were asked questions addressing the construct of dissociative amnesia. These questions were: "Do you think that memories of your most aversive war experience have been stable across your life?" (with answers coded as yes, no, or I don't know); "Has the accessibility of your war memories changed across your life?" (with answers coded as no, it has always been the same; yes, it has decreased; yes, it has increased; or I don't know); and "Has there ever been a period in your life that the war memories were not fully accessible?" (with answers coded as yes, the memories were there, but I tried really hard not to think of them; yes, because memories were completely lost, no, they have always been accessible; or I don't know ). Following this, the veterans were asked if their 
memories about relatively neutral events during the war had been stable across time. In addition, they had to indicate whether their traumatic and neutral memories consisted of visual images, auditory images, olfactory sensations, and/or bodily sensations (with answers coded as yes, no, or / don't know). The veterans were also asked to what extent they suffered from flashbacks related to the war. Answers were coded as never, less than once every month, monthly, weekly, 2-4 times a week, or daily. If flashbacks were indeed reported, participants had to indicate whether they contained visual images, auditory images, olfactory sensations and/or bodily sensations (with answers coded as yes, no, or I don't know). Finally, veterans were asked whether the content of the flashbacks corresponded to the traumatic war events. Responses to this item were coded as yes, no, sometimes, or I don't know. Similar questions were asked about veterans' nightmares of their most upsetting war experiences.

\section{Materials}

Participants completed the Dissociative Experiences Scale (DES; Cronbach's alpha $=.96$; Bernstein \& Putnam, 1986), a 28-item self-report measure that asks respondents how often they experience dissociative symptoms like derealization and depersonalization. Items are scored on 100-mm Visual Analogue Scales (VASs). Scores are averaged to obtain a mean DES score (range 0-100), with higher scores indicating higher levels of dissociative symptoms.

\section{RESULTS}

\section{Dissociative amnesia}

Table 2.1 shows the frequency of self-reported experiences that might be interpreted as evidence for dissociative amnesia. Fifty-six participants (46.3\%) reported that their traumatic memories had always been accessible, while 62 of them (51.2\%) pointed out that the traumatic memories had always been there, but that there were periods during which they had tried hard not to think of them. Two participants felt that there had been times during which their traumatic memories had been inaccessible. Seventy-six participants (62.1\%) indicated that their most traumatic memories had been stable across time, while 66 veterans (54.6\%) noted that their neutral memories had been stable across the years (Sign Test: $p=.27$ ). This suggests that traumatic memories were just as stable as memories of neutral events. 


\section{Sensory qualities}

The lower part of Table 2.1 shows the number of participants attributing visual, auditory, olfactory, and/or bodily features to their trauma and neutral memories. Sign Tests indicated that these two types of memories were comparable with regard to the sensory characteristics attributed to them (all $p$ 's $>0.19$ ).

\section{Flashbacks and nightmares}

Table 2.2 shows self-reported frequency of flashbacks and nightmares. A majority of the veterans ( 74 and $69 \%$, respectively) reported that these types of intrusions were experienced with a frequency of once every week or less. We scored the frequency categories (anchors: $0=$ never and $5=$ daily) and then conducted a paired samples $t$-test to compare flashbacks and nightmares with each other. This showed that nightmares were more frequently experienced than flashbacks: $t(119)=4.42, p<.001$. Flashbacks, however, were more often reported to mirror the adverse war events compared to nightmares (Sign Test: $p$ $=.001)$. Furthermore, Sign Tests indicated that nightmares were reported to contain more visual details than flashbacks $(p<.001)$, while flashbacks were said to contain more auditory and olfactory information $(p=.04$ and $p<.001$ respectively). 
Table 2.1 Frequency (\%) of self-reported experiences concerning the change in accessibility of war memories, the stability of traumatic and neutral memories, as well as the sensory qualities associated with war and neutral memories ( $N=$ 121).

\begin{tabular}{|c|c|c|c|}
\hline & & $\begin{array}{l}\text { Traumatic } \\
\text { memories }\end{array}$ & $\begin{array}{l}\text { Neutral } \\
\text { memories }\end{array}$ \\
\hline \multirow[t]{4}{*}{ Accessibility } & $\begin{array}{l}\text { Memories have always been } \\
\text { accessible }\end{array}$ & $56(46.3)$ & \\
\hline & $\begin{array}{l}\text { Memories were there, but } \\
\text { one tried hard not to think } \\
\text { of them }\end{array}$ & $62(51.2)$ & \\
\hline & $\begin{array}{l}\text { Memories were completely } \\
\text { lost }\end{array}$ & $2(1.7)$ & \\
\hline & I don't know & $l(0.8)$ & \\
\hline Stability & & $76(62.1)$ & $66(54.6)$ \\
\hline \multirow{4}{*}{$\begin{array}{l}\text { Sensory } \\
\text { qualities }\end{array}$} & Visual & $106(87.6)$ & $103(85.1)$ \\
\hline & Auditory & $76(62.8)$ & $79(65.2)$ \\
\hline & Olfactory & 55 (45.5) & $60(49.6)$ \\
\hline & Bodily & $53(43.8)$ & $54(44.6)$ \\
\hline
\end{tabular}

\section{Dissociative experiences and PTSD symptomatology}

The mean DES score $(M=34.5 ; S D=21.8)$ in our sample was comparable to DES scores that have previously been reported for PTSD samples (Van IJzendoorn \& Schuengel, 1996). The mean CAPS score in our sample was $56.55(S D=10.78)$. A Pearson correlation between these two measures failed to attain significance ( $r=$ $-.11, p=.23)$. On the basis of their CAPS scores, we divided our sample into a subgroup meeting the diagnostic criteria for PTSD $(n=88)$ and a group not meeting the diagnostic criteria for PTSD $(n=33)$. These subgroups did not differ in terms of dissociative symptoms as indexed by the DES: $t(119)=1.49, p=.14$. 
Table 2.2 Frequency (\%) and sensory qualities of flashbacks and nightmares about the adverse war events $(N=121)$.

\begin{tabular}{lll}
\hline & Flashbacks & Nightmares \\
\hline Frequency & $10(8.3)$ & $2(1.7)$ \\
Never & $18(14.9)$ & $6(5.0)$ \\
Less than once every month & $29(24.0)$ & $18(14.9)$ \\
Monthly & $33(27.3)$ & $57(47.1)$ \\
Weekly & $22(18.2)$ & $26(21.5)$ \\
2-4 times a week & $9(7.4)$ & $12(9.9)$ \\
Daily & & \\
\hline Sensory characteristics & $84(69.4)$ & $104(86.0)$ \\
Visual & $65(53.7)$ & $52(43.0)$ \\
Auditory & $35(28.9)$ & $14(11.6)$ \\
Olfactory & $61(50.4)$ & $74(61.2)$ \\
Bodily & & \\
\hline
\end{tabular}

\section{DISCUSSION}

Our findings do not support the idea that trauma invariably leads to dissociative amnesia and intrusions with a strong sensory component. For example, the veterans in our study indicated that their traumatic war memories had been just as stable across time as their more neutral memories. In our sample of 121 veterans, only two veterans reported having experienced episodes during which their war memories had been inaccessible. Interestingly, these two veterans conveyed that their neutral memories had been stable across time. It should also be noted that these two veterans showed elevated scores on instruments tapping symptom overreporting (Geraerts, Kozarić-Kovačić, Merckelbach, Peraica, Jelicic, $\&$ Candel, 2006a). Thus, it cannot be ruled out that they simulated their alleged amnesia symptoms because of external incentives such as service-connected disability payments ${ }^{3}$.

To our knowledge, this is the first study to show that relatively young veterans who have been exposed to traumatic war experiences only 10 to 15 
years ago, do only rarely - if at all - suffer from dissociative amnesia. This is important because reports from the young or middle-aged participants in our sample are unlikely to be confounded by the effects of cognitive aging (Schwarz et al., 1998). Our findings also concur with a growing body of laboratory evidence indicating that high levels of emotional stress facilitate rather than undermine memory (e.g., Cahill, Prins, Weber, \& McGaugh, 1994; Jelicic, Geraerts, Merckelbach, \& Guerrieri, 2004).

In more general terms, our results are in accordance with studies showing that dissociative amnesia is relatively rare in, for example, concentration camp survivors (e.g., Merckelbach et al., 2003a; Schelach \& Nachson, 2001; Wagenaar \& Groeneweg, 1990). Indeed, in their thorough review of the literature, Pope, Barry, Bodkin, and Hudson (2006) were able to locate only 13 explicit cases of dissociative amnesia, a statistic that the authors left with reservations about the merits of the concept of dissociative amnesia. One could counter that some theories - for example Freyd's (1996) betrayal trauma theory - do predict that traumatic events for which anonymous enemies are responsible are well remembered, whereas traumas that contain an element of betrayal by personal authority figures often fall prey to dissociative amnesia. In the context of the Balkan war traumas, this is not a very convincing argument because many war veterans had faced deep loyalty conflicts (e.g., choosing to flee with your children or leaving them behind to live in a host family). Although dissociative amnesia was found to be rare in our group of war veterans, $51 \%$ of them indicated that they voluntarily tried to suppress their traumatic memories. This corresponds to a study by Melchert and Parker (1997), who concluded that participants with memories of childhood abuse often referred to intentional avoidance of their abuse memories when they were reporting that these memories had been inaccessible for some time. Thus, voluntary thought suppression of traumatic memories should be taken into account when studying poor autobiographical memory for traumatic events. Further research along these lines is not only relevant to clinical practice, but may also inform the triers of fact when they have to decide about, for example, the plausibility of dissociative amnesia claims raised in court (Sparr \& Bremner, 2005).

We found no evidence that traumatic memories are qualitatively different from relatively neutral memories when it comes to the sensory characteristics attributed to them. That is, participants attributed a similar amount of visual, auditory, olfactory, and bodily sensations to these two types of 
memories. We cannot completely rule out the possibility that the relatively neutral memories of our veterans were, in fact, memories with very sad connotations. Meanwhile, other studies (e.g., Porter \& Birt, 2001) on the phenomenology of traumatic memories have also reported that such memories have many similarities with non-aversive memories in terms of overall quality, clarity or coherence, a finding that also argues against the special status that the traumamemory argument attributes to traumatic memories. A prominent view in clinical literature is that traumatic memories are stored at a lower, perceptual level, which would make them less coherent and more fragmented than ordinary memories (e.g., Brewin, 2001; Ehlers \& Clark, 2000). Of course, our findings are at odds with this view, as are studies reporting that among undergraduates who have been exposed to traumatic events, those with PTSD do not rate their traumatic memory as less coherent and more fragmented compared to those without PTSD (e.g., Berntsen, Willert, \& Rubin, 2003).

We also examined to what extent our participants experienced high frequency intrusions. Only a minority of veterans said to have flashbacks or nightmares on a daily basis or several times a week. Because reports about the frequency of flashbacks and nightmares were based on retrospective estimates, the true frequency of these intrusions might be inflated. Although especially flashbacks were reported as reflecting the distressing war events quite adequately, many participants indicated that both their flashbacks and nightmares did not contain auditory, olfactory, or bodily impressions. This suggests that these two types of intrusive imagery do not reflect the sensory elements of the traumatic events in an accurate way (vanOyen Witvliet, 1997). Again, these findings are difficult to reconcile with models of PTSD in which flashbacks and nightmares are taken as evidence for the perceptual organization of traumatic memories (e.g., Brewin et al., 1996; Ehlers \& Clark, 2000).

Based on the assumption that dissociative symptoms are a direct consequence of trauma, several authors have reasoned that PTSD symptoms are primarily dissociative in nature (e.g., Gershuny \& Thayer, 1999). Although DES scores found in our sample are comparable to those previously reported for clinical samples (Van IJzendoorn \& Schuengel, 1996), our results indicate that PTSD-related symptoms and dissociative experiences are not necessarily intimately associated with each other. This is not an isolated finding. Both Yehuda and colleagues (Yehuda, Elkin, Binder-Brynes, Kahana, Southwick, et al., 1996) and Merckelbach et al. (2003a, 2003b) found in their samples of 
concentration camp survivors that dissociative experiences and PTSD symptoms are largely distinct phenomena. As our sample consisted of young and middleaged veterans, our failure to find a straightforward connection between dissociative experiences and PTSD symptomatology cannot be explained by a reduction of dissociative experiences due to aging.

Summing up, the present findings do not support the existence of special memory mechanisms that are unique to traumatic events. We believe that the prospects of further research addressing the special status of traumatic memories are not very good. A more promising avenue for further research would be to examine how in some victims, the traumatic memory becomes the central component of their life narrative and in this way contributes to PTSDrelated symptoms (e.g., Berntsen et al., 2003). 

CHAPTER 3

Retrieval Inhibition of TraumaRelated Words in Women Reporting Repressed or Recovered Memories of Childhood Sexual Abuse

An adjusted version of this chapter is in press as: Geraerts, E., Smeets, E., Jelicic, M., Merckelbach, H., \& van Heerden, J. (in press). Retrieval inhibition of traumarelated words in women reporting repressed or recovered memories of childhood sexual abuse. Behaviour Research and Therapy. 


\begin{abstract}
Several authors have argued that survivors of childhood sexual abuse (CSA) who report to have repressed their traumatic memories are more skilled in forgetting emotional stimuli than survivors who have always remembered the abuse. The current experiment employed a list-wise directed forgetting task to investigate whether women reporting repressed $(n=16)$ or recovered $(n=23)$ memories of CSA are better at forgetting disturbing material, relative to women reporting having always remembered their abuse $(n=55)$ or reporting no history of abuse ( $n=20)$. We found no support for the hypothesis that women reporting repressed or recovered memories of CSA are especially versed in inhibiting retrieval of trauma-related words. Additional analyses revealed that participants characterized by a repressive coping style did not display a superior retrieval inhibition mechanism for negative material.
\end{abstract}

\title{
INTRODUCTION
}

Some authors have argued that experiences may be so traumatic that victims deal with them in an avoidant-dissociative way (e.g., Terr, 1994). This style would enable survivors of childhood sexual abuse (CSA) to disengage attention from threatening stimuli and would result in impoverished, i.e. repressed or dissociated, memories of traumatic events (Harvey \& Herman, 1994).

The concept of repressed or dissociated memories is controversial and has led to, what is sometimes dubbed, 'the memory wars' (e.g., Loftus, 1997b; Schacter, 1995). On the one hand, many authors claim that amnesia for trauma and/or subsequent recovery of traumatic memories can be demonstrated in clinical populations (e.g., Brown, Scheflin, \& Whitfield, 1999; Terr, 1994). A number of psychologists, on the other hand, have questioned the existence of repressed and recovered memories of trauma because of the lack of solid evidence for such memories (e.g., Kihlstrom, 2004; McNally, 2003a).

Some CSA survivors are capable of not thinking about their traumatic experiences for years (e.g., Cloitre, 2004). Yet, as pointed out by McNally (2003a), not thinking about a traumatic event is not the same as repressing memories of that event. Meanwhile, that some victims seem capable of not thinking about CSA for many years, may imply that there are individual differences in the ability to keep unpleasant events out of awareness. In a series 
of studies, McNally, Clancy, and their colleagues (Clancy, McNally, \& Schacter, 1999; Clancy, Schacter, McNally, \& Pitman, 2000; McNally, 2001, 2003a, 2003b, 2004; McNally, Clancy, Schacter, \& Pitman, 2000a, b; McNally, Metzger, Lasko, Clancy, \& Pitman, 1998) explored whether those who report having recovered memories of abuse possess superior abilities to forget unwanted material relative to those who report having always remembered their abuse. In doing so, these researchers were the first to apply experimental methods to investigate memory functioning in people reporting repressed and recovered memories of CSA. One paradigm that they used in this way was directed forgetting (McNally, Clancy, Barrett, \& Parker, 2004b; McNally, Clancy, \& Schacter, 2001). Some authors have suggested that this paradigm may be employed to study individual differences in the ability to put disturbing material out of consciousness (e.g., Bjork, 1989; Brewin \& Andrews, 1998). In the typical directed forgetting experiment, participants are presented with words and they are instructed either to remember or to forget these words. Next, memory for both the to-be-remembered (TBR) and the to-be-forgotten (TBF) words is tested. The basic result in this paradigm is that when participants are given a surprise recall of the entire set of stimuli, they recall less of the TBF words than of the TBR words (Bjork, Bjork, \& Anderson, 1998).

There are two versions of the directed forgetting paradigm. In the wordmethod, words are assigned TBF or TBR by instructions given immediately after presentation of each word. McNally et al. (2001) used this version to examine forgetting of trauma-related words in women who believed they had repressed or recovered memories of CSA, and women who reported no history of abuse. Since this version especially taps encoding mechanisms (Basden, Basden, \& Gargano, 1993), McNally and co-workers examined whether these groups differed in their ability to intentionally avoid the encoding of neutral (e.g., stairs), positive (e.g., elation), and trauma-related (e.g., incest) words when instructed to do so. McNally et al. (2001) replicated the standard directed forgetting effect. That is, less TBF than TBR words were recalled. However, groups did not differ in their forgetting abilities, even when the emotional valence of the words was taken into account. These results suggest that women with repressed or recovered memories are not characterized by a superior ability to avoid the encoding of trauma-related words.

A second version of the directed forgetting paradigm is the list-method. Here, participants are instructed midway through the presentation of words to 
forget the first half of the list (the TBF set) and to remember the second half of the list (the TBR set). When forget instructions are given in this way, an evenhanded amount of processing would have already been allocated to the TBF words. Therefore, with this method, retrieval is thought to be inhibited on subsequent recall tests. Such retrieval inhibition would render the TBF words temporarily less accessible (Bjork, 1989). This method was used in a recent study of McNally et al. (2004b) that relied on people who reported repressed, recovered or continuous (i.e. permanently accessible) memories of CSA or who had no history of abuse. In line with previous findings, less TBF than TBR words were recalled, while, overall, trauma-related words were better remembered than positive words. Again, this pattern suggests that CSA survivors, including those reporting repressed and recovered memories, are not superior at inhibiting retrieval of trauma-related words.

The present study sought to replicate and extend the results of McNally et al. (2004b). Using the list-method version of the directed forgetting paradigm, we investigated whether women who reported having forgotten their sexual abuse (i.e., repressed and recovered memory group) display a superior ability to inhibit retrieval of trauma-related words relative to participants who had never forgotten their abuse or who said they had never been abused. A subsidiary aim of our study was to explore whether a repressive coping style (e.g., Derakshan \& Eysenck, 1997) is related to heightened retrieval inhibition. Repressive copers (or repressors) are people who do not easily report negative affect, but who do respond physiologically to emotional stimuli (Myers, 2000b). Interestingly, there is tentative evidence that repressors exhibit more directed forgetting than nonrepressors, but only so for negative material (Myers, Brewin, \& Power, 1998). With this in mind, we examined whether repressors display a heightened ability to inhibit retrieval of trauma-related words relative to the other groups (low anxious, high anxious, and defensive high-anxious individuals).

\section{METHOD}

\section{Participants}

We recruited participants through advertisements in local newspapers. In these advertisements, we invited women who a) assumed they had been sexually abused as a child, b) had recovered memories of having been sexually abused as a child, c) had a history of sexual abuse which has never been forgotten and d) 
had no history of sexual abuse to participate in a study on memory and personality. Childhood sexual abuse was defined as abuse ranging from fondling to penetrative acts until the age of 12 . The study was approved by the standing ethical committee of the Faculty of Psychology, Maastricht University.

After providing written informed consent, a semi-structured memory interview was conducted by EG in order to classify participants into one of the four groups (see also McNally et al., 2004b). Individuals reporting repressed, recovered, and continuous memories of CSA were asked whether they had obtained information that could validate the CSA memories. When participants could furnish the name of a corroborator, this person was contacted by EG.

The repressed memory group comprised 16 women (mean age $=43.9$ years, $S D=6.8$ ) who believed that they had been sexually abused as a child, but had no explicit autobiographical memories of CSA. It was, of course, impossible for us to determine whether they had been abused. The term 'repressed memory' describes their belief. The recovered memory group consisted of 23 women (mean age $=41.6$ years, $S D=10.9$ ). They said having previously forgotten and subsequently recalled memories of CSA. Eight participants (35\%) had recovered memories of CSA during psychotherapy. Most of the other women in this group recovered memories of CSA after having been exposed to certain cues. The majority (22 women; 96\%) reported that their recovered memories had a significant impact on their lives. Only one participant said that she had been able to find corroborative evidence for the abuse. The continuous memory group comprised 55 women (mean age $=43.1$ years, $S D=14.4$ ) who said that they had never forgotten their abuse. Nineteen (35\%) provided the name of a person who could corroborate the abuse. The control group comprised 20 women (mean age $=41.5, S D=12$ ) who said that they had, neither during childhood, neither during adulthood ever been sexually abused.

\section{Measures}

A number of self-report scales and tasks were administered to the sample. Here, we discuss those that are directly relevant to the issues of retrieval inhibition and repressive coping style.

Self-report scales. Dissociative Experiences Scale (DES; Bernstein \& Putnam, 1986) (Cronbach's alpha $=.92$ ) is a 28-item self-report measure that quantifies dissociative experiences. Items are scored on 100-mm Visual Analogue Scales 
(VASs) to obtain a total dissociation score (range 0-100), with higher scores indicating higher dissociative tendencies.

In order to study repressive coping style in our participants, we administered the Marlowe-Crowne Social Desirability Scale (MC; Crowne \& Marlowe, 1960) and the Manifest Anxiety Scale (MAS; Taylor, 1953). The MC (Cronbach's alpha $=.89$ ) was employed as a measure of defensiveness. It contains 33 dichotomous (yes/no) items. Higher scores on this scale indicate a higher level of defensiveness. The MAS (Cronbach's alpha $=.91$ ) was administered to measure trait anxiety. It contains 50 dichotomous (yes/no) items. Higher scores reflect a higher trait anxiety.

Adopting the procedure of Myers et al. (1998), MC and MAS scores were used to classify participants in repressors, low-anxious, high-anxious, and defensive high-anxious participants. Weinberger, Schwartz, and Davidson (1979) defined individuals as repressors, when they were highly defensive (i.e., high on the MC) and low on trait anxiety (i.e., low on the MAS). Similarly, low-traitanxious participants who are also low on defensiveness are defined as truly low anxious, while high-anxious participants are defined as those with low defensiveness, but high trait-anxiety scores. Finally, the defensive-high anxious participants score high on both scales. Tertiary splits were used to identify 4 extreme scoring groups: Repressors scored 20 or more on the MC and 16 or less on the MAS; low-anxious participants scored 14 or less on the MC and 16 or less on the MAS; high-anxious participants scored 14 or less on the MC and 27 or more on the MAS; defensive high anxious participants scored 20 or more on the MC and 27 or less on the MAS. Eighteen women qualified as repressors: 1 woman (6\%) from the repressed memory group, 2 women (9\%) from the recovered memory group, 6 women (11\%) from the continuous memory group, and 9 women (45\%) from the control group. Seven participants met the criteria for being low-anxious persons: 2 women (13\%) from the repressed memory group, 2 women (2.8\%) from the recovered memory group, 1 (2\%) woman from the continuous memory group, and 2 (1\%) women from the control group. Sixteen participants qualified as high-anxious persons: 4 women (25\%) from the repressed memory group, 2 women (9\%) from the recovered memory group, 10 women (18\%) from the continuous memory group, but no woman $(0 \%)$ from the control group. Finally, 8 participants qualified as defensive high-anxious individuals: 3 women (19\%) from the repressed memory group, 2 women (9\%) from the recovered memory group, 3 women (5\%) from the continuous memory 
group, but no woman (0\%) from the control group. Participants who did not meet criteria for these four categories were excluded from analysis.

Directed Forgetting task. Two lists of trauma-related and positive words were presented to each participant on a personal computer. Each word appeared for $3 \mathrm{~s}$ on the centre of a screen in white lower case letters against a dark blue background, with $5 \mathrm{~s}$ intervals between presentations. The first list was preceded by three filler (neutral) words. The two lists consisted of 10 CSA-related words (e.g., assault, sperm) and 10 positive words (e.g., sincere, friendly). Within each list, CSA and positive words appeared in random order. The two lists were counterbalanced across participants. Words did not differ in word frequency and word length across lists and across positive and trauma-related words (Hermans \& de Houwer, 1994).

It was important to verify that any differential recall between the TBF and TBR words would be a consequence of directed forgetting rather than a recency effect (Myers et al., 1998). Therefore, the two lists were presented to a separate control group, which consisted of 20 female undergraduate students at Maastricht University whose mean age was 19.05 years $(S D=1.2)$. Unlike the standard list version of directed forgetting, they were not instructed that the first list was merely to practice and should be forgotten.

\section{Procedure}

All participants were individually tested during a session that lasted for approximately 2 hours. First, women completed the self-report scales. Following this, they underwent the directed forgetting task. As an introduction to this, women were told that they were taking part in an emotional judgement task, with no indication that they had to remember words.

Following McNally et al. 's procedure (2004b), participants were asked to rate each word in terms of their emotional meaning on a 7-point scale with -3 anchored at very negative and +3 anchored at very positive. After presentation of the first list, the following instruction was given: "What you have done so far was practice. You can forget about those words. I will now show you the actual set of test words that I want you to rate for emotionality in the same way you did for the practice words". The second list was then presented, after which a mathematical distractor task had to be completed within 3 min (easy addition and subtraction 
problems). Next, participants were given a surprise recall task, in which they were asked to recall as many words as possible from both lists within $5 \mathrm{~min}$.

\section{RESULTS}

Table 3.1 shows psychometric data for the subgroups in our sample. One-way Analyses of Variance (ANOVAs) revealed that the subgroups did not differ significantly in age or level of education: both $F \mathrm{~s}(3,110)<1.0$, ns. However, with respect to the self-report scales, they differed significantly on every other variable. Post-hoc tests (LSD) indicated that the repressed, recovered, and continuous memory group scored higher on trait anxiety (MAS) and lower on defensiveness (MC) than the control group (all $t$ 's $>3.7$, all $p$ 's $<.001$ ). Moreover, both the repressed and recovered memory groups reported more dissociative symptoms (DES) than the continuous memory group and the control group (all $t$ 's $>2.1$, all $p$ 's $<.03$ ).

Table 3.1 Demographic data and mean scores of subgroups on the Dissociative Experiences Scale (DES), Marlowe-Crowne Social Desirability Scale (MC), and Manifest Anxiety Scale (MAS). Standard deviations are in parentheses.

\begin{tabular}{lllll}
\hline & $\begin{array}{l}\text { Repressed } \\
n=16\end{array}$ & $\begin{array}{l}\text { Recovered } \\
n=23\end{array}$ & $\begin{array}{l}\text { Continuous } \\
n=55\end{array}$ & $\begin{array}{l}\text { Control } \\
n=20\end{array}$ \\
\hline Measure & $M$ & $M$ & $M$ & $M$ \\
DES & 31.5 & 30.1 & 22.2 & 12.9 \\
& $(11.6)$ & $(19.4)$ & $(12.6)$ & $(9.0)$ \\
MC & 15.2 & 16.7 & 16.8 & 20.3 \\
& $(6.1)$ & $(4.8)$ & $(5.1)$ & $(5.0)$ \\
MAS & 25.1 & 23.2 & 23.8 & 14.1 \\
& $(8.0)$ & $(8.0)$ & $(9.9)$ & $(5.1)$ \\
\hline
\end{tabular}

Wordlist data of the additional control group (20 female undergraduates) were first inspected to check for recency effects that might interfere with directed forgetting. There was no significant difference in mean recall for the first list of negative words $(M=3.4, S D=1.4)$ and the second list of negative words $(M=3.8, S D=1.4), t(19)<1.0, n s$. Nor was there a significant difference in mean recall of the first list of positive words $(M=1.7, S D=1.4)$ and the second list of positive words $(M=2.2, S D=1.2), t(19)<1.0$, ns. One-way 
Analysis of Variance (ANOVA) performed on the number of words recalled yielded no significant effect for list order, largest $f(1,18)=.32$, ns. Thus, it can be concluded that, in the absence of a forget instruction, there was no evidence that women tended to recall the two lists differently.

Proportion of words recalled for the four subgroups are shown in Table 3.2. A 4 (Group: repressed versus recovered versus continuous versus control group) $\times 2$ (Instruction: TBF or TBR) $\times 2$ (Valence: CSA-related versus positive words) ANOVA with repeated measures on the last two factors yielded significant main effects for Instruction $F(1,110)=40.1, p<.001$, and Valence, $F(1,110)=$ 83.1, $p<.001$, but not for Group, $F(3,110)<1.0$, ns. Post-hoc contrasts (LSD) indicated a substantial directed forgetting effect with overall, fewer words being recalled from the TBF list than from the TBR list, $t(113)=18.2, p<.001$. Moreover, CSA-related words were better recalled than positive words, $t(113)=$ 20.1, $p<.001$. Importantly, the critical Group $\times$ Instruction $\times$ Valence interaction, which would indicate superior forgetting skills in repressed or recovered memory groups, did not attain significance: $F(3,110)=.97, p=.41$. Similarly, all other interactions remained non-significant, all $F(3,110)$ 's $<1.0$, all $p$ 's $>.30$.

Following Myers et al. (1998), we examined whether repressors exhibit a specific memory deficit. A 4 (Group: repressors, low-anxious, high-anxious and defensive high-anxious) $\times 2$ (Instruction: TBF versus TBR) $\times 2$ (Valence: CSArelated versus positive words) ANOVA with repeated measures on the last two factors yielded again significant main effects for Instruction, $F(3,45)=19.2, p<$ .001 and Valence, $F(3,45)=47.4, p<.001$, but not for Group, $F(3,45)=.51$, $n s$. There were no other significant effects, $p$ 's $>.17$. Most importantly, the critical Group x Instruction $x$ Valence interaction fell short of significance, $F(3$, $45)=.88, p=.42$. Thus, unlike Myers et al. (1998), we found no evidence that repressors are better forgetters of negative information, relative to high-anxious, low-anxious, or defensive high-anxious women'. 
Table 3.2 Mean proportion of words recalled as a function of group, instruction (TBF vs. TBR) and valence (CSA vs. positive words). Standard deviations are in parentheses.

\begin{tabular}{lllll}
\hline & $\begin{array}{l}\text { Repressed } \\
n=16\end{array}$ & $\begin{array}{l}\text { Recovered } \\
n=23\end{array}$ & $\begin{array}{l}\text { Continuous } \\
n=55\end{array}$ & $\begin{array}{l}\text { Control } \\
n=20\end{array}$ \\
\hline $\begin{array}{l}\text { Instruction } \\
\text { Valence }\end{array}$ & $M$ & $M$ & $M$ & $M$ \\
TBF CSA & .23 & .24 & .24 & .25 \\
& $(.06)$ & $(.08)$ & $(.07)$ & $(.07)$ \\
TBR CSA & .33 & .30 & .34 & .33 \\
& $(.07)$ & $(.07)$ & $(.08)$ & $(.08)$ \\
TBF positive & .11 & .13 & .15 & .21 \\
& $(.04)$ & $(.05)$ & $(.07)$ & $(.07)$ \\
TBR positive & .23 & .22 & .24 & .21 \\
& $(.06)$ & $(.05)$ & $(.07)$ & $(.06)$ \\
\hline
\end{tabular}

\section{DISCUSSION}

The purpose of this study was to examine whether women who said they had repressed or recovered CSA memories would show superior forgetting abilities. Contrary to what is often suggested in clinical literature (e.g., Brewin \& Andrews, 1998), but perfectly in line with the findings of McNally, Clancy, and their associates $(2001,2004 \mathrm{~b})$, women with repressed or recovered memories did not exhibit superior abilities to inhibit trauma-related material. In fact, all groups showed better recall of trauma-related words than of positive words. This is difficult to reconcile with the idea that compared to control participants, traumatized people would possess a better retrieval inhibition mechanism and as a consequence would be better in forgetting trauma-related words (Cloitre, 1998). While Moulds and Bryant (2002) reported enhanced forgetting of traumarelated words in patients with acute stress disorder, DePrince and Freyd (2004) found that those scoring high on dissociation exhibited memory deficits for trauma-related words when they viewed these words under divided attention conditions. Employing DePrince and Freyd's procedure, McNally, Ristuccia, and Perlman (2005), however, found that adults reporting recovered memories of CSA (like adults with continuous CSA memories and controls) remembered the trauma-related words all too well, irrespective of divided or selective attention 
conditions. The trauma-related words used in the current experiment were more associated with CSA (see also McNally et al., 2004b, 2005) than were negative words employed in some previous directed forgetting experiments (Cloitre et al., 1996; Myers et al., 1998; Myers \& Derakshan, 2004a). Therefore, we assume that the attention-grabbing power of these trauma-related words enhanced their memorability for all participants, including the control group.

The fact that we essentially replicated the findings of McNally, Clancy, and co-workers $(2000,2004 \mathrm{~b})$ makes clear that there is no solid empirical evidence for the assumption that women with repressed or recovered CSA memories have a superior ability to inhibit retrieval of such memories. In fact, current memory literature does not make one very optimistic about the chance of finding such a connection. After all, a growing body of research indicates that high levels of real-life stress facilitate rather than undermine the quality of memory. For example, studies on children who have been kidnapped (Terr, 1983), but also studies on witnesses to homicide (Yuille \& Cutshall, 1986), survivors of a ferry sinking (Thompson, Morton, \& Fraser, 1997), and concentration camp survivors (Kuch \& Cox, 1992; Merckelbach, Dekkers, Wessel, \& Roefs, 2003a; Schelach, \& Nachson, 2001; Wagenaar \& Groeneweg, 1990) noted that their memories of traumatic events were usually very vivid and did not show any signs of amnesia. Also, the majority of laboratory studies found that emotional memory is more likely to be enhanced than impaired (e.g., Cahill, Prins, Weber, \& McGaugh, 1994). Raised levels of arousal may render a memory more distinctive and hence easier to recollect (e.g., Jelicic, Geraerts, Merckelbach, $\&$ Guerrieri, 2004). Thus, on the basis of the empirical literature on emotional memory, it is hard to understand how traumatic events could be dissociated or repressed (McNally et al., 2004b). Meanwhile, research investigating recovered memories and proneness to forming false memories, indicates that people with recovered CSA memories are more prone to falsely recall and recognize neutral and trauma-related material (Clancy et al., 2000; Geraerts, Smeets, Jelicic, van Heerden, \& Merckelbach, 2005).

Our study also looked at the extent to which women qualified as repressors. However, our results do not confirm that people characterized by a repressive coping style display a superior retrieval inhibition mechanism. Furthermore, in contrast to Myers et al. (1998), there was no evidence for a specific memory deficit. That is, repressors were no better forgetters of negative material than were women who relied on other types of coping style. Note, 


\section{CHAPTER 3}

however, that participants in the Myers et al. (1998) study did not claim having repressed or recovered memories of CSA. Moreover, overall, our participants exhibited heightened anxiety levels, while repressors, by definition, report low anxiety levels. As a consequence, half of the repressors in our study came from the control group, i.e., were women who said that they had no CSA experiences. Nevertheless, our findings are difficult to reconcile with studies that found repressors to be particularly good at suppressing negative childhood experiences (Barnier, Levin, \& Maher, 2004a; Myers \& Brewin, 1994). Also, the fact that only a small minority of the repressors had repressed or recovered memories of CSA casts doubts on the idea that there must be an intimate link between such memories and repressive coping.

Directed forgetting cannot serve as a lie detection procedure. Thus, the failure of our participants with repressed or recovered CSA memories to show superior forgetting of trauma-related words does not implicate that their memories were false. What this failure suggests, however, is that clinical intuitions about dissociative or repressive memory inhibition may be less plausible than previously thought. 
PART 2

FALSE AND RECOVERED MEMORIES 

CHAPTER 4

Fantasy Proneness, but not SelfReported Trauma is Related to DRM Performance of Women Reporting Recovered Memories of Childhood Sexual Abuse

An adjusted version of this chapter is published as: Geraerts, E., Smeets, E., Jelicic, M., van Heerden, J., \& Merckelbach, H. (2005). Fantasy proneness, but not self-reported trauma is related to DRM performance of women reporting recovered memories of childhood sexual abuse. Consciousness and Cognition, 14, 602-612. 


\begin{abstract}
Extending a strategy previously used by Clancy, Schacter, McNally, and Pitman (2000), we administered a neutral and a trauma-related version of the Deese/Roediger-McDermott paradigm to a sample of women reporting recovered ( $n=23$ ) or repressed memories $(n=16)$ of childhood sexual abuse (CSA), women reporting having always remembered their abuse $(n=55)$, and women reporting no history of abuse $(n=20)$. We found that individuals reporting recovered memories of CSA are more prone than other participants to falsely recalling and recognizing neutral words that were never presented. Moreover, our study is the first to show that this finding even held when trauma-related material was involved. Correlational analyses revealed that fantasy proneness, but not self-reported traumatic experiences and dissociative symptoms were related to false recall and false recognition.
\end{abstract}

\title{
INTRODUCTION
}

McNally, Clancy, and their colleagues were among the first to apply experimental methods to investigate memory functioning in women reporting repressed and recovered memories of childhood sexual abuse (CSA). In one of their studies, Clancy, Schacter, McNally, and Pitman (2000) made use of the Deese-RoedigerMcDermott (DRM) task (Deese, 1959; Roediger \& McDermott, 1995), a paradigm that is very effective in eliciting false memories. In the DRM paradigm, participants study a list of words that are strong semantic associates of a word not presented on the list - the critical lure. For example, participants may study words like bed, rest, awake, tired, and so forth, all of which are strongly related to the nonpresented critical item, sleep. On a subsequent test, participants often falsely recall and recognize the critical lure (e.g., sleep).

Clancy et al. (2000) used this paradigm to examine whether participants reporting recovered memories of CSA would be more prone than others to develop false memories in the DRM paradigm. In their study, control women reporting no history of abuse, and women reporting recovered, repressed, or continuous memories of CSA underwent the DRM task. Clancy et al. (2000) found that, relative to the other groups, women reporting recovered CSA memories more often falsely recognized the nonpresented critical lures. This suggests that these women relied more on memory for gist than on verbatim memory traces of 
the individual words they had studied (e.g., Brainerd \& Reyna, 1998). Two further studies employed the DRM paradigm to examine memory functioning in people reporting traumatic experiences. Bremner, Shobe, and Kihlstrom (2000) studied women with continuous memories of CSA who were suffering from posttraumatic stress disorder (PTSD). The authors found that these women displayed a higher frequency of false recognition than abused women without PTSD. Zoellner, Foa, Brigidi, and Przeworski (2000) reported that victims of criminal assaults with or without PTSD more often falsely recalled critical nonpresented words than did nontraumatized participants. Thus, the literature on DRM performance of people reporting traumatic experiences allows for two interpretations. On the one hand, one could argue that the raised frequencies of false recall in people with recovered memories show that they are especially susceptible to develop pseudomemories. On the other hand, there are indications that people who have been traumatized exhibit memory impairments of which heightened levels of false recall on the DRM paradigm might be a manifestation (Zoellner et al., 2000).

Although the DRM paradigm creates striking memory illusions, Freyd and Gleaves (1996) questioned the relevance of the DRM paradigm to real world examples of alleged false memories (e.g., in recovered CSA memories or eyewitness testimony). They noted that the real world scenarios where false memories may occur typically involve highly emotional events (e.g., CSA), whereas words used in the DRM paradigm are not emotionally charged and hence not trauma-related. Freyd and Gleaves (1996) hypothesized that the frequency of false recall and recognition in the DRM paradigm would be lowered when traumarelated items would be used, due to their emotional distinctiveness. Our study is the first to address this issue by employing neutral and trauma-related DRM lists to traumatized individuals. We investigated whether participants who reported having recovered CSA memories displayed higher rates of false recall and recognition for neutral and trauma-related words relative to other participants.

A subsidiary aim of our study concerned the issue of whether certain traits are associated with performance on the DRM task. More specifically, we examined whether individual differences in fantasy proneness and dissociation are connected to false recall and recognition in the DRM task. It might be speculated, for example, that people who are, possibly due to heightened levels of fantasy proneness, predisposed to false memory effects in the DRM task, would also be predisposed to have pseudo-memories. Conversely, CSA might create dissociative tendencies that may lead to enhanced false memory effects on 
the DRM task. Previous research, for example, has shown that people scoring high on the Dissociative Experiences Scale (DES; Bernstein \& Putnam, 1986) are susceptible to memory distortions induced by various laboratory tests (e.g., Eisen \& Lynn, 2001), including the DRM paradigm (Clancy et al., 2000; Winograd, Peluso \& Glover, 1998). A number of authors have noted that there is a considerable overlap between dissociation and fantasy proneness (e.g., Rauschenberger \& Lynn, 1995; Merckelbach \& Muris, 2001). We also obtained participants' scores on the Childhood Trauma Questionnaire (CTQ; Bernstein, Stein, Newcomb, Walker, Pogge et al., 2003). If false memories in the DRM paradigm are a manifestation of memory impairment due to traumatization, one would expect a robust correlation between false memories on the DRM task and CTQ scores. If, on the other hand, the DRM paradigm primarily taps susceptibility to pseudo-memories, one would expect a significant association between such false memories and fantasy proneness.

\section{METHOD}

\section{Participants}

Following the procedure of Clancy et al. (2000), we recruited participants through advertisements in local newspapers. In these advertisements, we invited women to come to our lab when they a) had recovered CSA memories, b) believed they had been sexually abused as a child, c) had a history of sexual abuse which had never been forgotten or d) had no history of sexual abuse. The study was described as a research project on memory and personality. The study was approved by the standing ethical committee of the Faculty of Psychology, Maastricht University.

After providing written informed consent, a semi-structured memory interview was conducted in order to classify participants into one of the groups (see also Clancy et al., 2000). Participants reporting CSA memories were asked whether they had obtained information that could validate the CSA memories.

The recovered memory group consisted of 23 women (mean age $=41.6$ years, $S D=10.9$ ) who said having previously forgotten and subsequently recalled memories of CSA. Only one participant could give corroborative evidence for the abuse, namely a statement of the perpetrator himself. However, in most cases, women lost contact with their families after having confronted them with recovered CSA memories. The repressed memory group comprised 16 women 
(mean age $=43.9$ years, $S D=6.8$ ) who believed that they had been sexually abused as a child. The continuous memory group comprised 55 women (mean age $=43.1$ years, $S D=14.4$ ) who said that they had never forgotten their abuse. Nineteen (35\%) provided the name of a person who could corroborate the abuse. The control group comprised 20 women (mean age $=41.5, S D=12$ ) who said that they had, neither during childhood, neither during adulthood ever been sexually abused.

\section{Measures}

A number of self-report scales and tasks were administered to the sample. Here, we only discuss those that are directly relevant to the issue of DRM performance and its correlates.

Self-report scales. The Dissociative Experiences Scale (DES; Cronbach's alpha $=.92$; Bernstein \& Putnam, 1986) is a 28-item self-report measure that asks respondents how often they experience dissociative symptoms like derealization and depersonalization. Items are scored on 100-mm Visual Analogue Scales (VASs). Scores are summed to obtain a total DES score (range 0100), with higher scores indicating higher dissociative tendencies. The DES exhibits high internal consistency and test-retest correlations ranging from .74 to .84. Van IJzendoorn and Schuengel (1996) have shown that the DES has excellent psychometric properties.

The Creative Experiences Questionnaire (CEQ; Cronbach's alpha = .79; Merckelbach, Muris, \& Rassin, 1999) is a measure that is based on Wilson and Barber's (1983) listing of fantasy proneness characteristics. The CEQ includes 25 dichotomous (yes/no) items covering experiences related to daydreaming, imagining, and intense fantasizing. Psychometric research (for a review, see Merckelbach, Horselenberg, \& Muris, 2001) has shown that the CEQ possesses adequate reliability in terms of internal consistency and test-retest stability. Furthermore, the CEQ has predictive validity in the sense that certain categories of persons who are known to exhibit fantasy-prone characteristics (e.g., people with paranormal experiences, amateur actors) display higher scores on this scale than control participants.

The Childhood Trauma Questionnaire (CTQ; Cronbach's alpha = .82; Bernstein et al., 2003) is a widely used psychometrically sound self-report scale of aversive childhood experiences. The short form consists of 25 items that 
address five areas of childhood maltreatment, namely emotional, physical, and sexual abuse, and emotional and physical neglect. Items are rated on 5-point scales anchored 1 (never) and 5 (very often). A number of recent nonclinical (e.g., Irwin, 2001; Merckelbach, Horselenberg, \& Schmidt, 2002) as well as clinical studies (e.g., Carrion \& Steiner, 2000; Gast, Rodewald, Nickel, \& Emerich, 2001) on trauma and dissociation employed this measure. Moreover, Bernstein, Ahluvalia, Pogge, and Handelsman (1997) showed that the psychometric properties of the CTQ are satisfactory.

$D R M$ paradigm. The ten neutral word lists used in the current study were derived from lists previously employed in our lab (Peters, Jelicic, Haas, \& Merckelbach, in press). Extensive pilot work showed that they produce rates of false recall and recognition comparable to those reported by Roediger and McDermott (1995). Adopting the procedure of Peters et al., the ten traumarelated word lists were constructed as follows. For each critical trauma-related lure, we developed a corresponding word list by obtaining the first 15 associates listed in Lauteslager, Schaap, and Schievels' (1986) and Van Loon, Vervoorn, and Van Bekkum's (1991) word association norms. For example, the first five associates corresponding to assault were rape, police, beating, child, and violence. On all lists, associates were presented in decreasing order of associative strength. The ten neutral and ten trauma-related lists were counterbalanced across participants.

The recognition test consisted of 120 words; 60 (30 neutral and 30 trauma-related words) had been presented in the study phase, while 60 (30 neutral and 30 trauma-related) were new items. The 60 studied items were obtained by selecting 3 items from each list from serial positions 1, 8, and 10 . The 60 new items included the 20 critical lures associated with the study words (e.g., needle, assault), 20 (10 neutral and 10 trauma-related) words unrelated to any words on the list, and 20 (10 neutral and 10 trauma-related) words weakly related to words on the list.

\section{Procedure}

All participants were tested individually during a session that lasted for approximately 2 hours. First, women completed the self-report scales and after a delay of 30 minutes, they underwent the DRM task. Participants were instructed that they would see several lists of words on a computer screen and that 
following each list, they would be asked to write down these words. They were told to write down the last few words they had seen (which is a standard instruction for this task) and then to write down the rest of the words they remembered in any order. They were instructed to write down as many words they could remember, provided they were reasonably confident that these words had been on the list (i.e., they were told not to guess). During the study phase, each word remained for $3 \mathrm{~s}$ on the computer screen. Participants were given 2.5 $\min$ to recall each list. After the $20^{\text {th }}$ list, there was a brief conversation lasting 2 to $3 \mathrm{~min}$. Subsequently, participants were given a sheet with the old and new words and they were asked to indicate whether or not each word had appeared on any of the studied lists.

\section{RESULTS}

\section{Self-report scores}

One-way Analyses of Variance (ANOVAs) revealed that subgroups did not differ significantly in age or educational level: both $F \mathrm{~s}(3,110)<1.0$, ns. However, subgroups differed significantly with respect to all self-report scales. Both the recovered and repressed memory subgroups reported more dissociative symptoms (DES) than the continuous memory group and the control group (all $t$ 's $>2.1$, all $p$ 's $<.03$ ). Post-hoc tests (LSD) indicated that women with recovered, repressed, or continuous CSA memories scored higher on fantasy proneness (CEQ) and childhood trauma (CTQ) than control women reporting no history of abuse (all $t$ 's $>3.8$, all $p$ 's $<.001$ ).

\section{Recall}

Neutral lists. Correct recall (i.e., mean proportion of recall of studied words), false recall of critical lures and nonstudied words other than the critical lures (i.e., mean proportion of recall of nonstudied critical lures and of nonstudied words other than the critical lures) are shown in Table 4.1. Because we had no specific predictions about correct recall, we performed ANOVAs followed by post-hoc contrasts (LSD). Results revealed that all groups displayed equivalent rates of correct recall: $F(3,110)<1.0$, ns. Participants recalled $56 \%$ of the words presented in the neutral lists correctly. 
To test whether recovered memory participants displayed higher levels of false recall than the other groups, we computed the false recall rate (i.e. false recall of critical lures minus false recall of nonstudied words other than the critical lures) and applied contrast weights of $3,-1,-1$, and -1 to the recovered, repressed, continuous, and control subgroups, respectively. Women with recovered memories of CSA had a higher rate of false recall compared to the repressed, continuous, and control group, $t(110)=4.30, p<.001$, effect size $r=.43$.

Trauma-related lists. ANOVAs followed by post-hoc contrasts (LSD) showed that all participants displayed similar rates of correct recall for traumarelated words, $F(3,110)<1.0$, ns, with a mean proportion of recall of $43 \%$. Performing the earlier mentioned contrast analysis on false recall rate, we found a nonsignificant difference between the groups: $t(110)=.84, p>.05$, effect size $r$ $=.19$. Curiously enough, for the trauma-related lists, critical lures were recalled at a low rate of $15 \%$.

\section{Recognition}

Neutral lists. Hit rate (i.e., mean proportion of correct recognition) and false alarm for critical lures and nonstudied words other than the critical lures (i.e., mean proportion of recognition of nonstudied critical lures and of nonstudied words other than the critical lures) are shown in Table 4.2. ANOVAs indicated that all groups exhibited similar rates of correct recognition of neutral words, $F(3$, $110)<1.0$, ns. Overall, studied words were recognized at a rate of $74 \%$.

To test whether recovered memory participants displayed higher rates of false recognition than the other groups, we computed the false recognition rate (i.e. false recognition of critical lures minus false recognition of nonstudied words other than the critical lures) and again applied contrast weights of $3,-1,-1$, and -1 to the recovered, repressed, continuous, and control group, respectively. A significant difference was found, $t(110)=3.17, p=.002$, effect size $r=.30$, demonstrating that women with recovered memories of CSA more often falsely recognized critical lures than the other women. 
Table 4.1 Proportion of recalled studied words, critical lures, and nonstudied words other than the critical lure for neutral and trauma-related lists. Standard deviations are in parentheses.

\begin{tabular}{lllll}
\hline & $\begin{array}{l}\text { Recovered } \\
n=23\end{array}$ & $\begin{array}{l}\text { Repressed } \\
n=16\end{array}$ & $\begin{array}{l}\text { Continuous } \\
n=55\end{array}$ & $\begin{array}{l}\text { Control } \\
n=20\end{array}$ \\
\hline Word Type & $M$ & $M$ & $M$ & $M$ \\
Neutral studied words & .56 & .56 & .55 & .59 \\
& $(.11)$ & $(.08)$ & $(.11)$ & $(.09)$ \\
Neutral critical lures & .61 & .46 & .42 & .44 \\
& $(.18)$ & $(.21)$ & $(.18)$ & $(.16)$ \\
Neutral nonstudied words & .14 & .22 & .21 & .14 \\
other than critical lures & $(.19)$ & $(.20)$ & $(.19)$ & $(.12)$ \\
Trauma-related studied & .42 & .43 & .42 & .46 \\
words & $(.09)$ & $(.08)$ & $(.11)$ & $(.08)$ \\
$\begin{array}{l}\text { Trauma-related critical } \\
\text { lures }\end{array}$ & .20 & .16 & .14 & .13 \\
$\begin{array}{l}\text { Trauma-related } \\
\text { nonstudied words other }\end{array}$ & $(.10)$ & $(.17)$ & $(.11)$ & $(.13)$ \\
than critical lures & .20 & .17 & .13 & .13 \\
\hline
\end{tabular}

Trauma-related lists. The groups showed equivalent rates of accurate recognition for trauma-related words: $F(3,110)<1.0$, ns. Overall, $83 \%$ of the studied words were correctly recognized. Analysis with contrast weights indicated that women with recovered CSA memories had a higher rate of false recognition of trauma-related critical lures than the other groups, $t(110)=2.46, p=.015$, effect size $r=.28$. 
Table 4.2 Proportion of recognized studied words, critical lures, and nonstudied words other than the critical lure for neutral and trauma-related lists. Standard deviations are in parentheses.

\begin{tabular}{lllll}
\hline & $\begin{array}{l}\text { Recovered } \\
n=23\end{array}$ & $\begin{array}{l}\text { Repressed } \\
n=16\end{array}$ & $\begin{array}{l}\text { Continuous } \\
n=55\end{array}$ & $\begin{array}{l}\text { Control } \\
n=20\end{array}$ \\
\hline Word Type & $M$ & $M$ & $M$ & $M$ \\
Neutral studied words & .76 & .75 & .72 & .74 \\
& $(.09)$ & $(.09)$ & $(.15)$ & $(.15)$ \\
Neutral critical lures & .86 & .78 & .73 & .72 \\
& $(.08)$ & $(.17)$ & $(.19)$ & $(.09)$ \\
Neutral nonstudied words & .06 & .09 & .04 & .06 \\
other than critical lures & $(.04)$ & $(.06)$ & $(.03)$ & $(.03)$ \\
Trauma-related studied & .85 & .79 & .83 & .86 \\
words & $(.09)$ & $(.15)$ & $(.12)$ & $(.10)$ \\
$\begin{array}{l}\text { Trauma-related critical } \\
\text { lures }\end{array}$ & .91 & .81 & .74 & .73 \\
$\begin{array}{l}\text { Trauma-related } \\
\text { nonstudied words other }\end{array}$ & $(.09)$ & $(.14)$ & $(.17)$ & $(.08)$ \\
than critical lures & .20 & .16 & .16 & .17 \\
\hline
\end{tabular}

\section{Individual differences and DRM performance}

Table 4.3 shows Pearson correlations between DRM scores, dissociation, fantasy proneness, and childhood trauma. DES scores were significantly associated with unrelated intrusions on recall tests (neutral lists: $r=.23, p<.05$; trauma-related lists: $r=.25, p<.001)$ and false recognition of unrelated trauma words $(r=.37$, $p<.001)$. However, correlations between DES and false recall and recognition of critical lures fell short of significance (all $r$ 's $<.16, p$ 's $>.09$ ). CEQ correlated significantly with false recall and recognition of neutral and trauma-related critical lures (all $r$ 's $>.19$, all $p$ 's $<.05$ ). Self-reported childhood trauma (CTQ) did not correlate significantly with any false recall or recognition parameter (all r's $<.15$, all $p$ 's $>.12$ ). 
Table 4.3 Pearson product-moment correlations between dissociative experiences (DES), fantasy proneness (CEQ), self-reported childhood trauma (CTQ), and recall and recognition parameters.

\begin{tabular}{|c|c|c|c|c|}
\hline & & $D E S$ & CEQ & CTQ \\
\hline \multirow[t]{4}{*}{ Recall } & Neutral critical lures & .11 & $.21 *$ & .10 \\
\hline & $\begin{array}{l}\text { Neutral nonstudied } \\
\text { words other than } \\
\text { critical lures }\end{array}$ & $.23 * *$ & .07 & .09 \\
\hline & $\begin{array}{l}\text { Trauma-related critical } \\
\text { lures }\end{array}$ & .10 & $.22 *$ & .02 \\
\hline & $\begin{array}{l}\text { Trauma-related } \\
\text { nonstudied words other } \\
\text { than critical lures }\end{array}$ & $.25 *$ & .01 & .15 \\
\hline \multirow[t]{4}{*}{ Recognition } & Neutral critical lures & .10 & $.22^{*}$ & .14 \\
\hline & $\begin{array}{l}\text { Neutral nonstudied } \\
\text { words other than } \\
\text { critical lures }\end{array}$ & .09 & .09 & .08 \\
\hline & $\begin{array}{l}\text { Trauma-related critical } \\
\text { lures }\end{array}$ & .16 & $.19^{*}$ & .11 \\
\hline & $\begin{array}{l}\text { Trauma-related } \\
\text { nonstudied words other } \\
\text { than critical lures }\end{array}$ & $.37^{* *}$ & .05 & .07 \\
\hline
\end{tabular}

$* *$ Correlation is significant at the .01 level (2-tailed)

*Correlation is significant at the .05 level (2-tailed)

\section{DISCUSSION}

The purpose of this study was to determine whether women reporting recovered CSA memories would show enhanced false recall and recognition on a neutral and trauma-related version of the DRM paradigm. Our results replicate the robust false recall and recognition effects typically found with the DRM paradigm (Roediger \& McDermott, 1995). That is, overall, participants falsely remembered many of the critical lures. Replicating earlier findings of Clancy et al. (2000), our results also lend support to the idea that women reporting recovered CSA memories are more susceptible than other participants to this memory illusion. More specifically, women with recovered memories of CSA exhibited higher rates 
of false recall and false recognition of critical lures than the other participants. Our study was the first to show that this was true for both neutral and traumarelated word lists, although the effects were more convincing for recognition than for recall parameters. Taken together, our data are difficult to reconcile with Freyd and Gleaves' (1996) suggestion that the memory illusion tapped by the DRM paradigm would be less strong with trauma-related words, that is, that participants would have fewer false memories when the items are trauma-related relative to neutral items. While recall of trauma-related lures was, indeed, less frequent than recall of neutral lures, false memories did occur and were especially robust in the recognition modality. This smaller effect for recall of trauma-related words may have to do with the emotional salience and distinctiveness of the trauma-related words. This is in line with findings of Pesta, Murphy, and Sanders (2001) that emotional critical lures are subject to false remembering in the DRM task but at a lower rate than neutral critical lures.

A number of researchers have argued that susceptibility to false memories may be due to a deficit in source monitoring, i.e., incorrect judgments about the origin or source of information (Johnson, Hashtroudi, \& Lindsay, 1993). Accordingly, the presentation of semantically associated words activates a concept that is common to all words on the list, namely the critical nonpresented lure. Thus, the DRM paradigm requires participants to differentiate between internally generated thoughts and genuine memories of the studied words (Roediger, Watson, McDermott, \& Gallo, 2001). The present results suggest that women reporting recovered CSA memories may have a source monitoring deficit for all types of material, whether the content is neutral or trauma-related. It can be speculated that especially these women have difficulties with the identification of the origin of a memory and that they may have a tendency to adopt an internally generated thought as being a genuine memory. This could have serious implications, also in everyday life, both in potential impact on the memory and on the development of their knowledge and beliefs. Additionally, it might well be the case that source monitoring confusion can produce pseudo-memories. Therefore, it is very important to recognize that the influence of source monitoring on the origin of recovered memories warrants further study. Performance of people with recovered memories in paradigms that explicitly require source monitoring (e.g., false-fame studies, eyewitness suggestibility tests) should be investigated. 
In the current study, we also explored whether certain traits are associated with the tendency to develop false memories. Specifically, we examined whether individual differences in dissociation and fantasy proneness were connected to false recall and false recognition on the DRM task. Women who said they had recovered or repressed CSA memories scored higher on the DES than women who indicated they had always remembered their abuse or control women. However, unlike Clancy et al. (2000), we found no significant associations between DES scores and false memories on the DRM paradigm (see for a similar failure: Platt, Lacey, lobst, \& Finkelman, 1998). This failure could be due to the fact that women in the recovered and repressed memory group had higher scores on the DES than women in the continuous memory and control group, in comparison to equivalent DES scores for all subgroups in the study of Clancy et al. (2000). Moreover, it can be speculated that, perhaps, then, dissociative experiences are related to false memories that have a more episodic or autobiographical signature (e.g., Candel, Merckelbach, \& Kuijpers, 2003). On the other hand, fantasy proneness, a close cousin of dissociation, was significantly related to false recall and false recognition. One interpretation of the link between fantasy proneness and false memories is that self-reported traumatic childhood experiences -whether they have been recovered, repressed or are continuously remembered- contribute to fantasy proneness, thereby making traumatized people sensitive to memory illusions like those elicited by the DRM paradigm. Work by Zoellner et al. (2000) and Bremner et al. (2002) seems to support this line of reasoning. Yet, the results of the current study indicate that self-reported traumatic experiences are not related to false recall and false recognition. Note that the CTQ (Bernstein et al., 2003) not only contains items that refer to specific episodes of childhood trauma, but also items that measure the belief or impression that one has experienced aversive childhood events (Merckelbach \& Jelicic, 2004). In sum, then, our data suggest that when it comes to the psychometric correlates of false memories on the DRM paradigm, fantasy proneness rather than self-reported traumatization runs the show. It can be speculated that fantasy proneness includes an ability to associate semantically and hence allowing for more associations which can lead to 'recall' of internally generated thoughts.

Finally, the question arises whether our results have any bearing on the current controversy about recovered/false memories of CSA. Certainly, they lend support that the illusion of remembering events that never happened can happen 


\section{CHAPTER 4}

fairly easily and that cognitive impairments related to recovered memories of CSA enhance susceptibility for false recall and recognition effects. Of course, the finding that individuals falsely remember having seen a word in a laboratory context does by no means imply that their recovered CSA memories are false. Our results do, however, show that women with recovered CSA memories are, possibly due to a source monitoring deficit, more prone than others to develop certain types of memory distortions, even with trauma related material. 
CHAPTER 5

Dissociative Symptoms and How They Relate to Fantasy Proneness in Women Reporting Repressed or Recovered Memories

This chapter is published as: Geraerts, E., Merckelbach, H., Jelicic, M., Smeets, E. $\&$ van Heerden, J. (2006). Dissociative symptoms and how they relate to fantasy proneness in women reporting repressed or recovered memories. Personality and Individual Differences, 40, $1143-1151$. 


\begin{abstract}
Women with repressed or recovered memories have raised levels of dissociative symptoms. There are two interpretations of this. One emphasizes the defensive function of dissociation, while the other emphasizes the overlap between dissociation and fantasy proneness. This study aimed to investigate these two interpretations. Women with repressed $(n=16)$, recovered $(n=23)$, and continuous memories $(n=55)$ of childhood sexual abuse (CSA), and control participants $(n=20)$ completed measures of self-reported childhood trauma, depressive symptoms, trait anxiety, dissociation, and fantasy proneness. Women reporting repressed, recovered, and continuous CSA memories did not differ in self-reported childhood trauma, depression, and trait anxiety, but all scored significantly higher on these measures than the control group. However, contrast analyses revealed that women reporting repressed and recovered CSA memories also scored higher on dissociation than did those reporting either continuous CSA memories or no history of abuse. Our results further revealed that women who report CSA memories, whether repressed, recovered or continuous, have raised fantasy proneness levels. Hence, we found no support for the idea that dissociative symptoms can be fully accounted for by fantasy proneness.
\end{abstract}

\title{
INTRODUCTION
}

The idea that experiences may be so traumatic that victims deal with them in an avoidant-dissociative way has a long tradition in psychiatry and psychology (e.g., Brewin, 2003; Terr, 1994). This repressive or dissociative style would enable people who have experienced childhood sexual abuse (CSA) to disengage attention from aversive memories, which, in turn, would result in inaccessibility (i.e., amnesia) and sometimes subsequent recovery of these memories (Harvey \& Herman, 1994). Accordingly, many authors have argued that amnesia for trauma and subsequent recovery of genuine traumatic memories are relatively common among clinical populations (e.g., Andrews, Brewin, Ochera, Morton, Bekerian et al., 1999; Brewin, 2003; Brown, Scheflin, \& Whitfield, 1999). From a different point of view, the existence of repression, amnesia, and recovery of traumatic memories has been questioned because of the lack of solid evidence for these concepts (e.g., Ceci \& Loftus, 1994; Kihlstrom, 2004; McNally, 2003a; McNally, Clancy, Barrett, \& Parker, 2004b; Roediger \& Bergman, 1998). For example, 
McNally and colleagues (2004b) hypothesized that people may forget about their abuse since CSA episodes were not experienced as traumatic at the time of occurrence. It is possible that people did not recognize it as sexually abusive until after having thought about it much later in adulthood. Hence, their failure to think about these experiences can not be considered as instances of forgetting trauma. Furthermore, skeptics have warned that memories may be susceptible to distortions (Schacter, 1999) and that therapeutic interventions such as hypnosis, dream interpretation, journaling, and imagination - intended to recover memories of CSA - may unintentionally foster pseudo-memories of CSA (Loftus, 2003; Loftus \& Ketcham, 1994).

In a series of studies, McNally, Clancy, and their colleagues (e.g., McNally, 2003a; McNally, Clancy, \& Barrett, 2004a; McNally, Clancy, Schacter, \& Pitman, 2000a; see also Geraerts, Smeets, Jelicic, van Heerden, \& Merckelbach, 2005; Geraerts, Smeets, Jelicic, Merckelbach, \& van Heerden, in press a) explored whether women reporting repressed or recovered CSA memories are characterized by different clinical symptom levels and personality traits relative to women who report having always remembered their abuse. The authors found that women with repressed or recovered CSA memories scored higher on measures of dissociation than those reporting either continuous CSA memories or no abuse history (McNally et al., 2000a). This finding is consistent with the dissociative traumatic amnesia view that repressed and recovered memories are typical for victims who react with an avoidant-dissociative coping style to their aversive memories. However, McNally et al. (2000a) also noted that women with repressed and recovered memories scored higher on a measure of absorption than women with continuous CSA memories or no CSA history. Absorption is a close cousin of fantasy proneness (Kihlstrom, Glisky, \& Angiulo, 1994) and there is good evidence that these related traits have a genetic loading (Bergeman, Chipuer, Plomin, Pedersen, McClean et al., 1993; Jang, Paris, Zweig-Frank, \& Livesley, 1998). This makes it difficult to conceptualize them in terms of a defensive reaction to traumatic experiences. Accordingly, this particular aspect of the McNally et al.'s (2000a) study is more consistent with the skeptic position that holds that people high on fantasy proneness are more likely to develop pseudo-memories.

In the current study, we collected data about self-reported trauma, depression, anxiety, dissociation, and fantasy proneness in various subgroups of women. More specifically, our sample consisted of women who said that they had 
repressed their CSA memories, women who said that they had recovered their CSA memories, women who said they had never forgotten their CSA memories, and control women who said that they had no history of CSA. We tested a prediction flowing from the dissociative traumatic amnesia view, namely that women with repressed or recovered memories have higher dissociation levels than women with continuous CSA memories or control women. We also tested an implication of the skeptic position, namely that women with repressed or recovered memories score higher on fantasy proneness than the other subgroups.

\section{METHOD}

\section{Participants}

Following the procedure of McNally et al. (2000a), we recruited participants through advertisements in local newspapers. In these advertisements, we invited women to come to our lab when they a) had recovered CSA memories, b) firmly believed they had been sexually abused as a child, but had no memories of this, c) had a history of sexual abuse which they had never forgotten or d) had no history of sexual abuse. The women were told that the research project was about childhood sexual abuse and personality. The study was approved by the standing ethical committee of the university.

After providing written informed consent, a semi-structured memory interview was conducted in order to classify participants into one of the groups. Individuals reporting recovered, repressed, and continuous CSA memories were asked whether they had obtained information from others (e.g., sibling) or had physical evidence (e.g., letters, medical records) that could validate their CSA memories. When participants could furnish the name of a corroborator, this person was contacted by EG.

Repressed memory group. The repressed memory group involved 16 women (mean age $=43.9$ years, $S D=6.8$ ) who believed that they had been sexually abused as a child, but had no explicit autobiographical memories of CSA. These women cited a diversity of symptoms they thought indicated a history of CSA (e.g., relationship problems, depressive symptoms, eating disorders). Some reported vague feelings of nervousness when they were near certain relatives who, they believed, might have abused them. It was, of course, 
impossible for us to determine whether they had been abused. The term 'repressed memory' describes their belief.

Recovered memory group. The recovered memory group consisted of 23 women (mean age $=41.6$ years, $S D=10.9$ ) who said they had previously forgotten and subsequently recalled memories of CSA. Eight participants (35\%) had recovered memories of CSA during psychotherapy. Most of the other women in this group recovered memories of CSA after having been exposed to certain cues (e.g., a friend who tells about CSA experiences, the birth of their own child). Only one participant could give corroborative evidence for the abuse, namely a statement of the perpetrator himself. However, in most cases, women lost contact with their families after having confronted them with recovered CSA memories.

Continuous memory group. The continuous memory group comprised 55 women (mean age $=43.1$ years, $S D=14.4$ ) who said that they had never forgotten their abuse. Nineteen (35\%) provided the name of a person who could corroborate the abuse (e.g., a sibling who had been abused at the same time, the perpetrator himself). One participant gave us a court document that stated that her father had been indicted for sexually abusing her. Some women in this group indicated that witnesses who could provide evidence for the CSA had deceased.

Control group. The control group comprised 20 women (mean age $=41.5$, $S D=12$ ) who said that they had, neither during childhood, nor during adulthood ever been sexually abused.

\section{Self-report scales}

The Childhood Trauma Questionnaire (CTQ; Cronbach's alpha $=.82$; Bernstein, Stein, Newcomb, Walker, Pogge et al., 2003) is a widely used self-report scale of traumatic childhood events. The short form consists of 25 items that address five areas of childhood maltreatment, namely emotional, physical, and sexual abuse, and emotional and physical neglect. Each area is represented with five items. Items are rated on 5-point scales anchored 1 (never) and 5 (very often). Scores are summed to obtain a total CTQ score, with higher scores reflecting higher levels of self-reported childhood trauma. 
The Beck Depression Inventory (BDI; Cronbach's alpha $=.81$; Beck \& Steer, 1987) is a 21-item self-report scale focusing on the behavioural manifestations of depression. Items are rated on 4-point scales (range: $0-3$ ) and scores are then summed to obtain a total BDI score, with higher scores indicating higher levels of depression.

The Manifest Anxiety Scale (MAS; Cronbach's alpha $=.91$; Taylor, 1953) was administered to measure trait anxiety. It contains 50 dichotomous (yes/no) items. Higher total scores reflect higher trait anxiety.

The Dissociative Experiences Scale (DES; Cronbach's alpha $=.92$; Bernstein \& Putnam, 1986) is a 28-item self-report measure that asks respondents how often they experience dissociative symptoms like derealization and depersonalization. Items are scored on 100-mm Visual Analogue Scales (VASs; $0=$ never; $100=$ always). Scores are averaged across items to obtain a total DES score (range 0-100), with higher scores indicating higher dissociative tendencies.

The Creative Experiences Questionnaire (CEQ; Cronbach's alpha = .79; Merckelbach, Horselenberg, \& Muris, 2001) is an index of fantasy proneness. The CEQ includes 25 dichotomous (yes/no) items that cover experiences related to daydreaming, imagining, and intense fantasizing. Yes-answers are summed to obtain a total score (range: 0-25), with higher scores indicating higher levels of fantasy proneness.

\section{RESULTS}

Table 5.1 shows demographic and psychometric data for the subgroups in our sample. One-way ANOVAs revealed that subgroups did not differ significantly in age or educational level: both $F \mathrm{~s}(3,110)<1.0$, ns. However, ANOVAs indicated that there were significant group differences for each self-report scale. Post-hoc tests (LSD) showed that women with recovered, repressed, or continuous CSA memories scored higher on childhood trauma (CTQ), depressive symptoms (BDI), trait anxiety (MAS), and fantasy proneness (CEQ) than control women reporting no history of abuse (all $t$ 's $>3.7$, all $p$ 's $<.001$ ). Furthermore, both the repressed and recovered memory subgroups reported more dissociative symptoms (DES) than the continuous memory group and the control group (all $t$ 's $>2.1$, all $p$ 's $<$ $.03)$. 
Table 5.1 Demographic data and mean scores of subgroups on the Childhood Trauma Questionnaire (CTQ), Beck Depression Inventory (BDI), Manifest Anxiety Scale (MAS), Dissociative Experiences Scale (DES), and Creative Experiences Scale (CEQ). Standard deviations are in parentheses.

\begin{tabular}{lllllll}
\hline & $\begin{array}{l}\text { Repressed } \\
n=16\end{array}$ & $\begin{array}{l}\text { Recovered } \\
n=23\end{array}$ & $\begin{array}{l}\text { Continuous } \\
n=55\end{array}$ & $\begin{array}{l}\text { Control } \\
n=20\end{array}$ & $F$ & $p$ \\
\hline Measure & $M$ & $M$ & $M$ & $M$ & & \\
Age & 43.9 & 41.6 & 43.1 & 41.5 & .18 & .91 \\
(years) & $(6.8)$ & $(10.9)$ & $(14.4)$ & $(12.0)$ & & \\
Education & 5.4 & 5.1 & 4.7 & 5.5 & 1.2 & .31 \\
(level) & $(1.7)$ & $(1.5)$ & $(1.8)$ & $(1.8)$ & & \\
CTQ & 35.3 & 39.9 & 37.2 & 25.5 & 8.6 & $<.001$ \\
& $(10.3)$ & $(9.9)$ & $(11.3)$ & $(4.4)$ & & \\
BDI & 14.5 & 16.4 & 13.4 & 6.3 & 5.2 & $<.005$ \\
& $(7.6)$ & $(11.6)$ & $(9.0)$ & $(4.5)$ & & \\
MAS & 25.1 & 23.2 & 23.8 & 14.1 & 6.5 & $<.001$ \\
& $(8.0)$ & $(8.0)$ & $(9.9)$ & $(5.1)$ & & \\
DES & 31.5 & 30.1 & 22.2 & 12.9 & 7.4 & $<.001$ \\
& $(11.6)$ & $(19.4)$ & $(12.6)$ & $(9.0)$ & & \\
CEQ & 9.4 & 7.7 & 8.2 & 4.2 & 6.5 & $<.001$ \\
& $(5.2)$ & $(2.8)$ & $(3.6)$ & $(3.5)$ & & \\
\hline
\end{tabular}

Educational level varies on a scale from 0 (no primary school) to 8 (university degree).

The dissociative traumatic amnesia view that repressed and recovered CSA memories reflect a dissociative coping style implies that women with such memories should score higher on the DES than women with continuous CSA memories and control women. To test this implication, we applied contrast weights of $1,1,-1$, and -1 to the repressed, recovered, continuous, and control subgroups, respectively. The difference was highly significant, which supports the dissociative traumatic amnesia view, $t(110)=4.65, p<.001$, effect size $r=$ .42 .

The skeptic position implies that women with repressed and recovered memories score higher on fantasy proneness (CEQ) than women with continuous CSA memories or no history of abuse. Analysis with contrast weights of $1,1,-1$ and -1 to the repressed, recovered, continuous, and control subgroups, respectively, yielded a non-significant difference: $t(110)=2.8, p>.05$, effect 
size $r=.24$. As can be seen in Table 5.1, the recovered and the continuous memory groups had similar CEQ levels $[t(76)<1.0]$, while both groups had higher scores than the control group [ $\left.t^{\prime} \mathrm{s}>3.7, p^{\prime} \mathrm{s}<.001\right]$.

For the whole sample $(n=114)$, the correlation between self-reported childhood trauma (CTQ) and dissociation (DES) was .36 $(p<.01)$, while that between fantasy proneness and DES was .43 $(p<.01)$. The correlation between self-reported childhood trauma and fantasy proneness was $.34(p<.01)$. The overall correlation between trait anxiety and DES was $.45(p<.01)$. The link between self-reported childhood trauma and dissociative experiences remained significant, even if the contributions of fantasy proneness were partialled out: $r=$ $.24(p<.01)$. Likewise, the correlation between self-reported childhood trauma and fantasy proneness remained significant when corrected for the contribution of dissociative experiences: $r=.22(p=.016)$.

\section{DISCUSSION}

The purpose of this study was to examine differences in dissociation and fantasy proneness between women reporting repressed, recovered, continuous, and no memories of child sexual abuse. Our main findings can be summarized as follows. First, women reporting repressed, recovered, and continuous CSA memories did not differ from each other in terms of self-reported childhood trauma, depression, and trait anxiety. However, relative to the control group, women in the three CSA subgroups had significantly higher scores on all these measures. Thus, our data show that CSA experiences -in whatever form they are presented-are accompanied by raised anxiety and depression scores. Note that mean scores on the BDI of the subgroups reporting CSA suggest borderline clinical depression. This pattern is consistent with recent research indicating that the onset of depressive symptoms can be predicted by CSA (Kendler, Kuhn, \& Prescott, 2004). The raised trait anxiety levels in the CSA reporting subgroups, which can be compared with previously studied clinical samples (e.g., McNally et al., 2004b), are also consistent with the idea that aversive environmental factors rather than genetic factors determine trait anxiety (e.g., Eysenck, 1992). As well, dissociation (DES) scores of the three subgroups reporting CSA were higher compared to controls and came close to DES scores that have been previously found for clinical samples like patients with borderline personality disorder 
(Merckelbach, à Campo, Hardy, \& Giesbrecht, 2005; Van IJzendoorn \& Schuengel, 1996).

Second, in accordance with the dissociative traumatic amnesia view, women with repressed or recovered CSA memories had more dissociative symptoms than women with continuous CSA memories or control women. Our findings replicate those of McNally et al. (2000a), who also found that women with repressed or recovered memories are characterised by dissociation levels that exceed those of women with continuous CSA memories.

Third, unlike the McNally et al. (2000a) study, we found no evidence for the skeptic position that the pattern of dissociative symptoms in women with repressed, recovered, or continuous CSA reports is perfectly paralleled by their fantasy proneness levels. Rather it appears that women who report CSA memories, whether repressed, recovered or continuous, have raised fantasy proneness scores. Thus, whereas women reporting recovered or repressed CSA memories had more dissociative symptoms than women with continuous CSA memories, they were not more fantasy prone. This implies that fantasy proneness can not fully explain differences in dissociative symptoms across the various CSA groups. Some authors (Merckelbach \& Muris, 2001) have argued that fantasy proneness may compromise the accuracy of self-reports and that high fantasy proneness levels are typical for those reporting recovered or repressed memories. Although our correlational data show that there is a considerable overlap between dissociative symptoms and fantasy proneness - which replicates earlier findings (e.g., Rauschenberger \& Lynn, 1995; Merckelbach, Muris, \& Rassin, 1999) - they do not lend support to the assumption that heightened fantasy proneness is a typical feature of people reporting recovered or repressed memories. However, it should also be noted that partial correlations suggested that fantasy proneness plays a role in the link between self-reported trauma and dissociation. That is to say, partialling out the contribution of fantasy proneness led to a smaller, albeit still significant correlation between trauma and dissociation. At minimum, this suggests that apart from trauma, fantasy proneness contributes to dissociation.

The fact that all subgroups reporting childhood abuse experiences had raised fantasy proneness levels is consistent with the idea that early aversive events might foster this trait (e.g., Lawrence, Edwards, Barraclough, Church, \& Hetherington, 1995) and it might also help to explain why people with a history 
of trauma exhibit a heightened susceptibility to manipulations eliciting memory illusions (e.g., Bremner, Shobe, \& Kihlstrom, 2000).

To sum up, our data show that women with repressed or recovered memories of childhood sexual abuse resemble in many respects women who say that they have always remembered their abuse experiences. That is, women with repressed or recovered memories are as depressed and anxious as are women with continuous memories and they have similar levels of fantasy proneness. Accordingly, we feel that arguments against the plausibility of repressed and recovered memories can not be founded on this type of psychometric data. In this study, dissociative symptoms constitute the only dimension in which women with repressed or recovered memories differ from women with continuous memories. It is tempting to speculate about the meaning of this. The traditional dissociative traumatic amnesia interpretation is that repression and subsequent recovery of traumatic memories reflect an avoidant-dissociative style of coping with aversive experiences (e.g., Brewin, 2003). Another interpretation, that is not necessarily incompatible with the dissociative traumatic amnesia view, is that dissociative symptoms reflect a general lack of cognitive control (e.g., Merckelbach et al., 1999). It is conceivable that through this lack of cognitive control, people come to confuse the reinterpretation or reevaluation of a traumatic memory that has always been accessible with its recovery (see for a detailed analysis, Schooler, 2001). This particular scenario would explain why women with repressed, recovered, and continuous memories of abuse are very much alike in terms of clinical parameters, except for dissociative symptoms. Clearly, this interpretation warrants further study. 
PART 3

OVERREPORTING AND TRAUMA 

CHAPTER 6

Symptom Overreporting and Recovered Memories of Childhood Sexual Abuse

This chapter is in press as: Geraerts, E., Jelicic, M., \& Merckelbach, H. (in press). Symptom overreporting and recovered memories of childhood sexual abuse. Law and Human Behavior. 


\begin{abstract}
The authenticity of recovered memories is a much debated issue. Surprisingly, no study has systematically looked at symptom overreporting in people claiming recovered memories of childhood sexual abuse (CSA). In a first sample we administered the Structured Inventory of Malingered Symptomatology (SIMS) to individuals who said they had recovered CSA memories $(n=66)$, individuals who said their CSA had always been accessible (continuous memory group; $n=119$ ), and controls who said they had no CSA experiences $(n=83)$. In a second sample individuals reporting recovered $(n=45)$ or continuous $(n=45)$ CSA memories completed the Morel Emotional Numbing Test (MENT). Our aim was to compare these groups with regard to their tendency to overreport symptoms. The results indicate that people with recovered memories do not score higher on the SIMS and the MENT than other CSA survivors suggesting that symptom overreporting is not typical for people reporting recovered memories.
\end{abstract}

\title{
INTRODUCTION
}

Both in Europe and North-America, there have been many legal cases in which individuals sued or brought criminal charges against a family member, a teacher or a priest on the basis of memories of sexual abuse that they recovered more or less spontaneously or during psychotherapeutic treatment (e.g., Brown, Goldstein, \& Bjorklund, 2000; Gudjonsson, 1997). A number of authors (e.g., Brown et al., 2000; Loftus, 2003; McNally, 2003a) have argued that one distinct interpretation of such recovered memories is that they are in fact "false memories". Note, however, that the term "false memory" is ambiguous. It may refer to memories that are erroneously believed to be true and, indeed, the larger majority of authors use the term false memory in this sense. On the other hand, the term may refer to consciously fabricated accounts and symptoms.

Over the past years, a number of review papers (e.g., Frueh, Hamner, Cahill, Gold, \& Hamlin, 2000; Guriel \& Fremouw, 2003; Rosen, 2004) and empirical studies (e.g., DeViva \& Bloem, 2003; Franklin, Repasky, Thompson, Shelton, \& Uddo, 2003; Gold \& Frueh, 1999; Klotz Flitter, Elhai, \& Gold, 2003) have addressed the issue of feigning trauma-related memories and symptoms. Most authors in this domain have focussed on veterans who overreport their 
symptoms or even fabricate combat histories so as to acquire service-connected disability payments (Rosen, 2004, in press).

The problem of feigning trauma-related memories and symptoms is, however, not unique to veterans who seek compensation on the basis of their posttraumatic stress disorder (PTSD) symptoms. For example, although the tragic consequences of childhood sexual abuse (CSA) are obvious, there is reason to believe that some patients exaggerate or even fabricate psychiatric CSA-related symptoms (Cunnien, 1997). They may overreport their symptoms ${ }^{1}$ because of external incentives such as financial compensation or because of internal motives like the desire to adopt the patient role (Halligan, Bass, \& Oakley, 2003).

Is the tendency to fabricate trauma memories and symptoms especially pronounced in patients who have recovered CSA memories while undergoing psychotherapeutic treatment? There are two arguments to suspect that this may be the case. Firstly, in the literature, there are many compelling cases of people who recovered memories of traumatic events that never actually occurred, for example people claiming to have recovered memories of alien abduction or satanic ritual abuse (Clancy, 2005; McNally, 2003a; Peters, Horselenberg, Jelicic, \& Merckelbach, in press). Secondly, a recurrent finding is that people with recovered memories have raised scores on a personality trait known as fantasy proneness (McNally, Clancy, Schacter, \& Pitman, 2000a; Geraerts, Smeets, Jelicic, van Heerden, \& Merckelbach, 2005). People who score high on this trait typically spend a large part of their time fantasizing and they are also versed in fabricating stories (e.g., Merckelbach, 2004).

Symptoms reported by people with CSA memories are highly relevant to the forensic context if only because such symptoms might bolster their credibility and the persuasiveness of the trauma stories they tell. Relatedly, studies show that victims who tell their story in an emotional way are perceived as more credible than victims who tell their stories in a neutral way (Kaufmann, Drevland, Wessel, Overskeid, \& Magnussen, 2003; Vrij \& Fisher, 1997). Therefore, it is important to explore to what extent symptom overreporting occurs among people with recovered memories. Surprisingly, no study has systematically looked at the role of symptom overreporting in individuals who claim to have recovered CSA memories. Does symptom exaggeration occur more often in individuals reporting recovered memories than in individuals with continuous memories of CSA? Or does a history of abuse cause a tendency to exaggerate symptoms? That 
is, do individuals reporting recovered or continuous CSA memories show a higher tendency to overreport symptoms relative to controls with no history of abuse?

To explore this issue, we administered instruments tapping the tendency to endorse bizarre, implausible, and low frequency symptoms to our participants. That is, the Structured Inventory of Malingered Symptomatology (SIMS; Smith, 1997; Smith \& Burger, 1997) and the Morel Emotional Numbing Test (MENT; Morel, 1998) were employed. The SIMS is a self-report measure designed to screen for feigning of psychiatric symptoms and/or cognitive impairments. The SIMS is based on the idea that individuals who want to feign do not know how genuine symptoms manifest themselves. As a result, they may endorse atypical and bizarre symptoms that seem to be related to the condition they are feigning. Merckelbach and Smith (2003) found that, in a sample of undergraduates, sensitivity, specificity, and positive predictive power coefficients of the SIMS are high $(>.90)$, indicating that the SIMS is effective in screening for simulated symptomatology (see also Jelicic, Hessels, \& Merckelbach, 2006). Lewis, Simcox, and Berry (2002; see also Berry, Baer, Rinaldo, \& Wetter, 2002) showed that the SIMS also has diagnostic accuracy in defendants undergoing pretrial psychological evaluations for competency to stand trial or mental state at the time of an alleged criminal offence. The MENT is a forced-choice task to detect response bias in PTSD assessments. In their review paper, Guriel and Fremouw (2003) argued that the MENT is a promising tool for identifying malingering of trauma-related symptoms.

The study did not attempt a verification of the accuracy of the recovered or continuous CSA memories. Rather we were interested in whether those who tended to exaggerate their symptoms were overrepresented in the recovered CSA group compared to people with continuous CSA memories and people without CSA backgrounds.

\section{METHOD}

\section{Participants}

Inspired by previous work (e.g., Clancy, McNally \& Schacter, 1999; McNally, Clancy, Barrett \& Parker, 2004b, 2005), we recruited participants through advertisements in local newspapers. In these advertisements, we invited people to come to our laboratory when they a) believed to have previously forgotten and subsequently recalled memories of CSA, or b) had a history of sexual abuse that 
they had never forgotten. In the advertisements, the study was announced as a research project on childhood sexual abuse and personality. Controls were recruited through ads that described the study as an ongoing project about memory and personality. In these ads, nothing was said about childhood sexual abuse. Controls were only included if during a subsequent interview they denied having a history of abuse. The study was approved by the standing ethical committee of our faculty.

After they had been given a complete description of the study, written informed consent was obtained from all participants. Next, a semi-structured memory interview was conducted in order to classify participants into one of three subgroups. This was done on the basis of criteria that were used in previous work on similar samples (Geraerts, Arnold, Lindsay, Merckelbach, Jelicic, \& Hauer, in press b; Geraerts et al., 2005; Geraerts, Smeets, Jelicic, Merckelbach, van Heerden, in press a) and that we derived from research by McNally and coworkers (2000). People reporting recovered or continuous memories of CSA were asked whether others (e.g., sibling) or physical evidence (e.g., letters, medical records) could corroborate their CSA memories. When participants were able to provide the name of a person who presumably could corroborate the CSA, this person was contacted.

Our study used two independent samples, both consisting of Caucasian individuals. The first sample $(n=268)$ was recruited so as to compare participants' scores on the SIMS (Smith, 1997; Smith \& Burger, 1997; see also Widows \& Smith, 2005) and the Childhood Trauma Questionnaire (CTQ; Bernstein et al., 2003; see below). The second sample $(n=90)$, consisted only of people with recovered or continuous CSA memories and was recruited to examine their scores on the MENT (Morel, 1998), the CTQ, and the Impact of Event Scale (IES; Horowitz, Wilner \& Alvarez, 1979; see below).

In the first sample, the recovered memory group consisted of 66 people (62 women; mean age $=41.7$ years, $S D=12.6$ ). They all claimed to have recalled memories of CSA after a long period of amnesia for the abuse. Twenty-four of them (36\%) had recovered memories of CSA during psychotherapy. Most of the other people in this group recovered memories of CSA after having been exposed to certain cues (e.g., a friend who told them about his/her own CSA experiences, the birth of their own child). Fifteen participants said that to have been able to find corroborative evidence for the abuse. In $41 \%$ of the cases, participants lost 
contact with their families after having confronted them with their recovered CSA memories.

The continuous memory group comprised 119 people (105 women; mean age $=42.3$ years, $S D=13.5$ ) who said they had never forgotten their abuse. Fifty-one of them (43\%) provided the name of a person who could corroborate the abuse (e.g., a sibling who had been abused at the same time, the perpetrator himself). One participant gave us a court document stating that her father had been indicted for sexually abusing her. Some people in this group indicated that witnesses who could provide evidence for the CSA had died. In this group, 29 people (24\%) were or had been in psychotherapeutic treatment.

The control group comprised 83 people (75 women; mean age $=41.3$ years, $S D=12.1$ ) who said that they had never been sexually abused. None of these control people had ever received psychotherapeutic treatment.

For practical reasons that had to do with the development of an optimal Dutch version of the MENT (see below), we recruited a fresh sample and tested this sample with the MENT. This second sample consisted of 45 people (40 women; mean age $=39.3$ years, $S D=11.2$ ) with recovered CSA memories and 45 people (39 women; mean age $=38.9$ years; $S D=10.1$ ) who said they had never forgotten their abuse. In the recovered group, 18 participants (40\%) said they had recovered their memories during psychotherapy. In the continuous group, 10 participants (22\%) had received psychotherapeutic treatment related to their CSA experiences.

\section{Measures}

After they had been interviewed, participants in the first sample were given the Structured Inventory of Malingered Symptomatology (Smith, 1997; Smith \& Burger, 1997). The SIMS is a self-report instrument for screening symptom feigning. It consists of 75 dichotomous (i.e., true-false) items that can be grouped into five subscales. These subscales list unlikely or rare symptoms in several areas, notably low intelligence, affective disorders, neurological impairment, psychosis, and amnestic disorders. When respondents endorse bizarre experiences (e.g., "Sometimes my muscles go limp for no apparent reason so that my arms and legs feel as though they weigh a ton"), highly atypical symptoms (e.g., "At times, I am so depressed I welcome going to bed early to sleep it off"), and Ganser-like approximate answers (e.g., "There are six days in a week"), they receive points for symptom overreporting. Answers indicating 
symptom exaggeration are summed to obtain a total score. Rogers, Hinds, and Sewell (1996), using an adolescent sample, proposed a cut-off score of 16, and suggested that total SIMS scores above this level raise the suspicion of symptom exaggeration. In the current study, the internal reliability of the SIMS in terms of Cronbach's alpha was .87 .

Participants in both samples completed the Childhood Trauma Questionnaire (CTQ; Bernstein et al., 2003). The CTQ is a widely used scale to index self-reported traumatic childhood events. The short form consists of 25 items that address five areas of childhood maltreatment, namely emotional, physical, and sexual abuse, and emotional and physical neglect. Each area is represented with five items. Items are rated on 5-point scales anchored 1 (never) and 5 (very often). Scores are summed to obtain a total CTQ score, with higher scores reflecting higher levels of self-reported childhood trauma. In the current study, Cronbach's alpha's for the CTQ were .82 (sample 1) and .85 (sample 2), indicating good internal reliability. Bernstein and co-workers (2003) summarize psychometric data suggesting that the CTQ has acceptable internal consistency and good criterion-related validity.

Participants in the second sample were given the Morel Emotional Numbing Test (MENT; Morel, 1998), which is a forced-choice task to detect response bias in PTSD assessments. It consists of 60 two-alternative items. For the purpose of the current research project, we made a Dutch version of this test based on the descriptions provided by Morel (1998). This version of the MENT has been extensively validated in undergraduates and war veterans and has proven to be effective in screening for certain aspects of simulated PTSD (Geraerts, Kozarić-Kovačić, Merckelbach, Peraica, Jelicic, \& Candel, 2006a). That is, war veterans seeking monetary compensation for war-related PTSD scored significantly higher on the MENT relative to war veterans seeking treatment for their PTSD symptomatology. Additionally, undergraduates instructed to simulate PTSD symptoms made significantly more errors on the MENT relative to controls.

Briefly, the MENT comprises 20 coloured slides of 10 facial expressions posed by a man and a woman. Their expressions reflect happiness, frustration, sadness, anger, fear, calmness, surprise, shyness, confusion, and sleepiness. The slides are presented on a computer screen along with verbal labels describing emotions. The participant is instructed to identify the emotion word that best matches the expression of the face that is presented. In a first series of 20 trials, participants see one slide on the computer screen and are asked to circle one of 
two words (e.g., "happy"; "surprised") describing the slide. In a second run of 20 trials, participants view two slides, but only one word and are asked to identify the slide that best matches the word. In a final run of 20 trials, participants are shown two slides and two words which have to be matched to each other. Before the task is given to participants, they are primed with the instruction that PTSD patients suffer from emotional numbness and that this may cause them to have difficulties with the recognition of emotional expressions. The idea is that individuals who tend to overreport PTSD symptoms, will intentionally produce more errors on this simple test. Errors are summed across the three series of trials. Morel (1998) noted that patients suffering from severe psychiatric disorders make only a few errors on the MENT $(<6)$ and that high scores correlate with faking bad tendencies on the MMPI (Pearson $r=.71$ ). Morel (1998) recommended a cut-off score of 9 on the MENT, with scores above this level raising the suspicion of overreporting. In the current sample, the Cronbach's alpha of the MENT was .86, which suggests sufficient internal consistency.

We also had participants in sample 2 complete the Impact of Event Scale (IES; Horowitz et al., 1979), which is a 15-item self-report scale measuring the current level of trauma-related distress. It comprises two subscales tapping symptoms of intrusion and avoidance. In the current study, the total IES score was used for analysis. Joseph (2000) reviewed the psychometric properties of the IES and concluded that they are satisfactory. In this study, the Cronbach's alpha was .91 , indicating good internal reliability.

\section{Data Analysis}

To test whether people with recovered memories had heightened SIMS scores indicating symptom overreporting, we performed a one-way Analysis of Variance (ANOVA) with follow-up $t$-tests (LSD) on the SIMS scores of the three subgroups in sample 1. Furthermore, we calculated percentages of participants with SIMS scores above the cut-off $(>16)$ in each subgroup and subjected these percentages to a Chi-Square test. A similar Chi-Square was used to test whether having been in psychotherapy was related to high $(>16)$ or low $(\leq 16)$ SIMS scores. Moreover, a one-way ANOVA was conducted to evaluate group differences in CTQ. By calculating Pearson product-moment correlations, we tested whether raised SIMS scores were associated with heightened CTQ levels. 
Scores on the MENT, CTQ, and IES of the recovered and continuous memory subgroup in sample 2 were compared using independent samples $t$-tests. Next, Pearson product-moment correlations between MENT scores, IES, and CTQ were computed.

\section{RESULTS}

\section{First Sample}

Table 6.1 shows demographic and psychometric data for the subgroups in our sample. One-way ANOVAs revealed that the subgroups did not differ in age or educational level (both Fs $(2,265)<1.0, n s)$. However, ANOVAs showed that subgroups did differ with respect to their mean scores on the SIMS $(F(2,265)=$ 23.9, $p<.001)$ and CTQ $(F(2,265)=13.5, p<.001)$. Post-hoc tests (LSD) indicated that participants with recovered or continuous CSA memories had higher SIMS and self-reported childhood trauma (CTQ) scores than control people reporting no history of abuse (all $t^{\prime} \mathrm{s}>7.1$, all $p^{\prime} \mathrm{s}<.001$, all Cohen's $d$ 's $>.87$ ). Yet, it was not the case that people with recovered memories exhibited higher SIMS scores than people with continuous CSA memories, nor did the two CSA groups differ with respect to their CTQ scores (both $t^{\prime}$ 's $<.06, n s$, both $d$ 's $<$ $.007)$.

Next, scores on the SIMS subscales of the subgroups were compared to each other. Univariate analyses indicated that there was a significant difference between the subgroups on the scales measuring neurological impairment ( $F(2$, $265)=7.2, p=.001)$, affective disorders $(F(2,265)=22.9, p<.001)$, and amnestic disorders $(F 2,265)=8.3, p<.001)$. Post-hoc tests indicated that the CSA groups had significantly higher scores on these subscales than the controls (all $t$ 's $>3.1$, all $p$ 's $<.002$, all $d s>.51$ ). There were, however, no significant group differences with respect to SIMS subscales tapping low intelligence and psychosis (both $F \mathrm{~s}<2.5$, both $p$ 's $>.085$ ). Hence, the significant difference in SIMS scores between the CSA groups and controls was primarily carried by raised scores of the CSA groups on scales tapping affective, amnestic, and neurological symptoms. 
Table 6.1 Demographic data and mean scores (SD) of subgroups on the Structured Inventory of Malingered Symptomatology (SIMS) and Childhood Trauma Questionnaire (CTQ). The number (and percentage) of participants with a score above the recommended cut-off point on the SIMS and the range of the SIMS are also shown.

\begin{tabular}{llllll}
\hline & $\begin{array}{l}\text { Recovered } \\
n=66\end{array}$ & $\begin{array}{l}\text { Continuous } \\
n=119\end{array}$ & $\begin{array}{l}\text { Control } \\
n=83\end{array}$ & $F$ & $p$ \\
\hline Measure & $M$ & $M$ & $M$ & & \\
$\begin{array}{l}\text { Age (years) } \\
\begin{array}{l}\text { Education } \\
\text { (level) }\end{array}\end{array}$ & $5.79(1.7(12.6)$ & $42.3(13.5)$ & $41.3(12.1)$ & .16 & .90 \\
SIMS & $10.3(7.8)$ & $10.4(6.6)$ & $4.6(3.8)$ & 23.9 & $<.001$ \\
SIMS $>16$ & $10(15 \%)$ & $19(16 \%)$ & $1(0.01 \%)$ & & \\
$\begin{array}{l}\text { Range } \\
\text { CTQ }\end{array}$ & $1-37$ & $1-35$ & $1-29$ & & \\
\hline $\begin{array}{l}\text { Educational level varies on a scale from } 0 \text { (no primary school) to } 8 \text { (university } \\
\text { degree). }\end{array}$ & $41.3(8.7)$ & $40.1(11.6)$ & $22.2(5.1)$ & 13.5 & $<.001$ \\
& & & &
\end{tabular}

A Pearson product-moment correlation calculated for the first sample ( $n$ $=268$ ) showed that higher levels of self-reported childhood trauma were associated with a stronger tendency to overreport symptoms on the SIMS ( $r=$ $.41, p<.001)$. Table 6.1 also shows the range of the SIMS scores in the different subgroups and the number of participants in each subgroup with a score above the recommended SIMS cut-off (Rogers et al., 1996). A Chi-Square restricted to groups reporting CSA memories revealed no significant differences in the percentage of participants with above cut-off SIMS scores across groups: $X^{2}(1)=$ $.02, p=.88$. There were, however, significantly more participants in the CSA groups with above cut-off SIMS scores than in the control group: $X^{2}(2)=12.97, p$ $=.002$. A Chi-Square indicated that having been in psychotherapy was not related to high $(>16)$ or low $(\leq 16)$ SIMS scores: $\chi^{2}(1)=.05, p=.59$.

\section{Second Sample}

Demographic and psychometric data of our second sample are given in Table 6.2. Independent samples $t$-tests showed that the recovered and continuous memory subgroups did not differ in age or educational level (both $t$ 's $<1.0, n s$, both $d$ 's $<.21$ ). The two subgroups did not differ with regard to their MENT, CTQ, or IES 
scores (all $t^{\prime} \mathrm{s}<1.0, n s$, all $d^{\prime} \mathrm{s}<.19$ ). Pearson correlations calculated for the whole sample $(n=90)$ revealed that there was a significant association between MENT scores and IES $(r=.43, p<.001)$. However, scores on the MENT and the CTQ did not correlate significantly with each other $(r=.01, n s)$. As can be seen in Table 6.2, all participants scored below the MENT cut-off score of 9 (Morel, 1998).

Table 6.2 Demographic data and mean errors (SD) on the MENT of the two subgroups in sample 2 and their scores (SD) on the CTQ and the IES. The range of MENT scores is also shown.

\begin{tabular}{lllll}
\hline & $\begin{array}{l}\text { Recovered } \\
n=45\end{array}$ & $\begin{array}{l}\text { Continuous } \\
n=45\end{array}$ & $t$ & $p$ \\
\hline Measure & $M$ & $M$ & .19 & .85 \\
Age (years) & $39.3(11.2)$ & $38.9(10.1)$ & .98 & .28 \\
$\begin{array}{l}\text { Education } \\
\text { (level) }\end{array}$ & $5.6(2.1)$ & $5.4(1.7)$ & .08 & .93 \\
MENT & $3.1(2.6)$ & $3.0(1.2)$ & & .89 \\
Range MENT & $0-8$ & $0-8$ & .41 \\
CTQ & $41.2(8.8)$ & $39.7(9.1)$ & .15 & .15 \\
IES & $24.3(14.2)$ & $28.2(16.3)$ & 1.2 & .89 \\
\hline
\end{tabular}

Educational level varies on a scale from 0 (no primary school) to 8 (university degree).

\section{DISCUSSION}

Some authors have explicitly discussed recovered CSA memories in the context of malingering (Cercy, Schretlen, \& Brandt, 1997; Cunnien, 1997). At first sight, it seems plausible to assume that symptom overreporting might be especially pronounced in people with recovered CSA memories. For example, in the literature one can find case descriptions of patients who recovered memories of traumatic events that never actually occurred (e.g., Brandon, Boakes, Glaser, \& Green, 1998). A good example of highly implausible memories are recovered or repressed memories of alien abduction (Clancy, 2005; McNally, 2003a). On a related note, some studies have found that people with recovered CSA memories score high on a personality trait known as fantasy proneness (McNally et al., 2000). Fantasy prone individuals are versed in fabricating stories (Merckelbach, 
2004). Given that recovered-memory testimonies may give rise to far-reaching legal actions, there is a clear need to investigate the antecedents of recovered CSA memories. One distinct possibility that has not received much attention is that recovered or repressed memories are a form of malingering or symptom exaggeration.

With this in mind, we studied symptom overreporting in two samples, the first consisting of people with recovered, continuous, or no CSA memories and the second involving people with recovered or with continuous CSA memories. The issue can be tested because there do exist well-established scales to measure symptom exaggeration. Previous work has shown that both the SIMS and the MENT are sensitive to overreporting of symptoms (Smith \& Burger, 1997; Morel, 1998). Using these two promising measures to tap symptom overreporting (i.e., the SIMS in the first sample and the MENT in the second sample), we found no evidence for the idea that symptom overreporting is typical for people with recovered memories. Thus, in the first sample, people with recovered CSA memories did not score higher on an instrument measuring the tendency to endorse bizarre or atypical symptoms (i.e., the SIMS) compared to people who said that they had always remembered their CSA experiences. Likewise, in the second sample, participants with recovered memories had similar scores on a forced-choice task measuring the tendency to malinger emotion recognition difficulties (i.e., the MENT) compared to persons who had always remembered their abuse.

We did find evidence that people with CSA experiences - whether recovered or continuous - had raised scores on the SIMS relative to people without abuse experiences. This difference was especially evident for items measuring exaggeration of affective, amnestic, and neurological symptoms. One possibility is that these raised SIMS scores reflect a tendency of CSA participants as a group to overreport their symptoms. On the other hand, the finding that the CSA groups had a higher score on the SIMS compared to controls is reminiscent of a study by Edens, Otto, and Dwyer (1999) who observed that people who exhibit significant levels of distress have slightly heightened SIMS levels. Thus, in addition to a correlation between bona fide distress and psychopathology, there is also one between bona fide distress and raised SIMS scores, although it should be added that this correlation pertains to the lower portion (i.e., below the cutoff) of the SIMS distribution. Meanwhile, in the CSA subgroups of the first sample, there was a minority of people ( $\leq 16 \%$ ) who had SIMS scores above the cut-off. 
Of course, taking findings from Edens et al. (1999) into account (i.e., higher false positive rate for people exhibiting levels of current psychopathology), one cannot exclude the possibility that these individuals might be misclassified on the SIMS. Yet, it was not the case that the percentage of people with elevated SIMS scores was higher in the recovered memory subgroups than in the subgroup with continuous CSA memories. Nevertheless, the question arises as to why some participants in the CSA groups scored above the SIMS cut-off.

Individuals who participated in our study were well aware that they could not use our research data for legal or medical purposes. None of them indicated that they were currently involved in legal proceedings and only seven participants underwent treatment at the time the study was conducted. So, external incentives (e.g., financial compensation, medicolegal advantages; see Cunnien, 1997) cannot entirely explain why some participants with recovered or continuous CSA memories tended to overreport their symptoms. In the current context, the more likely explanation for this tendency is the wish to make a convincing impression on us. The psycholegal relevance of this is that in court the presentation of severe symptoms may lend support to the credibility of CSA accounts (Coleman, Stevens, \& Reeder, 2001). Thus, naïve triers of fact may reason that a CSA memory must be authentic because the person bringing it to court exhibits serious symptoms. However, our data show that even outside the court context, a minority of those with CSA memories, whether recovered or continuous, exaggerate their symptoms, which makes symptomatology an unreliable source for evaluating the authenticity of CSA memories. Interestingly, people who exaggerated their symptoms were identified in sample 1, but not in sample 2 . We suspect that this has to do with the sensitivity of the SIMS and the MENT. Whereas the SIMS addresses a broad range of symptom domains, the MENT focuses on one specific feature, namely emotional numbing.

Three limitations of the current study deserve some comment. To begin with, symptom overreporting was measured using tests rather than a clinical interview. So, we have no way of knowing to what extent participants who engaged in overreporting on the SIMS would also have exaggerated their symptoms during a psychiatric interview. Secondly, our results on overreporting are silent about the authenticity of the CSA memories, but overreporting of symptoms might be a good reason to adopt a critical stance to such memories. Thirdly, our findings pertain to adults recruited through advertisements in the community. Patterns of overreporting might be different in clinical samples with 


\section{CHAPTER 6}

recovered memories or in individuals who on the basis of such memories have filed a law suit.

In sum, then, although symptom overreporting does occur in people with CSA memories, we found no evidence for the idea that people with recovered memories, compared to people with continuous CSA memories, are characterized by the tendency to overreport symptoms. In many respects, people with recovered CSA memories were similar to those with continuous memories of CSA. This was true for their scores on instruments tapping symptom overreporting, but also for their scores on traditional scales such as the CTQ and the IES. 
PART 4

ASSESSING PRIOR REMEMBERING 

CHAPTER 7

Forgetting of Prior Remembering in Persons Reporting Recovered Memories of Childhood Sexual Abuse

An adjusted version of this chapter is in press as: Geraerts, E., Arnold, M. M., Lindsay, D. S., Merckelbach, H., Jelicic, M., \& Hauer, B. (in press). Forgetting of prior remembering in persons reporting recovered memories of childhood sexual abuse. Psychological Science. 


\begin{abstract}
Case studies of individuals who report recovered memories of childhood sexual abuse (CSA) suggest that some of them overestimated their prior forgetting of the abuse. A sample of people reporting either recovered or continuous memories of CSA, and controls reporting no history of abuse, participated in two experiments to examine this "forgot-it-all-along" phenomenon (e.g., Arnold \& Lindsay, 2002; Schooler, Ambadar, \& Bendiksen, 1997a). Participants in Experiment 1 were more likely to forget that they had previously recalled a studied item if they were cued to think of it differently on two recall tests, and this effect was stronger for participants with recovered memories. In Experiment 2, participants recalled autobiographical events three times over a period of four months, in either a positive or a negative emotional frame. Again, participants underestimated their prior remembering when autobiographical events had been recalled in different emotional frames on different occasions, and this underestimation was more pronounced for participants with recovered memories.
\end{abstract}

\title{
INTRODUCTION
}

Are individuals able to recall long-forgotten episodes of childhood sexual abuse (CSA)? Over the past 15 years, this issue has given rise to one of the most intense controversies in psychiatry and psychology (e.g., Loftus, 1997b; McNally, 2003a; Schacter, 1995). Perspectives in the early years of this debate were highly polarized. For example, many practitioners claimed that most recovered memories are essentially correct (Andrews, Brewin, Ochera, Morton, Bekerian, et al., 1999) and that amnesia for trauma and subsequent recovery of traumatic memories have been amply demonstrated in clinical populations (e.g., Brown, Scheflin, \& Whitfield, 1999). Conversely, many experimental psychologists raised doubts about the accuracy of such memories and challenged concepts such as "repression" (Kihlstrom, 2004; Loftus, 2003; Roediger \& Bergman, 1998).

For example, McNally (2004) noted that traumatic amnesia theorists (e.g., Brown, Scheflin, \& Whitfield, 1999) often misinterpret all kinds of memory problems (e.g., everyday forgetfulness) as if they signified amnesia for the trauma itself. Another point that McNally made was that even when sexual abuse victims do recall long-forgotten episodes of abuse, they often mention that the abuse was not perceived as terrifying at the time of its occurrence, and thereby 
falls short of traditional conceptions of a traumatic stressor. Also, not thinking about something (e.g., sexual abuse) for a long period of time should be insufficient evidence that it has been blocked from awareness by some defensive mechanism like repression or dissociation.

Over the years, the vehemence of what has been termed the "memory wars" gradually subsided and authors involved in the debate increasingly emphasized points of consensus (see Lindsay \& Read, 2001). Partly with the aim of fostering this middle-ground perspective, Schooler and his coworkers (Schooler, 1999, 2001; Schooler et al., 1997a; Schooler, Bendiksen, \& Ambadar, 1997b) described several case studies of individuals who experienced the "discovery" of apparently-long-forgotten memories of abuse. Of particular interest in the current context, in two of the cases the partners of the women who reported full-blown recovered-memory experiences said that, in fact, the women had talked about the abuse before they experienced recovered memories of abuse. In both cases the women seemed to be surprised to discover that they had talked about the abuse prior to their recovered-memory experiences. Schooler and colleagues proposed that these cases illustrated a "forgot-it-allalong" (FIA) phenomenon, which at its core entails the underestimation of prior recollections of past events (named in reference to Fischoff's, 1977, "knew-it-allalong effect", which refers to an overestimation of prior knowledge). To the extent that individuals assess their prior degree of forgetting on the basis of their current state, the emotional distress at the time of retrieval of CSA memories may lead them to underestimate their prior knowledge about the CSA event. Thus, these individuals may rely on the heuristic that "If I am this shocked and surprised now, then I must have previously completely forgotten about the experience" (Schooler et al., 1997a, p. 386).

Arnold and Lindsay $(2002,2005)$ developed a laboratory analogue that captured some aspects of Schooler et al's FIA mechanism by requiring participants to recall material in qualitatively different ways on two occasions (for other experimental demonstrations of FIA, see Joslyn, Loftus, McNoughton, \& Powers, 2001; Merckelbach, Smeets, Geraerts, Jelicic, Bouwen, \& Smeets, 2006; Padilla-Walker \& Poole, 2002; Parks, 1999). They argued that if the retrieval of CSA memories in qualitatively different contexts can lead to the underestimation of previous CSA recollections then this mechanism should transfer into the lab. In their basic procedure, participants studied a list of homographic target words, each accompanied by a biasing context word (e.g., hand-pa/m). In Test 1 
participants were tested on a subset of the study list, with some of the target items being cued with the studied-context word (e.g., hand-p**m) and the rest of the items cued with an other-context word (e.g., tree-p**m). In the final test, participants were tested on all of the studied items, and the studied-context cues were always given as recall prompts (Arnold \& Lindsay, 2002, Experiment 1). Additionally, after recalling each word the participants were required to judge whether they had recalled that word on the first test. The key result was that participants more often forgot their prior recall of the words when they had been cued in the other-context than the studied-context on the first test. These results provided compelling evidence that remembering a past event in a different way can result in a failure to remember a prior instance of recalling that event.

The forgetting of prior instances of recalling is probably more complex in the case of CSA than in the case of word lists. Nonetheless, the finding that people more often forget an instance of past remembering if it differs from their current recollections may be relevant to ongoing discussions about the authenticity of recovered CSA memories. For instance, it is possible that some victims of abuse may underestimate their prior recollections of the abuse when they (currently) recall the abuse in a qualitatively different manner, leading to a false impression of having had repressed memories.

There is evidence that individuals reporting recovered memories are more prone than others to memory distortions (e.g., Clancy, Schacter, Pitman, \& McNally, 2000; Geraerts, Smeets, Jelicic, van Heerden, \& Merckelbach, 2005; McNally, Clancy, Barrett, \& Parker, 2005; for an exception, see Clancy, McNally, \& Schacter, 1999). Relatedly, Melchert (1999) reported an association between reporting recovered memories and tendencies toward dissociation, which in turn appears to be related to susceptibility to memory errors (e.g., Porter, Birt, Yuille, \& Lehman, 2000). These findings led us to predict that the underestimation of prior remembering (i.e., the forgot-it-all-along phenomenon) will be greater for individuals reporting recovered CSA memories, in comparison to individuals who have no history of abuse and/or individuals with continuous memories of their abuse. Experiment 1 addressed this question using semantic material, whereas autobiographical events were used in Experiment 2. 


\section{EXPERIMENT 1}

\section{METHOD}

\section{Participants}

As part of an ongoing research project on recovered memories (Geraerts, Merckelbach, Jelicic, Smeets, \& van Heerden, 2006b; Geraerts et al., 2005; Geraerts, Smeets, Jelicic, Merckelbach, \& van Heerden, in press a) we recruited participants with recovered and continuous CSA memories, as well as people reporting no history of abuse, through advertisements in local newspapers. Participants were told that the research project was about childhood sexual abuse and memory. Childhood sexual abuse was defined as physical sexual contact ranging from fondling to penetrative acts until the age of 12 . The project was approved by the standing ethical committee of the Faculty of Psychology, Maastricht University.

A semi-structured memory interview was conducted to classify participants into one of the three groups. The recovered memory group consisted of 57 ( 48 women) participants (mean age $=42.6$ years, $S D=10.8$ ), who claimed that they had previously forgotten and then subsequently recalled memories of CSA. The continuous memory group comprised 69 (57 women) participants (mean age $=41.4$ years, $S D=11.6$ ) who said that they had never forgotten their abuse. The control group consisted of 68 (47 women) participants (mean age $=$ $38.9, S D=12.4$ ) who reported that they had never been sexually abused, either as children or as adults.

\section{Materials}

A set of 107 homographs with two dominant meanings (e.g., palm in the part-ofhand sense and in the type-of-tree sense) was composed, with four items used as primacy buffers and four items used as recency buffers. The target words were randomly divided into three lists of 33 words (test list factor), with each list appearing equally often across participants in the three different conditions of Test 1 (i.e., studied-context, other-context, and not-tested). A context word was assigned to each of the two different meanings of the target words, (e.g., hand and tree for the target palm). Further, two study lists were constructed (study list factor) to counterbalance the context of the studied words between participants (i.e., half of the participants studied palm with hand while the other half studied 
palm with tree). Finally, a sentence was constructed for each context-target word pair for the study phase, and it included the context word and a row of asterisks for the target word (e.g., He used the *** of his hand to swat the fly and $\mathrm{He}$ collected coconuts from the $* * *$ tree on the beach).

\section{Procedure}

Participants were told that for each study trial a context word and target word would be displayed on a computer screen for $2 \mathrm{~s}$, and that they were to repeat the words out loud in preparation for a memory test. Immediately after the wordpair was removed from the screen, the sentence containing the context word and a row of asterisks for the target word was presented for $3.5 \mathrm{~s}$, and participants were instructed to read the sentence aloud (making sure to fill in the target word). Finally, the target word appeared above the sentence for $1 \mathrm{~s}$, after which the screen went blank for $1 \mathrm{~s}$ before the next trial began.

The study phase was followed immediately by the first cued-recall test (Test 1), in which participants were told that they would be tested on a subset of the targets (cues were presented for two thirds of the studied targets). For each trial, a context word was presented with the first and last letters of a target word. Participants were told that for half of the trials the context words would correspond to those presented with the targets during the study phase whereas, for the other half of the trials the context words would not be the same as during the study phase (but related to the targets). Participants were warned to respond only with targets that they remembered seeing during the study phase, and that they should say "pass" if they were unable to remember an answer (i.e., they could not come up with the target from the study phase, or if they were guessing).

The second cued-recall test (Test 2) was presented immediately after the first. All of the target words were tested, and participants were informed that all of the context words on Test 2 corresponded to the context words presented with the targets during the study phase. For each trial, participants were given a context word with the first and last letters of the target word and asked to recall the target word from the study phase. If a participant gave an incorrect answer or said "pass," the experimenter supplied the correct target. Next, participants were required to judge whether they remembered recalling the target word during Test 1. They were instructed that their judgments should not be based on whether they had seen the Test 2 context word during Test 1, but on whether they 
remembered recalling the target word on Test 1 . Participants were also reminded that many of the items had not been presented on Test 1, and therefore could not have been recalled on that test.

\section{RESULTS AND DISCUSSION}

Although our interest focused on participants' judgments about their prior remembering, we will first describe recall performance on Test 1 and Test 2 before presenting the prior-remembering judgment data. All analyses are collapsed over the counterbalancing factors of test list and study list because initial omnibus ANOVAs showed no reliable effects of these factors (all $F_{s}<1$ ).

\section{Recall performance}

The proportion of targets recalled on Test 1 was significantly higher for items cued with studied-context words $(M=.90 ; S D=.08)$ than for items cued with other-context words $(M=.75 ; S D=.06), t(192)=8.31, p<.001$, Cohen's $d=$ 1.19. An analysis of variance (ANOVA) was performed on the proportion of target words recalled on Test 2, with the three subgroups (Group: recovered vs. continuous vs. control) as the between-subjects factor, and context on Test 1 (Context: studied, other, or not-tested) as the within-subjects factor. As expected, recall performance was near ceiling $(M=.93 ; S D=.07)$ and there were no significant main effects or interactions (all $F_{S}<1$ ).

\section{Judgments of previous recollection}

Table 7.1 shows the proportion of items judged on Test 2 as recalled on Test 1. The analyses reported here were performed on judgment data for items correctly recalled on both Test 1 and Test 2 (shown in bold in Table 7.1), although a similar pattern was found when analyses were restricted to items recalled on Test 1. An ANOVA was performed on the proportion of correct "yes" judgments obtained on Test 2, with the three subgroups as the between-subjects factor and context on Test 1 (studied-context vs. other-context) as the within-subjects factor. Replicating the findings from Arnold and Lindsay (2002, 2005), participants were significantly more likely to forget that they had recalled an item on Test 1 if it had been cued with the other-context word on Test 1 than if it had been cued with the studied-context word, $F(1,190)=381.56, M S E=0.029, p<$ $.001, \eta^{2}=.64$. As expected, there was a significant difference between the three 
groups, $F(2,190)=3.97, M S E=0.065, p=.02, \eta^{2}=.041$, and the critical interaction between group and context was significant, $F(2,190)=7.98$, MSE = $0.029, p<.001, \eta^{2}=.080$.

Univariate ANOVAs were performed to explore whether group differences in prior-remembering judgments followed a similar pattern for studied-context items versus other-context items. There was no difference between the groups on the proportion of correct "yes" judgments for the studiedcontext items, $F(2,190)=0.21, M S E=0.023, p=.81, \eta^{2}=.007$. However, a similar ANOVA performed on the proportion of correct "yes" judgments for the other-context items indicated a significant difference between the three groups, $F(2,190)=6.88$, MSE $=0.070, p=.001, \eta^{2}=.070$. Post-hoc analyses (LSD) indicated that for the other-context words the participants in the recovered memory CSA group were significantly more likely to forget that they had recalled an item on Test 1 than people reporting continuous CSA memories or controls, $t(123)=3.36, p=.001, d=.61$ and $t(122)=3.27, p<.001, d=.59$, respectively.

Further, the tendency of recovered memory participants to underestimate prior remembering cannot be explained by a general bias of saying "No, I didn't recall this" because they did not differ significantly from the other two subgroups in correctly saying "no" to not-tested items, $F_{\mathrm{s}}<2.05$, ps $\geq$ .13 . 
Table 7.1 Mean Proportion of Items Judged as "Recalled" as a Function of Recall Status on Test 1 and Test 2 for Experiment 1.

\begin{tabular}{|c|c|c|c|c|}
\hline $\begin{array}{l}\text { Test } 1 \\
\text { Cue }\end{array}$ & $\begin{array}{l}\text { Test } 1 / \text { Test } 2 \text { Recall } \\
\text { Status }\end{array}$ & $\begin{array}{l}\text { Recovered } \\
n=56\end{array}$ & $\begin{array}{l}\text { Continuous } \\
n=69\end{array}$ & $\begin{array}{l}\text { Control } \\
n=68\end{array}$ \\
\hline \multirow[t]{4}{*}{$\begin{array}{l}\text { Studied- } \\
\text { context }\end{array}$} & $\begin{array}{l}\text { Not recalled/not } \\
\text { recalled }\end{array}$ & $.02(.07)$ & $.11(.26)$ & $.04(.18)$ \\
\hline & Not recalled/recalled & $.10(.18)$ & $.29(.35)$ & $.15(.26)$ \\
\hline & Recalled/recalled & $.81(.15)$ & $.80(.16)$ & $.82(.15)$ \\
\hline & Recalled/not recalled & $.37(.37)$ & $.27(.42)$ & $.33(.44)$ \\
\hline \multirow[t]{4}{*}{$\begin{array}{l}\text { Other- } \\
\text { context }\end{array}$} & $\begin{array}{l}\text { Not recalled/not } \\
\text { recalled }\end{array}$ & $.04(.13)$ & $.08(.19)$ & $.07(.17)$ \\
\hline & Not recalled/recalled & $.14(.18)$ & $.25(.29)$ & $.18(.24)$ \\
\hline & Recalled/recalled & $.36(.24)$ & $.53(.29)$ & $.51(.26)$ \\
\hline & Recalled/not recalled & $.20(.33)$ & $.26(.37)$ & $.29(.39)$ \\
\hline \multirow{2}{*}{$\begin{array}{l}\text { Not- } \\
\text { tested }\end{array}$} & NA/not recalled & $.01(.06)$ & $.04(.08)$ & $.04(.09)$ \\
\hline & NA/recalled & $.11(.13)$ & $.14(.18)$ & $.13(.14)$ \\
\hline
\end{tabular}

Experiment 1 replicated the FIA effect that typically has been found with this judgment task (Arnold \& Lindsay, 2002). More importantly, participants who reported recovered CSA memories were more prone to forget that they had previously recalled a studied item when they had been cued to think of it differently on two recall tests. This FIA phenomenon may operate in real-life cases in which people reporting recovered CSA memories underestimate their prior recollections of abuse (e.g., Schooler et al. 1997a). However, one could counter that, in such cases, the underestimation of prior forgetting pertains to autobiographical material rather than neutral words and therefore the results from the present experiment cannot be generalized to recovered memory experiences. With this issue in mind, Experiment 2 was conducted to explore whether the FIA effect could be demonstrated with autobiographical events. 


\section{EXPERIMENT 2}

Experiment 2 was designed to assess whether people reporting recovered memories of CSA would also show a tendency to underestimate prior remembering when autobiographical material is involved. Participants were requested to recall autobiographical events in an emotionally negative or positive framing across three test sessions over a period of four months.

\section{METHOD}

\section{Participants}

Participants with recovered and continuous CSA memories and controls were recruited through advertisements in local newspapers. The recovered memory group consisted of 55 (46 women) participants (mean age $=42.2$ years, $S D=$ 10.0). The continuous memory group included 65 (53 women) participants (mean age $=41.5$ years, $S D=10.3)$. The control group comprised 65 (43 women) participants (mean age $=39.2, S D=11.2$ ).

\section{Materials}

A set of 25 cue phrases referring to common childhood experiences (e.g., being home alone, visiting the dentist) were selected. Participants were asked to recall aloud an autobiographical target event related to each of these cues in an emotionally positive or negative frame. For each event, they were asked to make an open-ended report. When reports were vague, the experimenter asked the participant to be more specific. Given the event cue "being home alone as a child," for example, a subject assigned a positive framing for that event might recall enjoying the feeling of freedom of having the house to his/herself; the same subject assigned a negative framing for that event in Session 2 might reminisce about feeling lonely after a while.

Target events were randomly divided into three lists of 8,8 and 9 events (test list factor), with each list appearing equally often across participants in the three different conditions of Test 1 (i.e., same-frame, other-frame, and nottested). Additionally, two study lists were constructed (study list factor) to counterbalance the framings of the autobiographical events across participants (i.e., half of the participants recalled being home alone as a child in a negative frame and half recalled it in a positive frame). 


\section{Procedure}

All participants were tested three times, with two months between each test session. During Test 0 (i.e., first recall of autobiographical events') participants were instructed to recall the 25 selected events in either a positive or negative frame. If participants could not remember an autobiographical event related to the selected event, the test proceeded with the next event.

After two months, participants were required to recall a subset (i.e., 16 items) of the autobiographical target events for a second time (Test 1). Moreover, participants were instructed that for half of the trials the framing cue presented with the events would correspond to the negative/positive framing cue presented with the autobiographical events during Test 0 , whereas for the remaining trials the framing would be the opposite from the framing cue presented in Test 0 (i.e., positive framing if the framing on Test 0 had been negative, and vice versa). The experimenter emphasized to participants that their task was to recall the same events that they had recalled in Test 0 , regardless of whether the framing cues were the same or different from those presented in Test 0 .

All of the target events were tested on Test 2, which occurred two months after Test 1 . Participants were informed that all of the framing cues on Test 2 corresponded to the framing cues presented with the targets during Test 0 . As in Test 1, participants were asked to recall the same autobiographical events that they had given in Test 0 . Following each recall attempt, participants were required to judge if they remembered recalling the target event during Test 1. They were reminded that some of the events had not been presented on Test 1 (and hence could not have been recalled on that test), and the experimenter emphasized that it was not their task to judge whether the framing cue had changed between the two tests, nor whether the target event had only been tested for on Test 1, but simply to indicate whether or not they had recalled the event during Test 1. 


\section{RESULTS AND DISCUSSION}

\section{Recall performance}

Raters were given typed transcripts of the two or three memory reports each subject had produced for each event (e.g., being home alone as a child). For each participant/event, judges assessed whether or not the subject had recalled the same event on each of the occasions, using a 3-point scale developed by Neisser and Harsch (1992) that evaluates consistency regarding the people, location, and activities described in memory reports. Inter-rater agreement was .92; disagreements were resolved as raters talked them through. Across participant/events, $3 \%$ of events were judged to have changed across occasions; in such cases the item was treated as a missing value. ${ }^{2}$

The proportion correctly recalled on Test 1 was near ceiling and not significantly higher for events recalled in the same-framing condition $(M=.93$; $S D=.09)$ than for events recalled in the other-framing condition $(M=.90 ; S D=$ $.07), t(184)=1.18, p=.24, d=.17$. An ANOVA was performed on the proportion of targets correctly recalled on Test 2, with the three subgroups as the between-subjects factor, and framing on Test 1 (same-framing, other-framing, or not-tested) as the within-subjects factor. As expected, recall performance was near ceiling $(M=.91 ; S D=.11)$ and there were no significant main effects or interactions (all $F_{\mathrm{S}}<1$ ).

\section{Judgments of previous recollection}

Table 7.2 shows the proportion of events judged on Test 2 as recalled on Test 1 . The analyses reported here were performed on the judgment data for events correctly recalled on both Test 1 and Test 2 (shown in bold in Table 7.2). An ANOVA was performed on the proportion of correct "yes" judgments, with the three subgroups as the between-subjects factor and framing on Test 1 (sameframe vs. other-frame) as the within-subjects factor. Participants were significantly more likely to forget that they had recalled an event on Test 1 if it had been recalled with the other-frame cue on Test 1 than if it had been recalled with the same-frame cue on Test $1, F(1,182)=411.51, M S E=0.033, p<.001$, $\eta^{2}=.693$. Additionally, there was a significant difference between the three groups, $F(2,182)=7.92$, MSE $=0.049, p=.001, \eta^{2}=.080$, as well as an interaction between group and framing $F(2,182)=6.20, M S E=0.033, p<.001$, $\eta^{2}=.064$. 
Univariate ANOVAs were performed to inspect to what extent the group differences in judgments of prior-remembering occurred for events presented with the same framing, versus those presented with the other framing. Results for the same-framing events indicated that there were no differences between the groups, $F(2,182)=0.97, M S E=0.017, p=.38, \eta^{2}=.011$. However, there was a significant difference between the three groups for the other-framing events, $f(2,182)=8.87, M S E=0.065, p<.001, \eta^{2}=.089$. Post-hoc analyses (LSD) showed that the recovered memory CSA participants were significantly more likely to forget that they had recalled an event on Test 1 if it had been cued in the other-framing context than people with continuous CSA memories and controls, $t(118)=3.90, p<.001, d=.72$ and $t(118)=3.34, p=.001, d=.61$, respectively. As in Experiment 1, the tendency of recovered CSA participants to underestimate prior remembering cannot be explained by a general bias of saying "No, I didn't recall this" because they did not differ from the other two subgroups in correctly saying "no" to not-tested items, $F_{\mathrm{s}}<1.96, p s \geq .14$.

Table 7.2 Mean Proportion of Items Judged as "Recalled" as a Function of Recall Status on Test 1 and Test 2 for Experiment 2.

\begin{tabular}{lllll}
\hline $\begin{array}{l}\text { Test } 1 \\
\text { Cue }\end{array}$ & $\begin{array}{l}\text { Test 1/Test 2 Recall } \\
\text { Status }\end{array}$ & $\begin{array}{l}\text { Recovered } \\
n=55\end{array}$ & $\begin{array}{l}\text { Continuous } \\
n=65\end{array}$ & $\begin{array}{l}\text { Control } \\
n=65\end{array}$ \\
\hline $\begin{array}{l}\text { Same- } \\
\text { framing }\end{array}$ & $\begin{array}{l}\text { Not recalled/not } \\
\text { recalled }\end{array}$ & $.01(.04)$ & $.06(.20)$ & $.02(.07)$ \\
& $\begin{array}{l}\text { Not recalled/recalled } \\
\text { Recalled/recalled }\end{array}$ & $.09(.15)$ & $.13(.21)$ & $.07(.15)$ \\
& Recalled/not recalled & $.86(.13)$ & $.88(.14)$ & $.89(.12)$ \\
\hline $\begin{array}{l}\text { Other- } \\
\text { framing }\end{array}$ & $\begin{array}{l}\text { Not recalled/not } \\
\text { recalled }\end{array}$ & $.09(.22)$ & $.04(.12)$ & $.06(.15)$ \\
& $\begin{array}{l}\text { Not recalled/recalled } \\
\text { Recalled/recalled }\end{array}$ & $.17(.26)$ & $.15(.18)$ & $.10(.14)$ \\
& Recalled/not recalled & $.13(.28)$ & $.20(.33)$ & $.08(.19)$ \\
\hline $\begin{array}{l}\text { Not- } \\
\text { tested }\end{array}$ & NA/not recalled & $.01(.06)$ & $.05(.14)$ & $.03(.08)$ \\
\hline NA/recalled & $.11(.16)$ & $.13(.20)$ & $.12(.17)$ \\
\hline
\end{tabular}

Lines in bold are those for which statistical analyses are reported in the manuscript. Standard deviations are in parentheses. NA = not applicable. 
Experiment 2 replicated the findings from Experiment 1, in that it showed that people reporting recovered CSA memories are more susceptible to the FIA effect. More importantly, the results of the present experiment demonstrated that this enhanced FIA effect for the recovered CSA participants is not restricted to neutral word stimuli. That is, people reporting recovered CSA memories showed an enhanced FIA effect even when mildly emotional autobiographical material was used over a time period of four months conditions that more closely mirror everyday life (if not memories of trauma).

\section{GENERAL DISCUSSION}

As predicted, individuals who reported recovered memories of CSA were particularly susceptible to the FIA effect. That is, compared to persons with continuous memories of CSA and those who reported no history of CSA, those who reported having recovered long-forgotten memories of CSA were especially likely to forget that they had previously recalled words or autobiographical events when cued to think about them differently across occasions of recall. Hence, our studies provide indirect support for Schooler's (1999) idea that the FIA effect might explain why some individuals reporting recovered CSA memories have the impression that there was a period in their life that they were amnestic for the abuse.

The mechanisms that drive forgetting of prior episodes of recalling words or innocuous childhood events are not necessarily the same as those involved in forgetting prior episodes of recalling CSA. For example, when participants in our experiments were judging their prior recollections they likely did not experience the emotional surprise that is associated with recovered memory experiences (i.e., like those reported by Schooler, 2001). Nonetheless, the fact that both of our experiments yielded evidence for a robust FIA effect, especially in people reporting recovered CSA memories, is consistent with Schooler's (2001) hypothesis that changes in the way an event is thought about on different occasions can contribute to the forgetting of prior episodes of recollection.

Our findings do not imply that the CSA memories reported by our participants are false. To the contrary, one possibility is that these CSA memories are fundamentally accurate, but that the prior accessibility of these memories was underestimated by some of our recovered memory participants due to a FIA 
mechanism. Alternatively, the large FIA effect in the recovered memory group may be a manifestation of a source monitoring problem that makes some people particularly susceptible to pseudo-memories and to the FIA effect Uohnson, Hashtroudi, \& Lindsay, 1993). From a source monitoring perspective, the FIA procedure requires subjects to differentiate, during the final test, between mental evidence of recalling the target during Test 1 versus mental evidence of thinking about the target earlier in the experiment. If individuals with recovered memories tend to have difficulty source monitoring, that deficit could lead to a particularly large FIA effect (just as it could lead such persons to be particularly prone to various memory illusions; e.g. Clancy et al., 2000; Geraerts et al., 2005). Of course, it may well be that our recovered-memory participants were accurate both with regard to the abuse and to their prior non-remembering of it, but the strong association between reporting recovered memories and showing a large FIA effect suggests that some individuals reporting recovered memories of CSA have forgotten their prior recollections of the abuse. 

PART 5

REPRESSIVE COPING AND MEMORY 

CHAPTER 8

Long Term Consequences of Suppression of Intrusive Thoughts and Repressive Coping

This chapter is in press as: Geraerts, E., Merckelbach, H., Jelicic, M., \& Smeets, E. (in press). Long term consequences of suppression of intrusive thoughts and repressive coping. Behaviour Research and Therapy. 


\begin{abstract}
The current experiment employed a thought suppression paradigm to investigate whether repressors $(n=40)$ are more skilled in suppressing positive and anxious autobiographical thoughts than low anxious $(n=40)$, high anxious $(n=40)$, and defensive high anxious $(n=40)$ individuals, both immediately and over a longer time period (i.e., seven days). Regardless of suppression instructions, repressors reported during their lab visit fewer target thoughts for their most anxious events than participants in the other three groups. However, over a seven days period, repressors showed the highest number of intrusive thoughts about their anxious autobiographical events. Thus, our results demonstrate that repressive coping might be adaptive in the short run, but counterproductive in the long run.
\end{abstract}

\title{
INTRODUCTION
}

The concept of repression was propagated by Freud (1915/1957), who defined it on the one hand as an automatic defense mechanism banning ego-threatening memories or experiences from consciousness, and on the other hand, as an active process, including an intentional turning away (see also Erdelyi, 1990, in press). Over the past century, many experimental studies have addressed the hypothesized features of repression, but none of them succeeded in finding solid evidence for the existence of repression as a fully automatic phenomenon (e.g., Holmes, 1990; McNally, 2003a).

According to more recent interpretations, repression can best be considered as a trait, reflecting a habitual style of coping with aversive events. One of the most influential approaches to study repression as a trait was introduced by Weinberger, Schwartz, and Davidson (1979). These authors proposed a fourfold classification of individuals differentiated by their coping styles. According to their classification, individuals are said to have a repressive coping style when they are highly defensive (e.g., high score on the MarloweCrowne Social Desirability Scale, MC; Crowne \& Marlowe, 1960), but also low in trait anxiety (e.g., low score on the Manifest Anxiety Scale, MAS; Taylor, 1953). These repressors are contrasted with low anxious (low anxiety, low defensiveness), high anxious (high anxiety, low defensiveness), and defensive high anxious (high anxiety, high defensiveness) individuals. 
One recurrent research finding is that repressors' defensive style goes hand in hand with a specific pattern of memory performance. A series of studies indicated that repressors have limited access to their childhood memories, but also to their more recent autobiographical memories. For instance, Myers and coworkers found that, relative to 'nonrepressors', repressors recalled significantly fewer negative autobiographical memories and took longer to retrieve such negative memories (Myers \& Brewin, 1994; Myers \& Derakshan, 2004a). There are good reasons to believe that repressors' coping style is not only associated with poor recall of negative autobiographical memories, but also with poor recall of experimentally presented negative material (e.g., Boden \& Baumeister, 1997; Derakshan, Myers, Hansen, \& O’Leary, 2004; Myers, Brewin, \& Power, 1998).

In a pioneering study, Barnier, Levin, and Maher (2004) used the thought suppression paradigm (Wegner, 1994) to find out if repressors are superior to controls in intentionally suppressing emotional events from their past. The socalled 'white bear' studies of Wegner and colleagues (e.g., Wegner, Schneider, Carter, \& White, 1987) yielded extensive evidence for the paradoxical nature of thought suppression. That is, these studies demonstrated that trying not to think about something actually increases the incidence of the unwanted target thoughts, particularly when subsequently mental control (i.e., trying to suppress a particular thought) is voluntarily given up (i.e., a post-suppression rebound). By using this paradigm, Barnier et al. (2004) investigated if repressors' ability to strategically suppress thoughts of events from their past (proud or embarrassing events) would differ from low anxious, high anxious, and defensive high anxious individuals. During an initial imagining period, participants were instructed to generate a recent proud or embarrassing event. Next, they were instructed either to avoid all thoughts of the target event or given permission to think of anything. Finally, in the expression period, participants were instructed to think of anything. During these periods, participants monitored their target thoughts. Results revealed that, for the proud event, all groups avoided target thoughts when instructed to suppress. However, for the emotionally negative embarrassing event, repressors reported fewer target thoughts than all other groups, even when not instructed to suppress. Moreover, irrespective of the instruction to suppress, repressors failed to show the typical post-suppression rebound effect. These findings suggest that repressors are natural suppressors, who are skilled in avoiding negative thoughts. 
One could argue that some avoidance of negative or even trauma-related thoughts may be adaptive, particularly if such avoidance is used in a flexible way and not taken to an extreme (Erdelyi, 1990). When trauma-related thoughts and emotions are too overwhelming, disengaging from one's thoughts and emotions might allow someone to gradually approach these cues. By this view, a repressive coping style may be regarded as an adaptive mechanism to deal with emotionally negative events. Indeed, increasing evidence has emerged that a repressive coping style seems to protect against the development of psychopathology, at least in some people (Bonanno, 2004). On the other hand, there is some evidence that avoidance of negative and trauma-related thoughts and emotions may lead to intrusive thoughts. In their dual presentation theory of posttraumatic stress disorder (PTSD; APA, 1994), Brewin, Dalgleish, and Joseph (1996) argued that individuals who prematurely inhibit the processing of an upsetting event have a tendency to display a repressive coping style. This style would promote PTSD, a condition that is far from adaptive (Rachman, 1994).

So far, no consensus has been reached about the function of avoiding versus attending to negative and trauma-related thoughts. Although a repressive coping style has been found to be related with adverse health outcomes (e.g., Burns, 2000; Myers, 2000a), no study has yet looked at the long term cognitive effects of repressive coping. Thus, it is conceivable that repressive coping is associated with immediate successful suppression (e.g., Barnier et al., 2004), but that in the long run it is contra productive in the sense that it leads to heightened levels of intrusive thoughts about negative target events. The present study aimed at investigating both short and long term effects of repressive coping on the frequency of thoughts about negative autobiographical events. Based on Barnier et al.'s (2004) study, the current experiment investigated thought suppression abilities of repressors, both for positive and negative-self referent material.

In order to relate our experiment to everyday thought control and clinical disorders (Rassin, Merckelbach, \& Muris, 2000), we asked participants to recall the most positive event and the most anxious event they experienced during the last years. Unlike Barnier et al. (2004), we did not employ an embarrassing event since it can be assumed that the use of an anxious event comes closer to repressors' concerns. Moreover, given that emotional (especially negative) thoughts may be more difficult to avoid than neutral thoughts (e.g., Markowitz \& Borton, 2002; McNally \& Ricciardi, 1996), we used both positive and 
negative events. These self-relevant emotional autobiographical memories became the target for thought suppression. Note that this self-reference dimension is important in finding differences between repressors and nonrepressors when it concerns negative material (Myers, 2000b). Using a diary method, we explored the long term effects of repressive coping. More specifically, participants recorded the frequency of intrusions about the negative and positive events in the 7 days after the experiment.

\section{METHOD}

\section{Participants}

A total of 160 undergraduate students from the Maastricht University participated in this study. They were selected on the basis of their scores on the MarloweCrowne Social Desirability Scale (MC; Crowne \& Marlowe, 1960), and the Taylor Manifest Anxiety Scale (TMAS; Bendig, 1956) from a pool of 409 undergraduates who completed the two scales during mass testing sessions. As outlined in Weinberger et al. (1979), participants were classified into four groups: repressors, low anxious, high anxious, and defensive high anxious groups. Tertiary splits were used to identify the four extreme scoring groups. Repressors scored 5 or under on the TMAS and 17 or over on the MC; low anxious participants scored 5 or under on the TMAS and 12 or under on the MC; high anxious participants scored 13 or over on the TMAS and 12 or under on the MC; defensive high anxious participants scored 13 or over on the TMAS and 17 or over on the MC. Unlike previous studies (e.g., Davis \& Schwartz, 1987), we had no difficulties in recruiting defensive high-anxious participants, but this might have to do with the fact that our initial sample was fairly large. Each of the four groups consisted of 40 participants. There were 114 women and 46 men, with a mean age of 19.9 years (range: 18-57 years). The study was approved by the standing ethical committee of the Faculty of Psychology, Maastricht University.

\section{Materials}

During the thought monitoring tasks, target thoughts were recorded by means of a joystick button that participants had to press whenever they had intrusive thoughts about the target event. To record intrusions of the positive and negative autobiographical target events in the seven days period following the experiment, 
participants were asked to use a tabular diary and to write down each intrusion's content (e.g., Holmes, Brewin, \& Hennessy, 2004).

Following Holmes et al. (2004), intrusive target thoughts were defined as 'spontaneously occurring' (not deliberate) memories about the positive and anxious autobiographical events. Participants were asked to carry the diary with them and record each relevant intrusion they had experienced. They were also asked to set aside a regular time each day to check whether they had completed their diary and to explicitly indicate when they had had no intrusions. The total number of intrusions was calculated from the diary entries. During a follow-up session, participants were instructed, by means of a diary compliance scale, to rate to what extent they had been unable (or had forgotten) to record their intrusive memories in the diary $(0=$ not at all true, $10=$ extremely true of me).

\section{Procedure}

Following the design of Barnier et al. (2004), the study involved two stages corresponding to the two autobiographical events. Each stage consisted of an imagining period, a suppression period, and an expression period. Autobiographical events were counterbalanced across participants so that half of them started with imagining a positive event, while the other half started with imagining an anxious event. Every participant performed the two stages of the study.

During the imagining period, participants were given 2 min to select and imagine the most positive or the most anxious event they had experienced during the last years. To encourage participants to think about these events, they were asked to write them down. Additionally, participants had to rate the valence $(0=$ very negative, $10=$ very positive $)$ and the clarity/vividness $(0=$ not at all clear/vivid, $10=$ very clear/vivid) of their memory about the target event, as well as the distress $(0=$ not at all distressing, $10=$ extremely distressing) and anxiety $(0=$ not at all anxious, $10=$ extremely anxious) associated with it. During a subsequent suppression/nonsuppression period, participants monitored their thoughts related to the autobiographical events (i.e., target thoughts) by means of a joystick during a 2 min period. Half of the subjects in each group received the instruction to suppress the target event (suppression condition) whereas the other half was told that they could think about anything, including the autobiographical target event (nonsuppression condition). Next, an expression period followed during which all participants were given $2 \mathrm{~min}$ to think about 
anything, including the autobiographical target event. Throughout the suppression and expression periods, participants indicated the occurrence of each target thought by pressing the joystick. Following this, a mathematical filler task (easy addition and subtraction problems) had to be completed for a 5 min period. Subsequently, participants completed the second stage of the experiment by imagining, suppressing (or nonsuppressing), and expressing the other autobiographical target event. Participants who had suppressed during the first stage of the experiment were now instructed to express the target thought and vice versa. Finally, participants were instructed in the use of the 7-day diary and in the ratings of distress and anxiety associated with the intrusions. At a 7 days follow-up session, participants returned to the lab and completed the diary compliance rating. Finally, participants were thanked and debriefed.

\section{RESULTS}

\section{Selected autobiographical events}

A 2 (Anxiety: high versus low) $\times 2$ (Defensiveness: high versus low) $\times 2$ (Instruction: suppression versus nonsuppression) $\times 2$ (Valence: positive versus anxious events) Analysis of Variance (ANOVA) of participants' rating of the valence of the target events yielded a significant main effect of Valence: $F(1,152)$ $=91.22, p<.001$, effect size $r=.64$. Participants rated their positive events as being very positive $(M=8.57, S D=1.68)$ and their anxious events as being very negative $(M=2.31, S D=1.15)$. A similar $2 \times 2 \times 2 \times 2$ ANOVA of ratings of clarity/vividness yielded non-significant results. Overall, participants rated their memories of the positive and anxious target events as being very clear and vivid $(M=9.01, S D=1.47 ; M=8.83 ; S D=1.36$, respectively).

A 2 (Anxiety) $\times 2$ (Defensiveness) $\times 2$ (Instruction) $\times 2$ (Valence) ANOVA of participants' rating of distress during the imagining period yielded a significant main effect of Valence, $F(1,152)=53.21, p<.001, r=.48$. A similar ANOVA of ratings of anxiety during this period also yielded a main effect of Valence, $F(1,152)=41.21, p<.001, r=.43$. In general, participants reported more distress and anxiety during the retrieval of the anxious target events ( $M=$ $5.17, S D=1.89 ; M=5.12, S D=2.11$, respectively) relative to the positive target events $(M=1.89, S D=1.09 ; M=1.01, S D=1.07$, respectively). Furthermore, since it could be feasible that repressors chose an autobiographical event that wasn't that negative, the valence $(0=$ very negative, $10=$ very positive $)$ of the 
memories was rated by two independent raters (inter-rater reliability for negative and positive events was 0.92 and .90, respectively). Univariate analyses indicated that repressors chose equally negative (in total, $M=1.89 ; S D=1.01$ ) and positive events (in total, $M=8.63 ; S D=1.12$ ) compared to the three other subgroups: all F's $<1$, ns.

In sum, all subgroups generated appropriate memories of positive and anxious events. These events differed in valence, but not in clarity and vividness. All participants reported higher levels of distress and anxiety during the imagining of the anxious target events relative to the positive target events.

\section{Suppression period}

Table 8.1 presents participants' mean number of target thoughts during the suppression period for the anxious and positive events. A 2 (Anxiety) $\times 2$ (Defensiveness) $\times 2$ (Instruction) $\times 2$ (Valence) Analysis of Variance (ANOVA) with repeated measures on the last two factors yielded significant main effects for Anxiety, $F(1,152)=10.6, p=.001, r=.25$, Defensiveness, $F(1,152)=11.2, p=$ $.001, r=.26$, and Instruction, $f(1,152)=43.0, p<.001, r=.47$, but not for Valence, $F(1,152)=2.2, n s, r=.11$. Furthermore, a significant interaction was found between Valence and Anxiety, $F(1,152)=23.4, p<.001, r=.37$, Valence and Defensiveness, $F(1,152)=15.9, p<.001, r=.31$, and between Anxiety and Defensiveness, $F(1,152)=14.8, p<.001, r=.30$. Furthermore, the critical interaction between Instruction, Anxiety, and Defensiveness was significant, $F(1$, 152) $=14.9, p<.001, r=.30$.

To test the prediction that repressors are natural suppressors of negative material, who, irrespective of instructions, report fewer intrusive negative thoughts relative to the other subgroups and irrespective of instructions, we conducted follow-up 2 (Anxiety) $\times 2$ (Defensiveness) $\times 2$ (Instruction) ANOVAs for the positive and anxious target events separately.

For the anxious events, the follow-up ANOVA yielded significant main effects for Anxiety, $F(1,152)=63.3, p<.001, r=.54$, Defensiveness, $F(1,152)$ $=54.3, p<.001, r=.51$, and Instruction, $f(1,152)=87.8, p<.001, r=.61$. Also, a significant interaction was found between Instruction and Anxiety, $F(1$, $152)=11.3, p=.001, r=.26$, Instruction and Defensiveness, $F(1,152)=6.4, p$ $=.012, r=.20$, and Anxiety and Defensiveness, $F(1,152)=61.4, p<.001, r=$ .54. Furthermore, the critical interaction between Instruction, Anxiety, and Defensiveness was significant: $f(1,152)=4.2, p=.040, r=.16$. As expected 
within the thought suppression paradigm, individuals told to suppress ( $M=3.11$, $S D=1.47$ ) reported fewer target thoughts than individuals not told to suppress $(M=5.10, S D=2.43)$. Irrespective of instruction, repressors $(M=1.65, S D=$ .92) reported significantly fewer target thoughts for the anxious events than low anxious $(M=4.88, S D=2.00)$, high anxious $(M=4.90, S D=1.75)$, and defensive high anxious individuals $(M=5.00, S D=2.04)$.

Table 8.1 Mean frequencies (and standard deviations) of target thoughts for anxious and positive autobiographical target events during the suppression/nonsuppression period reported by the four groups (each $n=40$ ).

Instruction

\begin{tabular}{lll} 
& Suppression & Nonsuppression \\
\hline Anxious event & & \\
Repressors & $1.51(0.83)$ & $1.81(1.01)$ \\
Low anxious & $3.76(0.85)$ & $6.02(2.20)$ \\
High anxious & $3.52(1.10)$ & $6.31(0.98)$ \\
Defensive high anxious & $3.73(1.63)$ & $6.33(1.53)$ \\
\hline Positive event & & \\
Repressors & $3.05(2.04)$ & $4.26(2.55)$ \\
Low anxious & $3.33(2.60)$ & $4.87(3.20)$ \\
High anxious & $3.16(1.39)$ & $4.35(1.39)$ \\
Defensive high anxious & $3.22(2.29)$ & $4.60(3.22)$ \\
\hline
\end{tabular}

For the positive target event, the follow-up ANOVA yielded significant main effects for Instruction, $F(1,152)=12.2, p<.001, r=.27$, but not for Anxiety and Defensiveness, both $F \mathrm{~s}<1.0$, ns, both $r$ 's $<.03$. Additionally, the critical interaction between Instruction, Anxiety, and Defensiveness failed to attain significance: $F(1,152)=.13, n s, r=.03$. Again, as expected in this paradigm, individuals told to suppress $(M=3.18, S D=2.09)$ reported fewer target thoughts than individuals not told to suppress $(M=4.51, S D=2.65)$. Irrespective of instruction, repressors $(M=3.65, S D=2.36)$ reported the same amount of target thoughts for the positive events compared to low anxious ( $M=$ 4.08, $S D=2.98)$, high anxious $(M=3.75, S D=1.49)$, and defensive high anxious individuals $(M=3.90, S D=2.84)$. 


\section{Post-suppression rebound effect}

Post-suppression data for the four groups are shown in Table 8.2. A rebound effect is defined as an increase in the frequency of target thoughts from the suppression to the expression period. Hence, positive values indicate an increase in frequency of target thoughts across these periods. A 2 (Anxiety) $\times 2$ (Defensiveness) $\times 2$ (Instruction) $\times 2$ (Valence) ANOVA with repeated measures on the last two factors yielded significant main effects for Instruction, $F(1,152)=$ 12.2, $p<.001, r=.27$, but not for Valence, $f(1,152)=.82, n s, r=.07$. We also found a significant interaction between Valence and Defensiveness, $f(1,152)=$ 4.06, $p=.04, r=.16$, as well as a borderline significant interaction between Anxiety and Defensiveness, $F(1,152)=3.02, p=.08, r=.14$. All other interactions remained non-significant, all $F(1,152)$ 's $<1.0$, all $p$ 's $>.22$.

A follow-up ANOVA performed on the rebound effect for the anxious target events yielded significant main effects for Anxiety, $F(1,152)=7.7, p=$ $.006, r=.22$, Defensiveness, $F(1,152)=9.8, p=.002, r=.25$, and Instruction, $F(1,152)=4.4, p=.040, r=.19$. As can be seen in Table 8.2 , the latter reflects an overall rebound effect. However, the interaction between Instruction, Anxiety, and Defensiveness fell short of significance: $F(1,152)<1, n s, r=.04$. Individuals told to suppress $(M=2.94, S D=3.00)$ showed a larger increase in the frequency of target thoughts from the suppression to the expression period than individuals not told to suppress $(M=1.95, S D=3.39)$. Irrespective of initial instructions, repressors exhibited a significantly smaller post-suppression rebound effect ( $M$ $=.35, S D=1.85)$ than low anxious $(M=3.23, S D=3.04)$, high anxious $(M=$ $3.15, S D=3.53)$, and defensive high anxious individuals $(M=3.05, S D=3.39)$.

A different pattern was found for positive autobiographical target events. Here, the follow-up ANOVA also yielded a significant main effect for Instruction, $F(1,152)=8.6, p<.005, r=.23$, again reflecting an overall rebound effect. The Anxiety and Defensiveness factors fell short of significance: both $F \mathrm{~s}<$ 1.0 , ns, both $r$ 's $<.01$. Neither was there a significant interaction between Instruction, Anxiety, and Defensiveness, $F(1,152)=.06, n s, r=.01$. Irrespective of instructions, repressors $(M=2.10, S D=4.67)$ showed a similar rebound effect for the positive events as low anxious $(M=2.07, S D=3.32)$, high anxious $(M=$ $2.00, S D=4.82)$, and defensive high anxious individuals $(M=2.18, S D=4.05)$. 
Table 8.2 Mean change (and standard deviations) in frequencies of target thoughts from suppression/nonsuppression to expression periods (i.e., postsuppression rebound effect).

Instruction

Suppression

Nonsuppression

\begin{tabular}{lll}
\hline Anxious event & & \\
Repressors & $0.21(1.82)$ & $0.50(1.90)$ \\
Low anxious & $3.92(2.38)$ & $2.56(3.51)$ \\
High anxious & $4.06(3.84)$ & $2.23(3.00)$ \\
Defensive high anxious & $3.64(1.78)$ & $2.51(4.44)$ \\
\hline Positive event & & \\
Repressors & $3.23(5.28)$ & $1.02(3.78)$ \\
Low anxious & $3.03(4.00)$ & $1.16(2.20)$ \\
High anxious & $2.94(4.72)$ & $1.12(4.86)$ \\
Defensive high anxious & $3.16(3.48)$ & $1.23(4.42)$ \\
\hline
\end{tabular}

\section{Intrusions during the 7 days period}

All participants rated their compliance concerning the completion of their diary. A 2 (Anxiety) $\times 2$ (Defensiveness) ANOVA on participants' compliance ratings yielded nonsignificant results, $F \mathrm{~s}<1, n s, r$ s $<.10$. The overall mean rating for diary compliance was $1.86(S D=1.94)$, indicating that participants believed they had recorded most of their intrusions.

A 2 (Anxiety) $\times 2$ (Defensiveness) $\times 2$ (Instruction) $\times 2$ (Valence) ANOVA of participants' rating of distress during the 7 days period yielded significant main effects of Anxiety, $F(1,152)=16.2, p<.001, r=.27$, Defensiveness, $F(1$, $152)=17.3, p<.001, r=.30$, and Valence, $f(1,152)=43.11, p<.001, r=$ .45. Moreover, a significant interaction effect was found between Valence, Anxiety, and Defensiveness, $F(1,152)=16.9, p<.001, r=29$. A similar ANOVA of ratings of anxiety during this period yielded main effects of Anxiety, $F(1,152)$ $=19.1, p<.001, r=.33$, Defensiveness, $f(1,152)=16.1, p<.001, r=.28$, and Valence, $F(1,152)=46.10, p<.001, r=.48$. Also, a significant interaction effect was found between Valence and Anxiety, $F(1,152)=14.7, p<.001, r=$ .30 , and between Valence, Anxiety, and Defensiveness, $F(1,152)=17.3, p<$ $.001, r=.32$. 
In general, repressors reported more distress and anxiety when having intrusions of the anxious target events $(M=8.56, S D=1.79 ; M=8.66, S D=$ 1.11 , respectively) than low anxious $(M=5.13, S D=1.79 ; M=5.11, S D=2.31$, respectively), high anxious $(M=5.17, S D=1.79 ; M=4.99, S D=2.11$, respectively), and defensive high anxious individuals $(M=5.22, S D=1.13 ; M=$ $5.12, S D=2.01$, respectively). For the positive events, intrusions were equally rated in distress and anxiety across the four subgroups (in total, $M=1.73, S D=$ $1.01 ; M=1.00, S D=1.03$ ).

Table 8.3 gives the mean frequencies of intrusions about the positive and anxious target events. A 2 (Anxiety) $\times 2$ (Defensiveness) $\times 2$ (Instruction) $\times 2$ (Valence) ANOVA with repeated measures on the last two factors yielded significant main effects for Anxiety, $F(1,152)=7.19, p=.008, r=.21$, Defensiveness, $F(1,152)=7.99, p=.005, r=.22$, Instruction, $F(1,152)=3.9, p$ $=.040, r=.15$, and Valence, $F(1,152)=173.4, p<.001, r=.73$. We also found significant interactions between Valence and Anxiety, $f(1,152)=12.7, p<.001$, $r=.28$, Valence and Defensiveness, $f(1,152)=12.3, p<.001, r=.27$, Anxiety and Defensiveness, $f(1,152)=6.94, p=.009, r=.21$, and Valence, Anxiety, and Defensiveness, $f(1,152)=12.99, p<.001, r=.28$.

To test whether repressors, irrespective of instruction, would show avoidance of their anxious events in the 7 days following the experimental manipulation, follow-up 2 (Anxiety) $\times 2$ (Defensiveness) $\times 2$ (Instruction) ANOVAs for the positive and anxious target events were conducted separately.

For the anxious targets, the follow-up ANOVA yielded significant main effects for Anxiety, $F(1,152)=13.2, p<.001, r=.28$, Defensiveness, $F(1,152)$ $=13.6, p<.001, r=.29$, and Instruction, $f(1,152)=3.4, p=.050, r=.15$. As can be seen in Table 8.3, the latter effect reflects an overall long-term rebound effect. Moreover, the interaction between Anxiety and Defensiveness was significant, $F(1,152)=13.2, p<.001, r=.28$. Regardless of instructions, repressors $(M=8.12, S D=2.09)$ reported significantly more intrusions for the anxious events than low anxious $(M=4.85, S D=2.51)$, high anxious $(M=4.85$, $S D=3.90)$, and defensive high anxious individuals $(M=4.88, S D=2.49)$. Overall, the majority of the intrusions (69\%) were experienced during the first three days after the test session. The range of the intrusions was 0 to 12 .

For the positive event, the follow-up ANOVA yielded nonsignificant effects for Anxiety, $F(1,152)=.71, n s, r=.07$, Defensiveness, $f(1,152)=.43$, $n s, r=.05$, and Instruction, $F(1,152)=.22, n s, r=.03$. Thus, for positive target 
events, there was no overall long-term rebound effect. Repressors $(M=1.93, S D$ $=2.01)$ did not differ significantly from low anxious $(M=2.35, S D=1.81)$, high anxious $(M=2.32, S D=1.59)$, and defensive high anxious individuals $(M=2.40$, $S D=1.17$ ) in terms of the frequency of intrusions for the positive autobiographical target events. Again, overall, the majority of the intrusions (64\%) were experienced during the first three days after the test session. The range of the intrusions was 0 to 7 .

Table 8.3 Mean frequency (and standard deviations) of intrusions over 7 days for anxious and positive autobiographical target events.

\begin{tabular}{lll} 
& \multicolumn{2}{c}{ Instruction } \\
& Suppression & Nonsuppression \\
\hline Anxious event & & \\
Repressors & $8.25(1.91)$ & $8.03(2.29)$ \\
Low anxious & $5.51(2.28)$ & $4.21(2.61)$ \\
High anxious & $5.23(4.20)$ & $4.53(3.65)$ \\
Defensive high anxious & $5.42(1.90)$ & $4.34(2.92)$ \\
\hline Positive event & & \\
Repressors & $2.05(2.18)$ & $1.80(1.85)$ \\
Low anxious & $2.46(1.82)$ & $2.27(1.83)$ \\
High anxious & $2.52(1.76)$ & $2.16(1.42)$ \\
Defensive high anxious & $2.33(1.74)$ & $2.56(1.19)$ \\
\hline
\end{tabular}

\section{DISCUSSION}

The aim of the present study was to examine whether repressors are more successful at suppressing anxious autobiographical events than are low anxious, high anxious or defensive high anxious individuals. Moreover, this was the first study to explore whether repressors would show fewer intrusive thoughts about these target events in everyday life, over a period of seven days. Replicating findings from Barnier et al. (2004), we found that for the negative autobiographical events (in our case, their most anxious event), repressors reported the lowest number of target thoughts during the suppression period. 
This low frequency of negative target intrusions was independent of instructions to suppress or express, suggesting that repressors rely on suppression as a habitual coping style to handle short-term negative intrusions (Myers, 2000b). However, for the positive event, repressors exhibited a similar pattern of target intrusions as the other subgroups. Here, repressors only suppressed thoughts about the positive target events when instructed to do so. Contrary to Barnier et al. (2004), we did find a robust post-suppression rebound effect. That is, overall, participants reported more target thoughts about positive and anxious autobiographical targets from the suppression period to the expression period when they previously had been instructed to suppress these thoughts. It seems like the phenomenon of rebound can be variable, particularly for emotional material. With their instruction-independent low frequency of negative intrusions throughout all experimental stages, the group of repressors was the only exception to this pattern. The question arises whether this group's low frequency of negative target intrusions during the experiment reflects genuine avoidance or unwillingness to report. The post-experimental (i.e., diary) data clearly argue against an interpretation in terms of unwillingness to report. That is, the postexperimental diary data indicated that, relative to the other three subgroups, repressors had the highest frequency of intrusive thoughts about their anxious autobiographical events. For the positive targets, all subgroups reported similar frequencies of intrusions. Also, it can be questioned whether the findings should be seen in the light of repressors' choice for the anxious autobiographical events. It is possible that repressors initially chose an anxious event that they often thought of, but perhaps knew was controllable and hence associated with low levels of distress. Therefore, during the suppression task they would be able to control it easily, but during the seven days they would return to thinking about it at the same rate as before it was subject to suppression. However, the evaluation of the emotionality of the chosen events by independent raters, as well as the heightened subjective distress and anxiety reported by the repressors during the seven days period exclude this alternative.

Our results strongly suggest that repressive coping is a strategic style in the sense that it differentiates between negative and positive target intrusions. For positive targets we found, even in repressors, the typical rebound effect (i.e., low frequency of targets during suppression; heightened frequency during subsequent expression; Wegner, 1994). However, for negative targets, repressive coping seemed to overrule the rebound effect in the sense that repressors kept 
their intrusions throughout the experimental stages uniformly low. These findings support a connection between a repressive coping style and the avoidance of negative material. After all, a growing body of research indicates that repressors are extremely self-protective (e.g., Furnham \& Traynar, 1999; Mendolia, Moore, \& Tesser, 1996).

Meanwhile, it is difficult to argue on the basis of the current data that repressive coping is an adaptive strategy. While some authors (e.g., Tomarken \& Keener, 1998) have conceptualized repressive coping as a trait that protects against psychopathology, others (Myers \& Brewin, 1994; Myers et al., 1998) have stressed repressors' deficit in retrieving negative autobiographical memories, and, accordingly, their vulnerability to certain forms of psychopathology.

Given that in our study, over a period of seven days, repressors reported the highest frequency of intrusive thoughts about anxious target events recalled during the first session, we tend to agree with those authors who doubt whether a repressive coping style can be seen as an adaptive coping strategy for dealing with emotionally negative events. The most parsimonious interpretation of our data is that repressive coping enables individuals to avoid negative and traumarelated thoughts in the short run, but in the long run, repressive coping leads to intrusive thoughts about these negative targets. Note that such interpretation nicely fits with work showing that in samples of traumatized individuals both intrusions about the trauma and avoidance of trauma cues predict so-called overgeneral memories, i.e., the tendency to describe autobiographical memories in a rather global way (Wessel, Merckelbach, \& Dekkers, 2000; Kuyken \& Brewin, 1995). More generally, our results can be linked to Brewin et al.'s (1996) dual presentation theory, which assumes that a repressive coping style may promote the development of PTSD symptoms because individuals with this style have a tendency to prematurely inhibit processing of the traumatic event. Although Palyo and Beck (2005) failed to find evidence for a link between repressive coping and PTSD, our data suggest that this issue warrants further study.

A methodological feature of the current study deserves some comment. That is, our study relied on what might be regarded as a relatively homogenous sample, namely undergraduates. Although numerous studies on repressive coping have used undergraduate students, it remains to be seen whether the immediate and long-term consequences of repressive coping found in this sample can be generalized to other populations. 


\section{CHAPTER 8}

Summing up, this study highlights important differences in how individuals handle emotionally negative autobiographical memories. Our results are in line with earlier findings suggesting that repressors are able to inhibit negative self-referent material, at least in the short run. To our knowledge, this is the first study indicating that in the long run, repressors suffer from intrusions related to anxious autobiographical events. Future studies may focus on this paradoxical characteristic of repressive coping in and outside the laboratory, and examine whether repressive coping is a risk factor for PTSD. 
CHAPTER 9

Suppression of Intrusive Thoughts and Working Memory Capacity in Repressive Coping

This chapter is in press as: Geraerts, E., Merckelbach, H., Jelicic, M., \& Habets, P. (in press). Suppression of intrusive thoughts and working memory capacity in repressive coping. American Journal of Psychology. 


\begin{abstract}
Previous research employing a thought suppression paradigm found that repressors are more skilled in suppressing anxious autobiographical thoughts than low anxious, high anxious, and defensive high anxious individuals. Another line of research showed that individual differences in working memory capacity are related to the ability to intentionally suppress intrusive thoughts. This study aimed at combining these findings and sought to investigate whether repressors' superior ability to suppress intrusive thoughts is related to a larger working memory capacity. Results indicate that in a thought suppression paradigm, repressors report fewer intrusive thoughts for their most anxious experiences than participants in the three other subgroups. Furthermore, the superior ability of repressors to avoid intrusive thoughts can, for a large part, be explained by their higher working memory capacity.
\end{abstract}

\title{
INTRODUCTION
}

The idea of repression was popularized by Freud, who employed in different publications radically different definitions of the concept. On the one hand, he considered repression to be an automatic defense mechanism banning aversive memories or experiences from consciousness (Freud, 1915/1957). On the other hand, he thought of repression as active and voluntary avoidance (Freud, 1926/1959; see also Erdelyi, 1990, in press). Over the past century, many experimental studies have addressed the hypothesized features of repression, but none of them succeeded in finding solid evidence for the existence of repression as a fully automatic phenomenon (e.g., Holmes, 1990; McNally, 2003a).

A largely independent line of research focused on repression as a habitual coping style. Thus, starting with Byrne (1964) and Weinberger, Schwartz, and Davidson (1979), repression was conceptualized as a trait, reflecting an avoidant processing style when confronted with threatening information. Most studies in this domain have followed Weinberger et al.'s (1979) classification of coping styles. These authors differentiate between repressors (low anxiety, high defensiveness), low anxious (low anxiety, low defensiveness), high anxious (high anxiety, low defensiveness), and defensive high anxious individuals (high anxiety, high defensiveness). These four subgroups are commonly defined by using a 
combination of anxiety and defensiveness self-reports. Although studies differ in their choice of anxiety measures (e.g., Taylor Manifest Anxiety Scale, Bendig, 1956; State Trait Anxiety Inventory, Spielberger, Gorsuch, Lushene, Vagg, \& Jacobs, 1983), most studies have used the Marlow-Crowne Social Desirability Scale (MC; Crowne, \& Marlowe, 1960) as an index of defensiveness.

Defensiveness is the core construct of this taxonomy and has been defined in terms of habitually avoiding threatening material and minimizing negative affect (for a review, see Weinberger, 1990). Accordingly, individuals scoring high on defensiveness tend to bias their self-evaluation in a positive direction. The large majority of studies that have adopted Weinberger's taxonomy have confirmed that repressors who are confronted with stressful situations report lower anxiety levels than their behavioural or physiological reactions would suggest. In Weinberger's words (1990, p. 338): "repressors are people who fail to recognize their own affective responses ... repressors as a group seem actively engaged in keeping themselves, rather than just other people, convinced that they are not prone to negative affect". Hence, repressors downplay their anxiety, as well as other emotions so that they appear more socially desirable.

A recurrent finding is that repressors' defensive style goes hand in hand with a certain pattern of performance on autobiographical memory tasks. A series of studies indicate that repressors have limited access to both childhood and more recent autobiographical memories. For example, Myers and co-workers noted that relative to 'non-repressors', repressors find it more difficult to retrieve negative autobiographical material, even though they seem to have experienced more childhood adversity (Myers \& Brewin, 1994; Myers, Brewin, \& Power, 1992). Repressors also show a memory deficit for experimentally presented negative material (e.g., Boden \& Baumeister, 1997; Derakshan, Myers, Hansen, \& O'Leary, 2004; Myers, Brewin, \& Power, 1998).

A third line of research focused on repression in the sense of active avoidance or, in other words, suppression. The by-now classic 'white bear' studies of Wegner and co-workers (e.g., Wegner, Schneider, Carter, \& White, 1987) yielded extensive evidence for the paradoxical nature of thought suppression. These studies demonstrated that trying not to think about certain thoughts actually increases the incidence of these unwanted thoughts, particularly when subsequently mental control (i.e., trying to suppress a particular thought) is voluntarily given up (i.e., a post-suppression rebound). In a recent study, Barnier, Levin, and Maher (2004) used the thought suppression 
paradigm (Wegner, 1994) to examine whether repressors in the sense of Weinberger's (1990) taxonomy, are superior to controls in suppressing emotional events from their past. More specifically, Barnier et al. (2004) investigated whether repressors' ability to strategically suppress thoughts about proud or embarrassing events that had happened to them would differ from low anxious, high anxious, and defensive high anxious individuals. During an initial imagining period, participants were instructed to generate a recent proud or embarrassing event. During the next suppression (or control) period, participants were instructed either to avoid all thoughts of the target events or given permission to think of anything, including the targets. During the third and final expression period, participants were allowed to think of anything, including the targets. Throughout the experiment, participants monitored their target thoughts. Results revealed that for the proud event, all groups avoided target thoughts when instructed to suppress. However, for the emotionally negative event, repressors reported fewer event-related thoughts than all other groups, even when not instructed to suppress. Curiously enough, repressors also failed to show the typical post-suppression rebound effect for negative targets. In a replication study in our laboratory, we found that repressors, irrespective of suppression instructions, were more successful in suppressing anxious autobiographical memories. However, for a positive target event, repressors exhibited a similar pattern of target intrusions as the other subgroups (Geraerts, Merckelbach, Jelicic, \& Smeets, in press c). Taken together, these two studies suggest that repressors rely on suppression as a habitual coping style to handle short-term negative intrusions.

Attempts to avoid or suppress intrusive thoughts are typically found in anxiety and depression disorders and may indicate a failure in normal inhibitory processes designed to prevent disturbing material from entering consciousness (e.g., Brewin, 1998). For example, posttraumatic stress disorder (PTSD; APA, 1994) is often characterized by a variety of intrusive cognitions including traumatic memories, flashbacks, and ruminative thoughts (Brewin, 2003). The question arises whether people differ in their vulnerability to experience such unwanted intrusive cognitions. Interestingly, recent findings suggest that a higher working memory capacity is related to having fewer intrusive thoughts (Brewin, 2005; Rosen \& Engle, 1998). Working memory capacity can be defined as the extent to which controlled attention can be brought to bear on the completion of a variety of tasks, including the exclusion of unwanted or irrelevant 
material from consciousness (Brewin \& Smart, 2005). In a series of elegant studies, Brewin and co-workers showed that under experimental conditions, participants with higher working memory capacity were better able to suppress thoughts of a white bear (Brewin \& Beaton, 2002) as well as personally relevant thoughts (Brewin \& Smart, 2005). This latter finding bears strong relevance to the issue of repressive coping.

A number of researchers noted that repressors are better at inhibiting negative self-referent material. This phenomenon has been ascribed to repressor's personality style (low anxiety, high defensiveness), but with the work of Brewin and associates in mind, one could speculate about the possibility that it is related to their enhanced working memory capacity. Thus the question arises whether repressive copers are better at inhibiting negative material because of an enhanced working memory capacity. The present study aimed at investigating this issue by employing a thought suppression paradigm focusing on anxious autobiographical events. We tried to replicate the finding that repressors are superior in suppressing negative intrusive thoughts, and if so, whether this is mediated by working memory capacity. To this end, we used the Random Number Generation (RNG) task, which taps the so-called central executive within Baddeley's (1986) working memory model. The central executive is thought to play a vital role in keeping memory representations active for later source memory evaluations. To measure other aspects of working memory, we also employed Forward and Backward Digit Span tasks of the Wechsler Adult Intelligence Scale (Wechsler, 1997). The Digit Span Forward task taps verbal working memory. The Digit Span Backward is mainly sensitive to the central executive.

\section{METHOD}

\section{Participants}

A total of 120 undergraduate students from the Maastricht University participated in this study. Following the procedure used in previous studies on repressors (e.g., Weinberger et al., 1979), our participants were selected on the basis of their scores on the Marlowe-Crowne Social Desirability Scale (MC; Crowne \& Marlowe, 1960) and the Taylor Manifest Anxiety Scale (TMAS; Bendig, 1956) from a pool of 360 undergraduates, who completed these two scales during mass testing sessions. As outlined in Weinberger et al. (1979), participants were classified into 
four groups: repressors, low anxious, high anxious, and defensive high anxious groups. Tertiary splits performed on MC and TMAS data were used to identify these four extreme scoring groups. MC scores vary from 0 to 33 , with higher scores indicating more defensiveness. TMAS scores range from 0 to 20 , with higher scores reflecting more state anxiety. Repressors scored 16 or over on the MC and 5 or under on the TMAS; low anxious participants scored 12 or under on the MC and 5 or under on the TMAS; high anxious participants scored 12 or under on the MC and 13 or over on the TMAS; defensive high anxious participants scored 16 or over on the MC and 13 or over on the TMAS. Unlike previous studies (e.g., Davis \& Schwartz, 1987), we had no difficulties in recruiting sufficient defensive high-anxious participants, but this might have to do with the fact that our initial sample was fairly large. Each of the four groups consisted of 30 participants. There were 90 women and 30 men, with a mean age of 21.1 years (range: 19-55 years). The study was approved by the standing ethical committee of the Faculty of Psychology, Maastricht University.

\section{Measures}

Random Number Generation. The Random Number Generation (RNG) task requires participants to generate random sequences of digits ranging from 1 to 10 on a computerized beep at a rate of one beep per sec (Friedman \& Miyake, 2004). In the current study, participants were asked to come up with 100 numbers. As an illustration of the concept of randomness (with replacement), participants were given the analogy of picking a number out of a hat, reading it aloud, putting it back, and then picking another. The importance of maintaining a regular response rhythm was underlined during the instructions and participants received a brief practice period consisting of 15 beeps. Various studies have used this task to tap executive functioning. The RNG task has been used extensively in clinical (e.g., Artiges, Salamé, Recasens, Poline, Attar-Levy et al., 2000; Horne, Evans, \& Orne, 1982) and nonclinical samples (e.g., Giesbrecht, Merckelbach, Geraerts, \& Smeets, 2004). Three different parameters of deviations from randomness have been identified (Ginsburg \& Karpiuk, 1994). Firstly, repetition (e.g., 7, 7), meaning that individuals merely repeat the same digit in succession, is the simplest form of non-randomness. This parameter represents the inability to inhibit previous responses effectively (i.e., output inhibition). Secondly, series (e.g., 1, 2, 3 or 3, 6, 9) entails some form of counting, such as forwards, backwards, by two's, and so forth. Series is related to deficits in schema 
inhibition. Thirdly, poker represents the failure to use every possible alternative before repeating any other digit and is indexed by the number of repetitions of the same digit within a sequence of five items (e.g., 1, 5, 9, 1, 3). The poker score is linked to monitoring of previous responses. Because all three parameters are measures of deviations from randomness, higher values indicate less random responding and, therefore, relatively poor executive functioning.

Digit Span. The Digit Span Forward and Backward tasks (Wechsler, 1997) were used to test verbal working memory storage and manipulation. The tasks require participants to orally repeat digit chains sequentially displayed on the computer screen in the same order (forward) or in the reversed order (backward). The number of digits increases by one until the participant consecutively fails two trials of the same digit span length. The amount of correctly reproduced strings was used as a measure of verbal working memory.

Thought suppression. Given that previous studies (Barnier et al., 2004; Geraerts et al., 2005) showed that repressors are particularly skilled in suppressing negative self-referent thoughts, we focused on negative autobiographical memories as targets for thought suppression. This type of memory is, of course, also most relevant to everyday thought control and clinical disorders (Rassin, Merckelbach, \& Muris, 2000).

The first phase of the experiment was an imagining period, during which participants were given 2 min to select and imagine the most anxious event they had experienced during the last year. To encourage participants to think about this event, they were asked to write it down. Additionally, participants had to rate the valence $(0=$ very negative, $10=$ very positive $)$ and the clarity/vividness $(0=$ not at all clear/vivid, $10=$ very clear/vivid $)$ of their memory about the target event, as well as the distress $(0=$ not at all distressing, $10=$ extremely distressing) and anxiety $(0=$ not at all anxious, $10=$ extremely anxious) associated with it. During a subsequent suppression period, participants monitored for a 2 min period their thoughts related to the autobiographical event (i.e., target thoughts) by pressing a joystick. As earlier work has indicated that repressors' superior ability in avoiding unwanted thoughts is evident without an explicit comparison between control and suppression conditions, we did not include a non-suppression control condition. Thus, during the second phase of the experiment, we had all participants suppressing their target event. Next, an 
expression period followed during which all participants were given $2 \mathrm{~min}$ to think about anything, including the autobiographical target event. Throughout the suppression and expression periods, participants indicated the occurrence of each target thought by pressing the joystick.

\section{Procedure}

Participants were tested individually in a quiet laboratory room with an experimenter present. They first completed the RNG task and the digit span tasks. After identifying their most anxious autobiographical event, they completed the suppression and expression phases of the thought suppression paradigm.

\section{RESULTS}

\section{Selected autobiographical events}

A one-way Analysis of Variance (ANOVA) showed that the four subgroups did not differ in their valence ratings of the target events: $F(3,116)<1$, ns, effect size $r$ $=.16$. In general, participants rated their anxious events as having been rather negative $(M=2.01, S D=1.07)$. Neither did the four subgroups differ in clarity/vividness ratings of the target memories: $F(3,116)<1, n s, r=.11$. Overall, participants rated their memories of the anxious target events as being relatively clear and vivid $(M=8.93 ; S D=1.13)$. Subgroups did also not differ with regard to distress ratings $(F(3,116)<1, n s, r=.17)$ or anxiety ratings $(F(3$, $116)<1, n s, r=.14)$ of the target events.

\section{Suppression period}

Table 9.1 shows participants' mean number of target thoughts during the suppression period. A one-way ANOVA yielded a significant main effect for Group, $F(3,116)=10.3, p<.001, r=.46$. Post-hoc tests (LSD) indicated that repressors reported significantly fewer target thoughts for the anxious events than the other subgroups (all $t^{\prime} \mathrm{s}>4.5$, all $p$ 's $<.001$ ).

\section{Post-suppression rebound effect}

Table 9.1 also shows post-suppression data for the four groups. A rebound effect is defined as an increase in the frequency of target thoughts from the suppression to the expression period. Hence, positive values indicate an increase 
in frequency of target thoughts across these periods. A one-way ANOVA yielded a significant main effect for Group, $F(3,116)=6.38, p<.001, r=.38$. Post-hoc tests (LSD) indicated that repressors exhibited a significantly smaller postsuppression rebound effect compared to the other three subgroups (all $t$ 's $>3.3$, all $p$ 's $<.002)$.

Table 9.1 Mean frequencies (and standard deviations) of target thoughts during the suppression period, and mean change (and standard deviations) in frequencies of target thoughts from suppression to expression periods (i.e., postsuppression rebound effect).

\begin{tabular}{lll} 
& Suppression period & Rebound \\
\hline Repressors & $1.90(1.89)$ & $1.16(1.59)$ \\
Low anxious & $4.03(1.73)$ & $3.03(2.63)$ \\
High anxious & $4.03(1.52)$ & $3.96(2.93)$ \\
Defensive high anxious & $3.63(2.23)$ & $3.00(2.79)$ \\
\hline
\end{tabular}

\section{Working memory capacity}

RNG task. Table 9.2 shows participants' mean scores on the working memory parameters. A one-way Analysis of Variance (ANOVA) of the RNG repetition data yielded a significant difference between the subgroups: $F(3,116)=9.9, p<.001$, $r=.45$. Post-hoc tests (LSD) showed that repressors were better able to inhibit previous responses (i.e., had fewer repetitions) than the other subgroups (all $t$ 's $>2.8$, all $p$ 's $<.006$ ).

A similar ANOVA performed on the series parameter also yielded a significant difference between the subgroups: $F(3,116)=5.5, p<.002, r=.35$. Post-hoc tests (LSD) indicated that repressors were better in schema inhibition (i.e., generated fewer series) relative to the other groups (all $t^{\prime} \mathrm{s}>2.0$, all $p$ 's $<$ $.047)$.

Finally, an ANOVA on the poker parameter yielded, again, a significant difference between the subgroups: $F(3,116)=3.8, p=.012, r=.30$. Repressors showed a lower score on this parameter relative to high anxious and defensive high anxious individuals (all $t$ 's $>3.3$, all $p$ 's $<.002$ ). However, there was no difference in poker scores between repressors and low anxious individuals: $t<1$, $n s$. 
Table 9.2 Mean scores (and standard deviations) of the four subgroups on factors of the Random Number Generation task and Digit Span (DS) tasks.

\begin{tabular}{llllll}
\hline & $\begin{array}{l}\text { Repeti- } \\
\text { tion }\end{array}$ & Series & Poker & $\begin{array}{l}\text { DS } \\
\text { Forward }\end{array}$ & $\begin{array}{l}\text { DS } \\
\text { Backward }\end{array}$ \\
\hline Repressors & .73 & 29.43 & 2.93 & 8.40 & 7.53 \\
& $(1.20)$ & $(16.51)$ & $(2.33)$ & $(2.92)$ & $(2.76)$ \\
Low anxious & 2.03 & 37.90 & 4.13 & 6.13 & 5.50 \\
& $(2.19)$ & $(15.78)$ & $(3.83)$ & $(2.28)$ & $(2.25)$ \\
High anxious & 3.00 & 44.43 & 5.53 & 5.47 & 5.00 \\
& $(1.91)$ & $(14.56)$ & $(3.63)$ & $(2.08)$ & $(1.80)$ \\
Defensive high & 3.30 & 41.73 & 5.43 & 5.87 & 5.40 \\
anxious & $(2.51)$ & $(14.32)$ & $(3.76)$ & $(1.79)$ & $(1.79)$ \\
\hline
\end{tabular}

\section{Digit span}

An ANOVA of participants' performance on the Digit Span Forward yielded a significant difference between the subgroups: $F(3,116)=9.8, p<.001, r=.45$. Post-hoc tests (LSD) indicated that repressors performed better on this task compared to the other three subgroups (all $t$ 's $>3.3$, all $p$ 's $<.001$ ). An ANOVA on the Digit Span Backward also yielded a significant difference between the subgroups: $F(3,116)=8.1, p<.001, r=.42$. Post-hoc tests (LSD) indicated that repressors, again, performed better on this task relative to the other three subgroups (all $t$ 's $>3.1$, all $p$ 's $<.003$ ).

\section{Modeling working memory capacity as mediator of intrusive thoughts}

We employed the mediational approach recommended by Baron and Kenny (1986) to explore whether repressors' superior suppression abilities were mediated by individual differences in working memory capacity and executive functioning. Two different models were tested. The first model investigated whether differences in executive functioning, as measured by the RNG task, were responsible for repressors' superior suppressive abilities. As repressors' score on repetition and series differed significantly from all the subgroups, standardized scores on these two factors were entered as mediator. The other model examined the mediational influence of working memory defined in a broad way. Here, working memory was defined as the mean score on the Digit Span Forward and Digit Span Backward task and this score was entered as mediator. 


\section{Executive functioning}

Firstly, we tested the unmediated model, consisting of the link between repressive coping and the post-suppression rebound effect without controlling for executive functioning. Repressive coping was found to statistically predict the rebound effect, meaning that repressors reported fewer intrusive thoughts during the suppression period as compared to the expression period, $B$ (unstandardized regression coefficient) $=-2.17, \beta$ (standardized regression coefficient) $=-.35, t$ $=-4.03, p<.001$.

Next, the mediated model was tested. This model included repressive coping, executive functioning, and rebound effect. Repressive coping predicted executive functioning, $B=-.83, \beta=-.39, t=-4.64, p<.001$, whereas executive functioning predicted mean change in frequencies of intrusions from the suppression to expression period, $B=1.70, \beta=.57, t=7.39, p<.001$. Additionally, the effect of repressive coping on rebound became smaller and was no longer significant, $B=-.76, \beta=-.12, t=-1.57, p=.12$. However, as it is not sufficient to show that the link between the predictor and criterion variable becomes non-significant when the mediator is added to the model (Frazier et al., 2004), we calculated Sobel's (1982) test. This test indicates whether the indirect influence of the predictor variable via the mediator is different from zero. A significant result was found, $Z=-3.95, p<.001$.

\section{Working memory}

Thereafter, the mediational influence of working memory on the rebound effect was tested. This model consisted of repressive coping, working memory, and rebound effect. In the mediated model, repressive coping predicted working memory, $B=4.81, \beta=.43, t=5.2, p<.001$, whereas working memory predicted mean change in frequencies of intrusions from the suppression to expression period, $B=-.28, \beta=-.51, t=-6.02, p<.001$. Additionally, the effect of repressive coping on rebound became smaller and was no longer significant, $B=-.79, \beta=-.13, t=-1.53, p=.13$. Finally, Sobel's (1982) test was calculated. Again, a significant result appeared, $Z=-3.94, p<.001$. 


\section{DISCUSSION}

The aim of the present study was to replicate the previous finding that repressors are more successful at suppressing anxious autobiographical events than are low anxious, high anxious or defensive high anxious individuals. Moreover, this is the first study to explore whether this superior suppression ability might be mediated by working memory capacity.

Replicating Barnier et al. (2004) and Geraerts et al. (in press c), we found that repressors reported the lowest number of intrusive thoughts during the suppression period. Contrary to Barnier et al. (2004), we did obtain a postsuppression rebound effect. That is, overall, participants reported more target thoughts about anxious autobiographical targets during the expression than during the suppression period. Repressors, however, deviated from this pattern in the sense that repressors kept their intrusions throughout the experimental stages uniformly low.

Our results are also consistent with previous work from Brewin and colleagues (Brewin \& Smart, 2005), who noted that successful intentional suppression of personally relevant intrusive thoughts is related to individual differences in working memory capacity. Our findings show that repressors have a superior working memory capacity relative to the other three subgroups. Repressors did not only exhibit superior executive functioning in the sense that they were better in output inhibition and schema inhibition (as measured with the RNG factors repetition and series), they also showed a superior ability for storage and manipulation of working memory (as measured with the Digit Span tasks). This was evident for both Digit Span Forward, tapping verbal working memory, and Digit Span Backward, tapping the central executive of working memory. Regression analyses revealed that working memory capacity, as indexed by Random Number Generation and Digit Span tasks, predicted the postsuppression rebound effect in the different subgroups. Thus, we found repressors' lack of rebound of anxious intrusive thoughts to be related to an enhanced working memory capacity.

Our results suggest that the idea of repressive copers being 'natural suppressors' can be further articulated by taking their enhanced working memory capacity into account. Perhaps, certain aspects of intelligence (as indicated by higher scores on the Digit Span tasks, which are part of the Wechsler Adult Intelligence Scale, Wechsler, 1997) are underlying repressors' superior ability to 
inhibit negative material. This could imply that repressive coping is more than just a general personality style. Our results suggest that repressors rely on their superior working memory capacity - and possibly intelligence - to suppress unwanted, negative self-referent intrusive thoughts. This is consistent with the position taken by Conway and Engle (1994) and Rosen and Engle (1998), who have argued that working memory capacity reflects the ability to use a limited resource to support a range of mental strategies such as keeping wanted representations active and inhibiting unwanted representations. As repressors perceive anxious autobiographical memories as threatening, it is conceivable that they will inhibit these events by relying on their superior working memory capacity. It is plausible to assume that repressors do not perceive positive events as unwanted material, and so they will not employ deploy higher working memory capacity to inhibit these positive events. Indeed, previous studies noted that with positive targets, repressors exhibit the typical pattern of suppression and enhanced post-suppression rebound (e.g., Barnier et al., 2004).

Four limitations of the current study deserve some comments. To begin with, our study is mainly correlational in nature. Although it seems likely that superior working memory capacity is a trait-like factor that contributes to the success of thought suppression, more compelling evidence for this formulation may be obtained when one would explicitly manipulate working memory capacity, e.g., by exposing participants to dual or single task conditions.

Secondly, an alternative interpretation of our findings would be that repressors have a strong tendency to report in a socially desirable way and this might explain their low levels of reported targets during the suppression phase of the experiment. However, our findings that repressors also exhibited superior working memory and reduced rebound effects are difficult to explain in terms of a reporting bias artefact. Also, intrusive thoughts were not withhold among other participants scoring high on social desirability. Nevertheless, it would be informative if future studies on repressors and thought suppression would include measures that do not depend on self-report, but are sensitive to thought intrusions (e.g., skin conductance; see Merckelbach, Muris, van den Hout, \& de Jong, 1991).

A third limitation of the current study is that we defined rebound effects of thought suppression in a rather liberal way. A stricter approach would be to define rebound effects not only in terms of changes in target frequencies from suppression to expression, but also with reference to target frequencies reported 


\section{CHAPTER 9}

by non-suppressing control participants. This, however, requires a complex experimental set-up that includes various control conditions, but the question arises whether theoretical progress would really benefit from such complex study (see also Geraerts et al., in press c).

Finally, our study relied on a relatively homogenous sample, namely undergraduates. Therefore, it remains to be seen whether our findings can be generalized to other populations, particularly clinical groups like patients with PTSD or obsessive compulsive disorder. On the basis of our data, one could speculate that repressive coping protects against the pathological intrusions that are typical for these groups. Clearly, the links between repressive coping, higher working memory capacity to inhibit negative events, and clinical conditions warrant further study (e.g., Palyo \& Beck, 2005).

Summing up, our results concur with earlier findings suggesting that repressors are superior in inhibiting negative self-referent material. Our study is the first to show that, at least in a thought suppression paradigm, working memory capacity serves as a mediating factor between repressive coping and anxious autobiographical intrusions. Future studies might focus on how repressors rely on their superior working memory capacity to cope with negative information in everyday life. 


\section{CHAPTER 10}

\section{General Discussion}

New findings that will be introduced in the General Discussion are submitted as: Geraerts, E., Schooler, J., Merckelbach, H., \& Jelicic, M. (2006). A corroborative investigation of continuous and discontinuous memories of childhood sexual abuse. 
This thesis aimed at investigating whether reports of amnesia exist on a nontrivial scale in samples of victims, and if so, whether repression provides a good account of such memory loss. To address this question, four accounts were considered that may render an impression of repression. First of all, the idea that traumatic events can indeed be forgotten and subsequently recovered was examined. Secondly, we explored whether repression might be a by-product of memory distortions, in particular pseudo-memories. More specifically, our studies looked at whether reports about recovered traumatic events are linked to a more general tendency to develop pseudo-memories. Next, the association between reports of traumatic experiences and overreporting of symptoms was examined. Finally, we investigated whether people reporting recovered memories may underestimate their prior remembering.

Moreover, a new line of research examining the link between repressive coping and memory functioning was presented. These studies focused on how short and long term effects of repressive coping relate to suppression of autobiographical memories. Additionally, we explored whether working memory capacity could be a mediating factor in the link between repressive coping and thought suppression of personally relevant material.

In this chapter, we discuss the most important findings from the empirical research. Implications and directions for future research are also given.

\section{AMNESIA AND TRAUMA}

Results from studies in Part $l$ of this thesis do not support the view that traumatic events like war atrocities and childhood abuse can be forgotten. Chapter 2 showed that in our sample of war veterans, amnesia and intrusions about war-related events had a low base rate. This stands in sharp contrast to what one would expect on the basis of theories emphasizing the special status of traumatic memories (e.g., Bremner, 2002; van der Kolk, 1994; van der Kolk \& Fisler, 1995). Only two of the 121 veterans indicated having experienced episodes during which their war memories had been inaccessible. It should be noted here that these two veterans also showed elevated scores on instruments tapping symptom overreporting (i.e., SIMS and MENT; Geraerts, Kozarić-Kovačić, Merckelbach, Peraica, Jelicic, \& Candel, 2006a). One could argue that someone interested in simulating and gaining financial benefits would be highly unlikely to claim that he forgot his trauma. However, these two veterans showed high scores 
on items tapping the simulation of amnestic disorders, as measured by the SIMS. Thus, it is not unlikely that the two simulated their alleged amnesia symptoms because of external incentives such as service-connected disability payments.

Furthermore, only a minority of the veterans said that they experienced literal flashbacks or nightmares on a regular basis. Although flashbacks were reported to reflect distressing war events, many participants indicated that flashbacks, and/or nightmares did not contain auditory, olfactory, or bodily details. This suggests that these two types of intrusive imagery do not reflect sensory elements of the traumatic events in an accurate way. Indeed, the concept of flashbacks entails the literal reinstatement of the sensory context of the traumatic event. The notion of a timeless, photographic relay, however, is inconsistent with the generally accepted idea of a dynamic, reconstructive cognitive system (McNally, 2003a). The same is true for traumatic nightmares. Although survivors of a traumatic experience often convey that their nightmares are relivings of the traumatic experience itself, there is little ground for suspecting that this is true in a literal sense. That is, dreams related to the traumatic event can be reconstructed and reexperienced during sleep, but such relivings can not be seen as exact reproductions (McNally, 2005a). The current results appear to strengthen this notion.

The findings described in Chapter 2 cast doubts on the idea that overall amnesia is a common outcome of severe trauma. The existence of special memory mechanisms that are unique to traumatic events is not supported. In a different vein, some authors have argued that forgetting of traumatic events is not due to a special memory mechanism, but reflects individual differences in the ability to put aversive experiences out of mind. For example, it has been suggested that mechanisms like retrieval inhibition could potentially account for the fact that some people manage not to think about their traumatic experience (Cloitre, 1998). However, results described in Chapter 3 indicate that those reporting repressed or recovered CSA memories do not possess superior abilities to forget trauma-related material on a list-wise directed forgetting task, relative to those reporting having always remembered their abuse. While it is true that directed forgetting experiments involve aversive material of a merely verbal nature, these results provide no evidence for the idea that retrieval inhibition enables abuse survivors to operate as skilled forgetters of trauma-related material. 


\section{FALSE AND RECOVERED MEMORIES}

In Part 2 of this thesis, we explored whether people reporting recovered memories of abuse are more prone to false memory effects than those who have never forgotten their CSA experiences or controls with no history of abuse. Results of Chapter 4 indicate that as a group, recovered memory participants show an enhanced false recall and recognition for critical lures on the DRM task. This is true for both neutral and trauma-related material. Such an enhanced susceptibility to false memory effects may be due to a deficit in source monitoring. It might be that these women have a tendency to misinterpret an internally generated thought as being a genuine memory. As a result, these source monitoring errors could produce pseudo-memories. Of course, one must be careful extrapolating these findings to autobiographical memories, especially for traumatic events (Freyd \& Gleaves, 1996; Pezdek \& Lam, in press). Yet, the results presented in Chapter 4 suggest that as a group, recovered memory participants are characterized by an information-processing style that might render them more prone to falsely believing that they have experienced certain traumatic events like childhood sexual abuse or even satanic ritual abuse. This could be especially the case when such events are suggested during the course of therapy or when broadly similar events like emotional neglect, have been experienced. Additionally, results from Chapter 4 revealed that the false memory effects found in the DRM task are related to fantasy proneness. Yet, Chapter 5 indicated that fantasy proneness could not fully explain the dissociative symptoms reported by the repressed and recovered memory group. That is, people reporting repressed or recovered CSA memories showed elevated levels of dissociation which were not paralleled by fantasy proneness. Thus, the three CSA groups - whether repressed, recovered, or continuous - had similar scores on a fantasy proneness measure (see also McNally, Perlman, Ristuccia, \& Clancy, in press). Clearly, there is a need for further research on the association between fantasy proneness, dissociation, and CSA memories.

If we assume that at least a subsample of those with recovered memories developed pseudo-memories about trauma as a result of a subtle interaction between inherent source monitoring difficulties and suggestive therapeutic strategies, their reports of amnesia become understandable. In this scenario, amnesia would be, in fact, a false impression of amnesia that arises in 
those who wonder why they haven't had access to their false trauma memories earlier in their life.

\section{SYMPTOM OVERREPORTING AND TRAUMA}

Part 3 of this thesis examined the extent to which symptom overreporting occurs in people with recovered memories. By using two special measures tapping symptom overreporting (i.e., the SIMS and the MENT), Chapter 6 found no solid evidence for the idea that intentional overreporting of symptoms is typical for people with recovered memories. However, results indicated that people with CSA experiences - whether recovered or continuous - had raised scores on the SIMS relative to people without abuse experiences. Why did some participants in the CSA groups even scored above the SIMS cut-off? Following the DSM-IV (APA, 1994) distinction between factitious disorders and malingering, it is common to differentiate between symptom overreporting motivated by the wish to adopt the patient role and overreporting motivated by external incentives (e.g., financial compensation, medicolegal advantages; see Cunnien, 1997). External incentives cannot fully account why a minority of the people with CSA experiences scored above the SIMS cut-off. People who participated in this study were well aware that the collected research data could not be used in court cases or for their medical records. Therefore, most of the participants who engaged in symptom overreporting on the SIMS seemingly did so because they wanted to demonstrate that their abuse accounts and trauma-related symptoms were genuine and severe. This is a source of symptom overreporting that might be closely related to the wish to adopt the patient role.

This result reminds us of a study by Clancy, McNally, and Schacter (1999). These authors found lower levels of imagination inflation in recovered memory participants relative to controls. The authors (p. 568) write that their "results suggest that women who report recovered memories of sexual abuse may be capable of counteracting any tendency for guided imagery to create false memories...". In more general terms, these as well as our results seem to imply that we cannot fully exclude a scenario in which at least some people with CSA memories - which might include recovered memories - overreport their prior forgetting so as to convey the message to others that their problems are very serious. 


\section{ASSESSING PRIOR REMEMBERING}

Studies described in Part 4 showed that individuals reporting recovered CSA memories were particularly susceptible to the FIA effect. In both studies, those who reported having recovered long-forgotten memories of CSA were especially likely to forget that they had previously recalled words or autobiographical events when cued to think about them differently across occasions of recall, relative to persons with continuous memories of CSA and those who reported no history of CSA. Thus, these studies provide indirect support for Schooler's (1999) idea that the FIA effect is typical for at least some individuals who report recovered memories of abuse.

Of course, one should be careful with extrapolating these findings to recall of traumatic memories. However, subjective FIA experiences elicited during real-life situations and FIA experiences elicited during laboratory situations do not necessarily reflect the operation of fundamentally different mechanisms. On the contrary, our results rather confirm that recovered memories of abuse and the FIA effect may be intimately linked to each other. It is likely that the FIA mechanism underlies some reports of having recovered memories of CSA. Certainly, our findings do not necessarily imply that the CSA memories reported by our participants are false. One possibility is that some of these CSA memories are essentially true, but that prior accessibility of these memories has been underestimated by some of our recovered memory participants, due to a FIA mechanism.

Results documented in Part 4 imply that some people recovering memories of childhood abuse episodes may have the impression that they have not thought about these memories for a long period. Some authors have suggested that this feeling of previous non-recall represents amnesia (i.e., an inability to retrieve memories; for a critical analysis, see Read \& Lindsay, 2000). However, as pointed out by McNally (2003a), merely because some people do not think about certain experiences for a long period of time does not mean that they have been unable to recall them. Their failure to think about these experiences cannot be considered as instances of amnesia. In fact, the findings described in Part 4 show that such amnesia interpretation is highly problematic. That is, people, especially those with recovered memories, are poor in remembering and dating their previous recollections of an event, thereby creating a false impression of repression. Parks (1999, p. 365) stated that 
an attitude of healthy caution should be adopted toward firstperson reports that a past event has not been recalled previously.... It is important to note that even researchers who are well aware that the concepts of repression and recovery are being questioned and want to defend them... and go to great efforts to establish the truth of specific recovered memories do not attempt to establish the absence of prior recall.... Instead the client is simply trusted on this point. Obviously, from the practical, societal point of view, all that matters is the truth of any memory, but from the theoretical point of view, it is immensely important to know whether the concept of recovery and its mirror image, repression - is valid; 'recovered' memories may not have been lost in the first place. (p. 369)

\section{REPRESSIVE COPING AND MEMORY}

Finally, Part 5 focused on repression as a trait, reflecting an avoidant processing style for coping with aversive events (i.e., repressive coping).

Chapter 8 documented both short and long term effects of repressive coping on the frequency of thoughts about autobiographical events. Results indicated that repressors rely on suppression as a habitual coping style to deal with short-term negative intrusions. Thus, these data support a connection between repressive coping and the avoidance of negative material. Yet, results also indicated that over a 7 days period, repressors reported the highest frequency of intrusive thoughts concerning their anxious autobiographical thoughts. These data challenge the popular view that repressive coping can be seen as an adaptive strategy for dealing with emotionally negative events.

The study described in Chapter 9 showed that repressors' ability to suppress short term negative intrusive thoughts is related to their enhanced working memory capacity. This finding suggests that the idea of repressive copers being 'natural suppressors' can be further articulated by taking their enhanced working memory capacity into account. This could entail that repressive coping is more than just a general personality style. Results appear to suggest that repressors rely on their superior working memory capacity to suppress unwanted, negative autobiographical intrusive thoughts. 
Studies in Part 5 of this thesis indicate that more research is needed to explore whether a repressive coping style leads to an enhanced vulnerability to certain forms of psychopathology and whether repressors rely on their superior working memory capacity to cope with negative information in everyday life. Also, it is tempting to speculate about repressive coping, recovered memories, and amnesia. Of course, it is true that there is now a large body of research implying that a relatively poor working memory capacity is a predictor of post-traumatic psychopathology (e.g., Macklin, Metzger, Litz, McNally, Lasko, et al., 1998; McNally \& Shin, 1995). Against that background one would expect people with superior working memory capacity to be relatively immune to the pathogenic effects of trauma. But then one distinct scenario that warrants future research is that in these natural suppressors, the asymmetry between successful short-term avoidance and long-term rebound of traumatic memories fuels the FIA effect.

\section{RECOVERED OR DISCOVERED?}

In exploring several possibilities that may render an impression of repression, the studies described in Chapters 2 to 7 have yielded two accounts that may help to understand reports of repression. On the one hand, Chapter 4 showed that reports of recovered memories are linked to false memory effects as measured by the DRM task. On the other hand, Chapter 7 indicated that recovered memory reports are intimately related to the FIA phenomenon. However, it is rather unlikely that a recovered memory report is both linked to false memory effects and to the underestimation of prior remembering. How can both studies yield seemingly conflicting conclusions? Careful inspection of the precise type of recovered memory experiences may provide an answer to this question.

Two remarkably different types of recovered memory experiences have been documented in the literature (e.g., McNally et al., 2004a; Shobe \& Schooler, 2001). In one type, people realize that they are abuse survivors, commonly attributing current life difficulties to these repressed memories of abuse. Here, abuse events are mostly gradually recalled over time, often by suggestions of a therapist. People usually indicate that they have learned (e.g., through hypnosis) that the abuse occurred to them. For example, in Case 1 discussed in this thesis (i.e., Elizabeth Janssen, p. 13-14), abuse events were gradually recalled, instigated by several therapeutic interventions as hypnosis and guided imagery. In the other type of recovered memory experience, people are suddenly reminded 
of events that they had not thought about for many years. They are shocked and surprised by their recollection, but not by the content of the memory as such. For example, Case 2 in this thesis (i.e., Mary de Vries, p. 14-15), describes a woman who suddenly recalled being abused by her stepfather when entering her former bedroom. This kind of recollection differs from the one in which the person is gradually recalling the abuse, often in the course of therapy. For this reason, Jonathan Schooler and co-workers (Schooler, 2000; Schooler et al., 1997a) referred to these suddenly recovered memories as discovered memories, reflecting situations "in which individuals sincerely perceive themselves to have discovered memories of experiences of which they think they had previously been unaware" (Shobe $\&$ Schooler, 2001, p. 100). This term keeps open the possibility that individuals could have discover experiences corresponding to memories that were not, at least in some sense, completely forgotten.

Given the two different types of recovered memory experiences, it is not too farfetched to speculate that especially people who report CSA memories recovered during therapy may score high on tasks yielding false memory effects, like the DRM task. Yet, they would show a rather standard score (i.e., a score similar to controls) on estimation tasks tapping the FIA effect. Conversely, one would expect that people exemplifying suddenly and spontaneously recovered memories, may be especially prone to tasks tapping the estimation of prior remembering (i.e., FIA tasks), whereas they would have normal scores (i.e., a score similar to controls) on false memory tasks (e.g., DRM task).

\section{Data supporting the distinction between recovered and discovered memories}

Because data concerning the moment of recovery (i.e., during therapy versus outside of therapy, being a rather spontaneous event) were collected for each person who participated in the CSA studies documented in this thesis, we were able to examine the evidence for the above-mentioned hypotheses ${ }^{1}$, at least on an exploratory basis (de Groot, 1994). To this end, data collected in the studies described in Chapters 4 and 7 were closely inspected regarding the type of recovered memory experience. Participants reporting recovered CSA memories were divided on the basis of the context of their recovery (i.e., during therapy versus outside of therapy). In the DRM study (Chapter 4), the recovered memory group was divided in eight women having recovered being abused during therapy and 15 women with spontaneously recovered (i.e., discovered) CSA memories. 
Similarly, in Experiment 7 of the FIA study (Chapter 7 ), 15 participants had recovered abuse events in therapy, while 42 reported having had a spontaneous recovery of the CSA. In Experiment 2, 14 participants recollected the abuse in the course of therapy, while 41 had a spontaneous recovery of the abuse events. Although these subgroups are relatively small, analyses were performed to explore whether CSA memories recovered during therapy are more likely to be associated with enhanced false memory effects (DRM) and rather standard FIA effects. Also, it was examined whether spontaneously recovered (i.e., discovered) memory experiences go hand in hand with heightened FIA effects and rather standard false memory effects.

For the DRM data, false recall and recognition of neutral and traumarelated critical lures were inspected. To test whether participants with CSA memories recovered during therapy displayed higher levels of false recall than the other groups, the false recall rate (i.e. mean proportion of recall of nonstudied critical lures and of nonstudied words other than the critical lures) was computed and contrast weights of $4,-1,-1,-1,-1$ were applied to the recovered-in-therapy, recovered-outside-of-therapy, repressed, continuous, and control subgroups, respectively. Women with CSA memories recovered during therapy had a higher rate of false recall for neutral critical lures relative to the other four subgroups, $t(109)=5.85, p<.001, d=1.12$. This contrast analysis was also performed on the false recall rate for trauma-related critical lures, yielding a nonsignificant result, $t(109)=.19, p=.85, d=0.04$. For the recognition of neutral critical lures, the false recognition rate (i.e., mean proportion of recognition of nonstudied critical lures and of nonstudied words other than the critical lures) was calculated. Similar contrast weights were applied. Again, a significant difference emerged, $t(109)=2.45, p=.02, d=$ 0.47 , indicating that women with memories recovered during therapy more often falsely recognized neutral critical lures than women in the other four subgroups. Similar results were found for the recognition of trauma-related critical lures, with women who reported that they had CSA memories recovered during therapy showing a higher rate of false recognition of trauma-related critical lures, $t(109)$ $=3.61, p<.001, d=0.69$.

For the FIA data, the proportion of correct "yes" judgments for the other-context items obtained on Test 2 was inspected. For Experiment 1, contrast weights of $3,-1,-1,-1$ were applied to the recovered-outside-oftherapy, recovered-in-therapy, continuous, and control subgroups, respectively. 
People with spontaneously recovered CSA memories were significantly more likely to forget that they had recalled an item on Test 1 if it had been cued in the other context than other subgroups, $t(190)=2.85, p=.005, d=0.41$. In Experiment 2, similar contrast weights were applied. Again, people with spontaneously recovered memories were significantly more likely to forget that they had recalled an autobiographical event on Test 1 if it had been cued in the other-framing context than other subgroups, $t(181)=3.53, p=.001, d=0.51$.

In conclusion, although exploratory, this post-hoc analysis appears to confirm the view that reports of CSA memories recovered in therapy are more likely to be associated with false memory effects. As in the original study documented in Chapter 4, this pattern was more convincing for recognition than for recall parameters. Moreover, reports of spontaneously recovered (i.e., discovered) CSA memories seem to be more closely linked to underestimation of prior remembering than reports of traumatic memories recovered in therapy. Hence, on the one hand, some CSA memories recovered during therapy may not correspond to genuine events and are likely to be false. On the other hand, inaccuracy in judging past memory states may be responsible for some claims of previous repression. Here, people are remembering a probably genuine event in the present and erroneously report that they failed to remember it in the past. Thus, both types of recovered memory experiences yield, in their way, false impressions of repression.

\section{Further support for the two types of recovered memory experiences}

Although the data above are preliminary due to the small sample sizes of the recovered memory subgroups, recent research conducted in our laboratory supports the view that CSA memories discovered outside of therapy are more likely to reflect genuine events relative to memories recovered in therapy (Geraerts, Schooler, Merckelbach, \& Jelicic, 2006c). In this study, people with recovered CSA memories ( $n=57$ ) responded to an extensive memory questionnaire. Participants were asked to characterize their prior degree of forgetting, the quality of their memory recovery if they had one, the nature and context of the abuse, the qualities of their current memory. Moreover, information from others (e.g., sibling) or physical evidence (e.g., letters, medical records) was sought to validate the CSA memories. The presence of corroborative 
evidence was evaluated by two raters blind to any additional information associated with each case.

Results indicated that memories recovered unexpectedly, outside of therapy, were significantly more corroboratable than memories that were reported to have been gradually recovered within the context of therapy, $X^{2}(2)=$ 7.71, $p<.05$. Table 10.1 shows that abuse events recovered during therapy could not be corroborated, while $37 \%$ of the CSA memories discovered outside of therapy were corroborated. This seems to confirm the view that memories recovered unexpectedly outside of therapy (i.e., discovered memories) are more likely to correspond to genuine abuse events, relative to memories recovered in therapy.

Moreover, in this study, $85 \%$ of participants reporting recovered memories failed to appreciate their abuse as traumatic at the time it occurred, in part due to lack of understanding the nature of the event (for related results, see Clancy \& McNally, in press). In fact, many of them rated the abuse as being more traumatic now than it was at the time of the abuse. This was especially the case for participants who suddenly recalled long forgotten and often corroborated episodes of abuse. Several of them were exposed to one or sometimes more episodes of abuse that were nonpenetrative (e.g., fondling). Such events were experienced as confusing or distressing but not essentially frightening. Individuals reporting them might have managed not to think about these experiences, particularly if retrieval cues were absent, e.g., in cases in which the victim or the perpetrator had moved away (see also Case 2 in this thesis). Years later, appropriate retrieval cues might be encountered, triggering the recollection of the long-forgotten abuse experiences, which the person now correctly understands to be sexual abuse. This realization often is accompanied by an onrush of emotions which is interpreted as the impact of remembering something for the first time.

The data of our new study support this notion (Geraerts et al., 2006c). That is, the lower the importance of the abuse was perceived at the time of the abuse, the higher the chance that the abuse was forgotten, $B=-.19, S E=.07, p$ $=.006$. Also, the larger the difference in perceived negativity of the abuse at the time of the abuse and current evaluations, the higher the chance that the abuse was forgotten, $B=.41, S E=.09, p<.001$. Of course, it should be emphasized that although abuse events in childhood are often perceived as non-traumatic, 
this does not diminish their moral reprehensibility (Rind, Tromovitch, \& Bauserman, 1998).

Table 10.1 Amount of corroborative evidence for abuse events recovered outside and in the course of therapy.

\begin{tabular}{lll}
\hline & Corroborative evidence & \\
& No & Yes \\
\hline $\begin{array}{l}\text { Recovered in therapy } \\
\begin{array}{l}\text { Discovered outside of } \\
\text { therapy }\end{array}\end{array}$ & 16 & 0 \\
\hline
\end{tabular}

Although such cases undoubtedly qualify as recovered/discovered memories of sexual abuse, they cannot be taken as evidence for amnesia. Contrary to the standard view of repression, people do not forget their abuse in the strict sense of the word, because the abuse was neither perceived as traumatic nor recognized as abuse. No special mechanisms, such as repression or dissociation, have to be put forward to clarify why these misapprehended abuse experiences did not come to mind for many years (see also McNally, 2005a). Also, no special mechanisms like repression are needed to explain reports of CSA memories recovered during therapy. Along with other findings (Clancy, et al, 2000), the current data discussed in Chapter 4 and in this General Discussion point out that these memories are often suggested by therapists and are likely to be false. Memories recovered during therapy, as well as discovered memories both render a scenario in which a false impression of previous nonavailability of abuse memories arises, while in fact, no special mechanisms like dissociation or repression are needed to account for these impressions of repression.

\section{FALSE IMPRESSIONS OF REPRESSION}

In conclusion, the current thesis does not support the view that repression provides a good account of reports of amnesia. Three possibilities other than repression have been explored that may well lead to the impression that traumatic memories have been previously repressed. The first is that the abuse event is remembered because the memory itself was created in the present, often 
as a result of therapeutic intervention. That is, the past event itself is the artefact of a memory distortion.

The second is that traumatic experiences are overreported. Research described in this thesis pointed out that no solid evidence was found for the idea that symptom overreporting of e.g. prior forgetting is typical for people with recovered memories. However, results indicated that some people with CSA experiences - whether recovered or continuous - engage in symptom overreporting because they may want to demonstrate that their abuse accounts and trauma-related symptoms were genuine and severe.

Finally, another kind of memory distortion that may lead to the impression of repression occurs when people attempt to assess their prior memory states. In this case, the abuse event really happened, and even though it was "remembered" the whole time, the person has the false impression that there was an extended period in the past when he or she could not remember the abuse. This is in part due to lack of understanding the nature of the event. Their failure to think about these experiences cannot be considered as instances of forgetting trauma. A combination of all these possibilities may account for a large proportion of these so-called impressions of repression.

Moreover, by focusing on repression as a trait (i.e., repressive coping), it was found that inhibition of negative autobiographical memories is not evident in repressors over a longer period of time. Also, findings relating working memory capacity and repressive coping suggest that repressive coping is more than just a general personality style.

\section{AVENUES FOR FUTURE RESEARCH}

It is important to replicate the present findings and further examine whether people reporting CSA memories recovered during therapy differ cognitively from people having spontaneously recovered memories of abuse. For example, are people reporting the first type of recovered memory experience more likely to show a higher susceptibility on tasks tapping false memory effects and/or source monitoring abilities than are people with the second type of experience (i.e. discovered memories)? And are people with these so-called discovered memories worse in assessing their own past memory states? Clearly, some headway on this matter can be made by conducting more extensive studies, with large samples, making an apparent distinction between people with memories recovered during 
therapy and people with spontaneously recovered memories. Likewise, because studies described in chapters 3 to 5 relied on the same sample, it is imperative that results found in these studies are replicated using independent samples. After all, with several studies relying on the same sample, one runs the risk that peculiarities of that sample become overrepresented. On the other hand, results found in our studies are definitely in line with findings reported by McNally and co-workers (Clancy et al., 2000; McNally et al., 2000a, 2001). Additionally, it would be interesting to explore the cognitive functioning of retractors (people who have retracted their claims of (SA), relative to people with memories recovered in therapy and people with spontaneously recovered memories (see also Öst et al., 2001, 2002). It is imperative that several cognitive tasks and interview methods are employed to elucidate these issues.

Furthermore, research is needed to clarify the memory functioning of people with a repressive coping style. Several cognitive tasks are needed to explore whether repressors are superior in inhibiting negative or even traumarelated material. At present, research employing directed forgetting and retrieval induced forgetting tasks, both with autobiographical material (e.g., Barnier, Conway, Mayoh, Speyer, \& Avizmil, in press; Barnier, Hung, \& Conway, 2004), is conducted in our laboratory to examine repressors' memory performance. More of these autobiographical memory tasks are needed to clarify whether repressors are natural suppressors of negative self-relevant material or whether other mechanisms play a role. Additionally, and perhaps most importantly, research is warranted investigating whether a repressive coping style leads to an enhanced vulnerability to certain forms of psychopathology.

\section{CLOSING REMARKS}

Clearly, even though corroborative evidence for the abuse events was sought, none of the studies described in this thesis can fully answer this question: were participants reporting repressed or recovered memories actually abused during their childhood? Nonetheless, the use of cognitive tasks is essential in illuminating several aspects of the recovered-memory debate. That is, one can examine how, in principle, certain individuals may either forget or end up falsely believing they have been abused. 
Findings reported in this thesis have implications for prevailing views about repression and recovery of traumatic memories. For example, in July 2000, the Ministry of Health in the Netherlands asked its professional advisory council (i.e., Health Council) to tackle the problem of accusations based on CSA memories recovered during therapy. One of the major conclusions in the final report called Disputed Memories (Health Council of the Netherlands, 2004) published by this Council was that traumatic memories recovered during suggestive therapy may be false. Indeed, results documented in the present dissertation support the view that abuse memories suggested by therapists are likely to be false. However, the Council report did not refer to a scenario in which spontaneously recovered (i.e., discovered) CSA memories may reflect genuine abuse events. The possibility that so-called discovered memories are due to an underestimation of prior remembering of the abuse events in question was not discussed by the Council. However, findings in this thesis point out that this scenario might underlie recovered memories. It is imperative that future studies take such findings into account.

The Council also summarized several studies employing surveys to examine therapists' attitudes towards traumatic memory and suggestive techniques (e.g., Andrews, Morton, Bekerian, Brewin, Davies, \& Mollon, 1995; Polusny \& Follette, 1996). These studies indicated that a non-trivial part of the therapists considered recovered memories to represent authentic events. Moreover, a considerable percentage of these therapists used techniques such as hypnosis, dream interpretation, and guided imagery. For example, in the Netherlands, a majority of treatments concerning sexual abuse victims, focus on recovery of traumatic memories. Results in this thesis, along with other findings (e.g., Clancy et al., 2000; McNally, Clancy, Barrett, \& Parker, 2005) indicate that at least a subsample of those with recovered memories develop pseudo-memories about their alleged trauma because of a subtle interaction between intrinsic source monitoring difficulties and suggestive therapeutic techniques. That is, therapists should be aware that certain conditions may amplify the recovery of false traumatic memories. This seems to be especially true for patients exemplifying certain personality characteristics like fantasy proneness.

By focusing on well known imperfections of human memory, it is my hope that both sides of the recovered memory debate are illustrated in this thesis. If individuals can remember bizarre events such as being abducted by space aliens, it shouldn't be more surprising that individuals might falsely 
remember being sexually abused. Similarly, if memory for past memory states is so susceptible to distortions, then one should not be surprised that a person can "forget" having remembered a genuine abuse event, thereby producing a false impression of repression. At the end of the day, recovered memories of both fictitious and actual events may come to be understood as being different examples of the striking ways in which impressions of repression can be created. 



\section{NOTES}

\section{CASES OF RECOVERED MEMORIES}

1. Both cases are based on stories of people who participated in the studies conducted during this PhD project. The names of the individuals have been changed, as well as several details to preserve anonymity.

\section{CHAPTER 1 - GENERAL INTRODUCTION}

1. It is not argued that these are the only possibilities that may create an impression of repression. For example, distortions about the nature of the event are not examined in this thesis (see Loftus et al., 1998). This thesis, however, will only focus on the possibilities mentioned in the Introduction.

\section{CHAPTER 2 - TRAUMATIC MEMORIES IN WAR VETERANS: NOT SO SPECIAL AFTER}

ALL

1. The authors noted that in this case, there is a serious possibility that drug abuse contributed to the poor memory of the traumatic episode.

2. Goodman and Paz-Alonso (in press) provide an in-depth analysis of these data, yielding a reduced estimate of $3.6 \%$ for the incidence of traumatic amnesia.

3. MENT scores were 21 and 13 while SIMS scores were 56 and 57, all reflecting scores in the highest decile.

\section{CHAPTER 3 - RETRIEVAL INHIBITION OF TRAUMA-RELATED WORDS IN WOMEN} REPORTING REPRESSED OR RECOVERED MEMORIES OF CHILDHOOD SEXUAL ABUSE

1. Even when women were classified into two groups, repressors and nonrepressors (see McNally et al., 2004; Myers et al., 1998), the main effect of Group did not reach significance: $F(1,111)<1.0, n s$. 
1. Strictly speaking, one should distinguish between reporting traumatic events that never happened and symptom exaggeration. Although (false) traumatic memories are not themselves symptoms, we refer to symptom overreporting because of expediency.

\section{CHAPTER 7 - FORGETTING OF PRIOR REMEMBERING IN PERSONS REPORTING RECOVERED MEMORIES OF CHILDHOOD SEXUAL ABUSE}

1. We refer to this as Test $O$ to enhance comparability across both experiments. That is, in Experiment 1 there was a study phase and a Test 1 and Test 2.

2. At first glance, this may seem at odds with prior evidence of inconsistency in autobiographical memory reports across widely separated occasions (e.g., Neisser \& Harsch, 1992; Talarico \& Rubin, 2003). We speculate that this is largely a matter of grain size (Goldsmith, Koriat, \& Weinberg-Eliezer, 2002). In our study, participants merely had to talk about the same event, not report the same details, to be counted as consistent. Also, the stability of the context across recall occasions, and the fact that the inter-test interval was no more than four months, may have supported consistency (see Rubin, Schrauf, \& Greenberg, 2004, for a similar observation).

3. We thank J. Don Read for comments on a draft of this article.

\section{CHAPTER 10 - GENERAL DISCUSSION}

1. We thank Jonathan Schooler who put forward this suggestion. 


\section{SUMMARY}

Are individuals able to forget a traumatic experience such as being sexually abused? This question has given rise to one of the most contentious controversies in psychiatry and psychology. This concept of repressed memories is controversial and has led to, what is sometimes dubbed, "the memory wars". On the one hand, many authors claim that amnesia for trauma and subsequent recovery of traumatic memories can be demonstrated in clinical populations (e.g., Brown, Scheflin, \& Whitfield, 1999; Terr, 1994). Conversely, a number of psychologists have questioned the existence of repressed and recovered memories of trauma because of the lack of solid evidence for such memories (e.g., Kihlstrom, 2004; McNally, 2003a). Additionally, skeptics have warned that memories may be susceptible to distortions (Schacter, 1999) and that therapeutic interventions such as hypnosis, dream interpretation, and imagination - intended to recover memories of childhood sexual abuse (CSA) - may unintentionally foster pseudo-memories of CSA (Loftus, 2003).

This thesis aimed at investigating whether reports of amnesia exist on a non-trivial scale in samples of victims, and if so, whether repression provides a good account of such memory loss. To address this question, studies reported in this thesis use methods of cognitive psychology to examine remembering and forgetting of people who report having experienced traumatic events like war atrocities or childhood sexual abuse. Because Loftus and colleagues (Loftus, Joslyn, \& Polage, 1998, p. 790) argued that "memory distortions other than repression may well lead to the impression that traumatic memories are often repressed", four possibilities are considered that may render an impression of repression. First of all, the idea that traumatic events can indeed be forgotten and subsequently recovered is examined. Secondly, it is explored whether repression might be a by-product of memory distortions, in particular pseudo-memories. Next, the association between reports of traumatic experiences and overreporting is examined. Finally, it is investigated whether people reporting recovered memories may underestimate their prior remembering. 
Moreover, a new line of research focuses on repression as a trait, reflecting an avoidant processing style for coping with aversive events (i.e., repressive coping; Myers, 2000a). These studies examine the short and long term effects of repressive coping on suppression of autobiographical memories.

Part 1 of this thesis focuses on the possibility that traumatic events like war atrocities and childhood abuse can be forgotten. Chapter 2 describes a study that was conducted with Croatian war veterans reporting combat experiences during the Balkan wars in the early 1990s. Results indicate that in our sample of war veterans, amnesia and intrusions about war-related events had a low base rate. This stands in sharp contrast to what one would expect on the basis of theories emphasizing the special status of traumatic memories (e.g., Bremner, 2002; van der Kolk, 1994). Hence, these findings cast doubts on the idea that amnesia is a common outcome of severe trauma.

Also in Part 1 , the concept of retrieval inhibition is examined. Because it is argued that traumatized people would possess a better retrieval inhibition mechanism and as a consequence would be better in forgetting trauma-related material (Cloitre, 1998), Chapter 3 elaborates on the concept of retrieval inhibition. Results indicate that those reporting repressed or recovered CSA memories, on a list-wise directed forgetting task, do not possess superior abilities to forget trauma-related material relative to those reporting having always remembered their abuse. Although directed forgetting experiments involve mere trauma-related words, these results nevertheless suggest that retrieval inhibition does not turn abuse survivors into skilled forgetters of trauma-related material.

Chapters in Part 2 describe studies that are relevant to the formation of pseudo-memories. Because it has been argued that some reports about recovered traumatic experiences are incorrect and hence represent pseudomemories, Chapter 4 explores whether people reporting recovered CSA memories are especially vulnerable to false memory effects relative to those who have never forgotten their CSA experiences or controls with no history of abuse. To investigate this matter in the laboratory, a variant of the Deese/RoedigerMcDermott (DRM; Deese, 1959; Roediger \& McDermott, 1995) paradigm was employed, making use of neutral, as well as trauma-related word lists. Results indicate that recovered memory participants show an enhanced false recall and 
recognition for critical lures on the DRM task. This was true for both neutral and trauma-related material. Such an enhanced susceptibility to false memory effects may be due to a deficit in source monitoring. If we assume that at least a subsample of those with recovered memories developed pseudo-memories about trauma as a result of a subtle interaction between inherent source monitoring difficulties and suggestive therapeutic strategies, their reports of amnesia become understandable. In this scenario, amnesia would be, in fact, a false impression of amnesia that arises in those who wonder why they haven't had access to their false trauma memories earlier in their life.

Related to this, Chapter 5 tests whether people with recovered and repressed CSA memories show heightened scores on measures that have been found to be associated with false memory effects. That is, it is explored whether people with repressed or recovered CSA memories score higher on measures tapping dissociative symptoms and fantasy proneness, relative to people reporting continuous CSA memories or controls reporting no history of abuse. Results point out that fantasy proneness could not fully explain the dissociative symptoms reported by the repressed and recovered memory group. That is, people reporting repressed or recovered CSA memories showed elevated levels of dissociation which were not paralleled by fantasy proneness. That is to say, the three CSA groups - whether repressed, recovered, or continuous - scored similarly on fantasy proneness.

Part 3 of this thesis relates recovered CSA memories to symptom overreporting. Chapter 6 examines whether people reporting recovered CSA memories have a higher tendency to overreport symptoms relative to people with continuous CSA memories and controls. To this end, instruments tapping the tendency to endorse bizarre, implausible and/or low frequency symptoms were employed. No solid evidence was found for the idea that symptom overreporting is typical for people with recovered memories. It is suggested that most of the participants who engaged in symptom overreporting did so because they wanted to demonstrate that their abuse accounts and trauma-related symptoms were genuine and severe.

Part 4 of this dissertation examines whether the impression of repression can be brought about by the overestimation of prior forgetting in individuals reporting recovered CSA memories. In other words, a person can 
forget having remembered a traumatic event, producing an "illusion of amnesia". Chapter 7 documents two studies exploring this so-called forgot-it-all-along phenomenon in people reporting recovered CSA memories. It was found that people with recovered memories were especially likely to forget they had previously recalled words or autobiographical events when cued to think about them differently across occasions of recall, relative to persons with continuous memories of CSA and those who reported no history of CSA. These studies provide indirect support that this forgot-it-all-along phenomenon is typical for at least some individuals who report recovered memories of abuse. Hence, some "recovered" memories concerning authentic abuse events may not have been lost in the first place.

Part 5 focuses on repressive coping and its link with memory functioning. The study described in Chapter 8 aimed at investigating both short and long term effects of repressive coping on the frequency of thoughts about negative autobiographical events. Results indicate that repressors rely on suppression as a habitual coping style to deal with short-term negative intrusions. Yet, over a seven days period, repressors reported the highest frequency of intrusive thoughts concerning their anxious autobiographical thoughts. These data challenge the popular view that repressive coping can be seen as an adaptive strategy for dealing with emotionally negative events.

Related to this, in Chapter 9 it is found that repressors' ability to suppress short term negative intrusive thoughts is related to their enhanced working memory capacity. This finding suggests that the idea of repressive copers being 'natural suppressors' can be further articulated by taking their enhanced working memory capacity into account.

The thesis ends with a General Discussion (Chapter 10). Main results are summarized and discussed. It is argued that one should make a distinction between two remarkably different types of recovered memory experiences. In one type, people realize that they are abuse survivors, commonly attributing current life difficulties to these repressed memories of abuse. Here, abuse events are mostly gradually recalled over time, often by suggestions of a therapist. In the other type of recovered memory experience, people are suddenly reminded of events that they had not thought about in many years. They are shocked and surprised at their recollection but not at the content of the memory as such. 
Future research should make a distinction between these recovered memory experiences. The use of cognitive tasks is essential in illuminating several aspects of the recovered-memory debate. At the end of the day, recovered memories of both fictitious and actual events may come to be understood as representing different examples of the striking ways in which impressions of repression can be created. 



\section{SAMENVATTING}

Kan men een traumatische ervaring zoals seksueel misbruik in de jeugd vergeten? Deze vraag heeft geleid tot één van de meest omstreden controverses in de psychiatrie en psychologie. Het concept van verdrongen herinneringen is controversieel en heeft geleid tot de zogenaamde "geheugenoorlogen". Er zijn auteurs die stellen dat amnesie voor het trauma en het daaropvolgende hervinden van traumatische herinneringen overtuigend zijn aangetoond in klinische populaties (bijv., Brown, Scheflin, \& Whitfield, 1999; Terr, 1994). Anderen echter hebben het bestaan van dergelijke verdrongen en hervonden herinneringen in vraag gesteld aangezien er weinig sterk empirisch bewijs zou zijn voor het bestaan van zulke herinneringen (bijv., Kihlstrom, 2004; McNally, 2003a). Sommigen van hen gaan nog een stap verder. Deze sceptici waarschuwen dat herinneringen vatbaar kunnen zijn voor distorties (Schacter, 1999) en dat therapeutische interventies zoals hypnose, droominterpretatie en imaginatie bedoeld om herinneringen aan seksueel kindermisbruik te hervinden - ongewild pseudo-herinneringen kunnen creëren.

Het doel van deze dissertatie is om te onderzoeken of rapportages van amnesie op grote schaal bestaan, en als dat zo is, of verdringing een goede verklaring biedt voor dit type geheugenverlies. Om deze vraag te beantwoorden, wordt er in de gerapporteerde studies gebruik gemaakt van cognitieve taken om het herinneren en vergeten van traumatische gebeurtenissen zoals oorlogsgruwelijkheden en kindermisbruik te onderzoeken. Omdat Loftus en collega's (Loftus, Joslyn, \& Polage, 1998) menen dat niet repressie, maar bepaalde geheugenfouten kunnen leiden tot de opvatting dat traumatische herinneringen vaak worden vergeten, worden er vier mogelijkheden nader bestudeerd die kunnen bijdragen tot een indruk van verdringing.

Allereerst wordt onderzocht of traumatische gebeurtenissen inderdaad kunnen worden vergeten en vervolgens worden hervonden. Daarnaast wordt nagegaan of verdringing kan worden uitgelegd door andere geheugenfouten, in het bijzonder pseudo-herinneringen. Hierna wordt de relatie tussen rapportages van traumatische gebeurtenissen en overrapportage van symptomen onder de 
loep genomen. Als laatste wordt onderzocht of individuen met hervonden herinneringen hun eerder herinneren onderschatten.

Hiernaast wordt een nieuwe lijn van onderzoek gepresenteerd waarbij verdringing wordt gezien als een karaktereigenschap. In deze visie reflecteert verdringing een vermijdende verwerkingsstijl die wordt gehanteerd om met aversieve gebeurtenissen te kunnen omgaan (ook wel "repressive coping"genoemd; bijv., Myers, 2000a). Deze studies onderzoeken de korte en lange termijn effecten van repressive coping op suppressie van autobiografische herinneringen.

Deel $l$ van dit proefschrift richt zich op de mogelijkheid dat traumatische gebeurtenissen zoals oorlogsgruwelijkheden en seksueel kindermisbruik kunnen worden vergeten. Hoofdstuk 2 beschrijft een studie die werd uitgevoerd met Kroatische oorlogsveteranen. Gevraagd werd naar hun oorlogservaringen tijdens de Balkanoorlog begin jaren 1990. In deze steekproef van veteranen lijken amnesie en intrusies over oorlogsgerelateerde gebeurtenissen zelden te worden ervaren. Dit is in scherp contrast met wat men zou verwachten op basis van theorieën die de speciale status van traumatische herinneringen benadrukken (e.g., Bremner, 2002; van der Kolk, 1994). Deze resultaten trekken dan ook het idee in twijfel dat amnesie een gevolg is van trauma.

In Deel 7 wordt ook het concept van ophalingsinhibitie onderzocht. Omdat sommige auteurs opperen dat getraumatiseerde mensen over krachtigere ophaalinhibitie zouden beschikken en dientengevolge beter in staat zouden zijn om traumagerelateerd materiaal te vergeten (Cloitre, 1998), wordt in Hoofdstuk 3 ophaalinhibitie bestudeerd bij personen die menen te zijn misbruikt in hun jeugd. Mensen met verdrongen en hervonden misbruikherinneringen lijken geen geprononceerder gericht-vergeteneffect te vertonen voor emotioneel materiaal. Deze resultaten bieden dus geen ondersteuning voor het idee dat mensen met verdrongen of hervonden herinneringen superieur zijn in het vergeten van traumagerelateerde woorden.

De hoofdstukken in Dee/ 2 beschrijven studies die relevant zijn voor het fenomeen van pseudo-herinneringen. Verschillende auteurs suggereren dat hervonden herinneringen aan traumatische gebeurtenissen niet authentiek maar berusten op pseudo-herinneringen. Hoofdstuk 4 doet verslag van een studie 
waarin wordt onderzocht of mensen met hervonden misbruikherinneringen vatbaarder zijn voor geheugenillusies dan degenen die verdrongen of continue herinneringen rapporteren, of zij die aangeven nooit te zijn misbruikt. Om dit thema te onderzoeken in het laboratorium, werd er gebruik gemaakt van het Deese/Roediger-McDermott (DRM; Deese, 1959; Roediger \& McDermott, 1995) paradigma bestaande uit neutrale en traumagerelateerde woordlijsten. De resultaten van dit onderzoek ondersteunen het idee dat mensen met hervonden herinneringen vatbaarder zijn voor geheugenillusies, zowel voor neutraal als traumagerelateerd materiaal. Deze verhoogde vatbaarheid wordt in verband gebracht met een gebrekkige bron-identificatie (source monitoring). Met andere woorden, als we aannemen dat ten minste een deel van de hervonden herinneringen-groep pseudo-herinneringen ontwikkelt als gevolg van een subtiele interactie tussen een gebrekkige bron-identificatie en suggestieve therapietechnieken, dan worden hun rapportages van zogenaamde amnesie begrijpelijk. In een dergelijk scenario kan amnesie worden gezien als een onjuiste impressie van geheugenverlies die ontstaat bij diegenen die zich afvragen waarom hun valse traumaherinneringen niet eerder toegankelijk waren.

Hoofdstuk 5 gaat na of mensen met verdrongen en hervonden misbruikherinneringen verhoogde scores hebben op maten die een samenhang vertonen met het ontwikkelen van geheugenillusies. Met andere woorden, er wordt onderzocht of mensen met verdrongen en hervonden herinneringen hoger scoren op maten van dissociatieve symptomen en fantasieneiging in vergelijking met mensen die continue herinneringen rapporteren of controleproefpersonen zonder een geschiedenis van misbruikervaringen. Uit de resultaten blijkt dat fantasieneiging niet volledig de dissociatieve symptomen van de verdrongen- en hervonden- herinneringgroepen kan verklaren. Dat wil zeggen dat de drie misbruikgroepen - hetzij verdrongen, hervonden of continu, gelijk scoren op fantasieneiging.

Deel 3 van dit proefschrift relateert hervonden herinneringen aan overrapportage van symptomen. Hoofdstuk 6 onderzoekt of mensen met hervonden herinneringen een grotere neiging hebben om hun symptomen te overrapporteren dan degenen met continue herinneringen en controles. Met dit als doel werden instrumenten gebruikt die de neiging meten om bizarre en implausibele symptomen te onderschrijven. Er werd geen steun gevonden voor het idee dat overrapportage kenmerkend is voor mensen met hervonden 
herinneringen. Wellicht dat proefpersonen hun symptomen overrrapporteerden omdat ze wilden aantonen dat hun misbruikervaringen en de hieraan gerelateerde symptomen authentiek waren.

Dee/ 4 van deze dissertatie onderzoekt of de indruk van verdringing kan worden veroorzaakt door het overschatten van eerder herinneren in mensen met hervonden herinneringen. Met andere woorden, een persoon kan vergeten dat $\mathrm{hij} / \mathrm{zij}$ een traumatische gebeurtenis heeft herinnerd, zodat een "illusie van amnesie" wordt gecreëerd. Hoofdstuk 7 beschrijft twee studies die dit zogenaamd "forgot-it-all-along" fenomeen bestuderen bij mensen met hervonden misbruikherinneringen. De resultaten tonen duidelijk aan dat mensen met hervonden herinneringen geneigd zijn om te vergeten dat ze woorden of autobiografische gebeurtenissen hebben herinnerd doorheen verschillende sessies, in vergelijking met degenen met continue misbruikherinneringen of mensen zonder een voorgeschiedenis van misbruikervaringen. Deze studies verschaffen indirect bewijs dat dit forgot-it-all-along fenomeen kenmerkend is voor een deel van de mensen die hervonden herinneringen rapporteren. Bij hen zijn "hervonden" herinneringen betreffende oorspronkelijke misbruikgebeurtenissen dus feitelijk nooit verloren geraakt.

In Deel 5 wordt de relatie tussen repressive coping en geheugenfunctioneren bestudeerd. Hoofdstuk 8 onderzoekt de korte en lange termijn effecten van repressive coping op de frequentie van gedachten betreffende negatieve autobiografische gebeurtenissen. "Repressors" lijken suppressie te hanteren als copingmechanisme om te kunnen omgaan met negatieve intrusies op korte termijn. Echter, over een periode van zeven dagen, rapporteren repressoren het hoogste aantal negatieve intrusies. Deze resultaten stellen de populaire visie op de proef dat repressive coping kan worden gezien als een adaptieve strategie om met emotioneel negatieve gebeurtenissen te kunnen omgaan.

Gerelateerd aan dit thema wordt in Hoofdstuk 9 gevonden dat het vermogen van repressoren om negatieve intrusies op korte termijn te onderdrukken samenhangt met een verbeterde werkgeheugencapaciteit.

Dit proefschrift eindigt met een Algemene Discussie (Hoofdstuk 10), waarin de resultaten van de afzonderlijke studies met elkaar in verband worden 
gebracht. In dit hoofdstuk wordt beargumenteerd dat het zinvol is onderscheid te maken tussen twee soorten hervonden-herinnering ervaringen. Bij het ene type realiseren mensen dat ze misbruikslachtoffers zijn, waarbij huidige problematiek wordt toegeschreven aan deze verdrongen misbruikherinneringen. Gebeurtenissen betreffende het misbruik worden veelal geleidelijk hervonden tijdens therapie, vaak aan de hand van suggesties van een therapeut. Bij het andere type van hervonden-herinnering ervaring worden mensen plotseling herinnerd aan gebeurtenissen waaraan ze jarenlang niet hebben gedacht. Ze zijn verbaasd omwille van hun herinnering. Toekomstig onderzoek moet een onderscheid maken tussen deze twee types van hervonden-herinnering ervaringen. Het gebruik van cognitieve taken lijkt essentieel om verschillende aspecten van het debat over hervonden herinneringen te belichten. Uiteindelijk zullen hervonden herinneringen van zowel fictieve als feitelijke gebeurtenissen worden gezien als verschillende voorbeelden van de saillante manieren waarop impressies van verdringing kunnen worden gecreëerd. 



\section{WORKS CITED}

Alpert, J. L. Brown, L. S., \& Courtois, C. A. (1998a). Symptomatic clients and memories of childhood abuse. What the trauma and child sexual abuse literature tell us. Psychology, Public Policy, and Law, 4, 941-995.

Alpert, J. L. Brown, L. S., \& Courtois, C. A. (1998b). Reply to Ornstein, Ceci, and Loftus (1998): The politics of memory. Psychology, Public Policy, and Law, 4, 1011-1024.

Alpert, J. L. Brown, L. S., \& Courtois, C. A. (1998c). Comment on Ornstein, Ceci, and Loftus (1998): Adult recollections of childhood abuse. Psychology, Public Policy, and Law, 4, 1052-1067.

American Psychiatric Association (1994). Diagnostic and statistical manual of mental disorders (4th ed) (DSMIV). Washington, DC: APA.

Anderson, M. C., Bjork, R. A., \& Bjork, E. L. (1994). Remembering can cause forgetting: Retrieval dynamics in long-term memory. Journal of Experimental Psychology: Learning, Memory, and Cognition, 20, 1063-1087.

Anderson, M. C., \& Green, C. (2001). Suppressing unwanted thoughts by executive control. Nature, 410, 366-369.

Anderson, M. C., \& Levy, B. (2002). Repression can (and should) be studied empirically: Reply from Anderson and Levy. Trends in Cognitive Sciences, 6, 502-503.

Anderson, M. C., Ochsner, K. N., Kuhl., B., Cooper, J., Robertson, E., Gabrieli, S. W., Glover, G. H., \& Gabrieli, J. D. E. (2004). Neural systems underlying the suppression of unwanted memories. Science, 303, 232-235.

Andrews, B., Brewin, C. R., Ochera, J., Morton, J., Bekerian, D. A., Davies, G. M., \& Mollon, P. (1999). Characteristics, context and consequences of memory recovery among adults in therapy. British Journal of Psychiatry, 175, 141-146.

Andrews, B., Morton, J., Bekerian, D. A., Brewin, C. R., Davies, G. M., \& Mollon, P. (1995). The recovery of memories in clinical practice: Experiences and beliefs of British Psychological Society practitioners. The Psychologist: Bulletin of the British Psychological Society, 8, 209-214.

Arnold, M. M., \& Lindsay, D. S. (2002). Remembering remembering. Journal of Experimental Psychology: Learning, Memory, and Cognition, 28, 521-529.

Arnold, M. M., \& Lindsay, D. S. (2005). Remembrance of remembrance past. Memory, 13, 533-549.

Artiges, E., Salamé, P. S., Recasens, C., Poline, J., Attar-Levy, D., De la Raillère, A., Paillère-Martinot, M., Danion, J., \& Martinot, J. (2000). Working memory control in patients with schizophrenia: A PET study during a random number generation task. American Journal of Psychiatry, 157, 1517-1519.

Baddeley, A. D. (1986). Working memory. Oxford: Oxford University Press.

Barnier, A. J., Conway, M. A., Mayoh, L., Speyer, J., \& Avizmil, O. (in press). Controlling memories of the past: Directed Forgetting of recently recalled autobiographical memories. Journal of Experimental Psychology: General.

Barnier, A. J., Hung, L., \& Conway, M. A. (2004b). Retrieval-induced forgetting of emotional and unemotional autobiographical memories. Cognition and Emotion, 18, 457-477.

Barnier, A. J., Levin, K., \& Maher, A. (2004a). Suppressing thoughts of past events: Are repressive copers good suppressors? Cognition and Emotion, 18, 513-531. 
Baron, R. M., \& Kenny, D. A. (1986). The moderator-mediator variable distinction in social psychological research: Conceptual, strategic, and statistical considerations. Journal of Personality and Social Psychology, 51, 1173-1182.

Basden, B. H., Basden, D. R., \& Gargano, J. G. (1993). Directed forgetting in implicit and explicit memory tests: A comparison of methods. Journal of Experimental Psychology: Learning, Memory \& Cognition, 19, 603-616.

Basoglu, M., Salcloglu, E., \& Livanou, M. (2002). Traumatic stress responses in earthquake survivors in Turkey. Journal of Traumatic Stress, 15, 269-276.

Bass, E., \& Davis, L. (1988). The courage to heal: A guide for women survivors of child sexual abuse. New York: Harper and Row.

Beck, A. T., \& Steer, R. A. (1987). Beck depression inventory manual. San Antonio, TX: Psychological Corporation.

Bendig, A. W. (1956). The development of a short form of the Manifest Anxiety Scale. Journal of Consulting Psychology, 20, 384.

Bergeman, C. S., Chipuer, H. M., Plomin, R., Pedersen, N. L., McClearn, G. E., Nesselroade J. R., Costa, Jr., P., \& McCrae, M. C. (1993). Genetic and environmental effects on openness to experience, agreeableness, and conscientiousness: an adoption/twin study. Journal of Personality, 61, 159179.

Bernstein, D. M., Laney, C., Morris, E. K., \& Loftus, E. F. (2005a). False memories about food can lead to food avoidance. Social Cognition, 23, 11-34.

Bernstein, D. M., Laney, C., Morris, E. K., \& Loftus, E. F. (2005b). False beliefs about fattening foods can have healthy consequences. Proceedings of the National Academy of Sciences, 102, 13724-13731.

Bernstein, D. P., Ahluvalia, T. , Pogge, D., \& Handelsman, L. (1997). Validity of the Childhood Trauma Questionnaire in an adolescent psychiatric population. Journal of the American Academy of Child and Adolescent Psychiatry, 36, 340-348.

Bernstein, D. P., Stein, J. A., Newcomb, M. D., Walker, E., Pogge, D., Ahluvalia, T., et al. (2003). Development and validation of a brief screening version of the Childhood Trauma Questionnaire. Child Abuse and Neglect, 27, 169-190.

Bernstein, E. M., \& Putnam, F. W. (1986). Development, reliability and validity of a dissociation scale. Journal of Nervous and Mental Disease, 174, 727-735.

Berntsen, D., Willert, M., \& Rubin, D. C. (2003). Splintered memories or vivid landmarks? Qualities and organization of traumatic memories with and without PTSD. Applied Cognitive Psychology, 17, 675-693.

Berry, D. T. R., Baer, R. A., Rinaldo, J. C., \& Wetter, M. W. (2002). Assessment of malingering. In J. Butcher (Ed.), Clinical personality assessment: Practical approaches, $2^{\text {nd }}$ ed. (pp.269-302). New York: Oxford University Press.

Bjork, E. L., Bjork, R. A., \& Anderson, M. C. (1998). Varieties of goal-directed forgetting. In J. M. Golding, \& C. M. MacLeod (Eds.), Intentional forgetting: Interdisciplinary approaches (pp. 103-137). Mahwah, New Jersey: Lawrence Erlbaum Associates.

Bjork, R. A. (1989). Retrieval inhibition as an adaptive mechanism in human memory. In H. L. Roediger III, \& F. I. M. Craik (Eds.), Varieties of memory and consciousness: Essays in honour of Ende/ Tulving (pp. 309-330). Hillsdale New Jersey: Lawrence Erlbaum Associates.

Blake, D. D., Weathers, F. W., Nagy, L. M., Kaloupek, D. G., Gusman, F. D., Charney, D. S., \& Keane, T. M. (1995). The development of a Clinician-Administered PTSD scale. Journal of Traumatic Stress, 8 , 75-90.

Boden, J. M., \& Baumeister, R. F. (1997). Repressive coping: Distraction using pleasant thoughts and memories. Journal of Personality and Social Psychology, 73, 45-62.

Bonanno, G. A. (2004). Loss, trauma, and human resilience: Have we underestimated the human capacity to thrive after extremely aversive events? American Psychologist, 59, 20-28. 
Bonanno, G. A., Noll, J. G., Putnam, F. W., O'Neill, M., \& Trickett, P. K. (2003). Predicting the willingness to disclose childhood sexual abuse from measures of repressive coping and dissociative tendencies. Child Maltreatment, 8, 302-318.

Brainerd, C. J., \& Reyna, V. F. (1998). When things that were never experienced are easier to 'remember' than things that were. Psychological Science, 9, 484-489.

Brandon, S., Boakes, J., Glaser, D., \& Green, R. (1998). Recovered memories of childhood sexual abuse: Implications for clinical practice. British Journal of Psychiatry, 172, 296-307.

Bremner, J. D. (2002). Does stress damage the brain? Understanding trauma-related disorders from a mindbody perspective. New York: Norton.

Bremner, J. D., Shobe, K. K., \& Kihlstrom, J. F. (2000). False memories in women with self-reported childhood sexual abuse: An empirical study. Psychological Science, 11, 333-337.

Brewin, C. R. (1998). Intrusive autobiographical memories in depression and posttraumatic stress disorder. Applied Cognitive Psychology, 12, 359-370.

Brewin, C. R. (2001). A cognitive neuroscience account of posttraumatic stress disorder and its treatment. Behaviour Research and Therapy, 39, 373- 393.

Brewin, C. R. (2003). Posttraumatic stress disorder: Malady or myth? London: Yale University Press.

Brewin, C. R. (2005). Thought suppression and working memory capacity. Paper presented at the Conference of the British Association for Behavioural and Cognitive Psychotherapies, Canterbury, United Kingdom.

Brewin, C. R., \& Andrews, B. (1998). Recovered memories of trauma: Phenomenology and cognitive mechanisms. Clinical Psychology Review, 18, 949-970.

Brewin, C. R., \& Beaton, A. (2002). Thought suppression, intelligence, and working memory capacity. Behaviour Research and Therapy, 40, 923-930.

Brewin, C. R., Dalgleish, T., \& Joseph, S. (1996). A dual representation theory of posttraumatic stress disorder. Psychological Review, 103, 670-686.

Brewin, C. R., \& Smart, L. (2005). Working memory capacity and suppression of intrusive thoughts. Journal of Behavior Therapy and Experimental Psychiatry, 36, 61-68.

Briere, J., \& Conte, J. R. (1993). Self-reported amnesia for abuse in adults molested as children. Journal of Traumatic Stress, 6, 21-31.

Brown, D., Goldstein, E., \& Bjorklund, D. F. (2000). The history and zeitgeist of the repressed-false-memory debate: Scientific and sociological perspectives on suggestibility and childhood memory. In D. F. Bjorklund (Ed.), False-memory creation in children: Theory, research, and implications (pp. 1-30). Mahwah, New Jersey: Lawrence Erlbaum Associates.

Brown, D., Scheflin, A. W., \& Hammond, D. C. (1998). Memory, trauma treatment, and the law. New York: Norton.

Brown, D., Scheflin, A. W., \& Whitfield, C. L. (1999). Recovered memories: The current weight of the evidence in science and in the courts. Journal of Psychiatry \& Law, 27, 5-156.

Burkett, B. G., \& Whitley, G. (1998). Stolen valor: How the Vietnam generation was robbed of its heroes and its history. Dallas: Verity Press.

Burns, J. W. (2000). Repression predicts outcome following multidisciplinary treatment of chronic pain. Health Psychology, 19, 75-84.

Byrne, D. (1964). Repression-sensitization as a dimension of personality. In B. A. Maher (Ed.), Progress in experimental personality research (Vol. 1, pp. 170-220). New York: Academic Press.

Cahill, L., Prins, B., Weber, M., \& McGaugh, J. L. (1994). $\beta$-Adrenergic activation and memory for emotional events. Nature, 371, 702-704.

Candel, I. (2003). The truth and nothing but the truth: The accuracy, completeness, and consistency of emotional memories. Dissertation, Maastricht University, Maastricht.

Candel, I., Geraerts, E., Wade, K., \& Raymaekers, L. (2006). Planting false events in children's memory: The role of valence. Manuscript in preparation. 
Candel, I., Merckelbach, H., \& Kuijpers, M. (2003). Dissociative experiences are related to commissions in emotional memory. Behaviour Research and Therapy, 41, 719-725.

Carrion, V. G., \& Steiner, H. (2000). Trauma and dissociation in delinquent adolescent. Journal of the American Academy of Child and Adolescent Psychiatry, 39, 353-359.

Ceci, S. J., \& Loftus, E. F. (1994). 'Memory work': A royal road to false memories? Applied Cognitive Psychology, 8, 351-364.

Cercy, S. P., Schretlen, D. J., \& Brandt, J. (1997). Simulated amnesia and the pseudo-memory phenomena. In R. Rogers (Ed.), Clinical assessment of malingering and deception (pp. 85-107). New York: Guilford.

Christianson, S.-Å. (1992). Handbook of emotion and memory. Hillsdale, New Jersey: Lawrence Erlbaum Associates.

Christianson, S.-Å., \& Lindholm, T. (1998). The fate of traumatic memories in childhood and adulthood. Development and Psychopathology, 10, 761-780.

Cima, M. (2003). Faking good, bad, and ugly. Malingering in forensic psychiatric inpatients. Dissertation, Maastricht University, Maastricht.

Clancy, S. A. (2005). Abducted: How people come to believe they were kidnapped by aliens. Cambridge, MA: Harvard University Press.

Clancy, S. A., \& McNally, R. J. (in press). Who needs repression?: Normal memory processes can explain forgetting of childhood sexual abuse. Scientific Review of Mental Health Practice.

Clancy, S. A., McNally, R. J., \& Schacter, D. L. (1999). Effects of guided imagery on memory distortion in women reporting recovered memories of childhood sexual abuse. Journal of Traumatic Stress, 12, 559-569.

Clancy, S. A., Schacter, D. L., McNally, R. J., \& Pitman, R. K. (2000). False recognition in women reporting recovered memories of sexual abuse. Psychological Science, 11, 26-31.

Cloitre, M. (1998). Intentional forgetting and clinical disorders. In J. M. Golding, \& C.M. MacLeod (Eds.), Intentional forgetting: Interdisciplinary approaches (pp. 395-412). Mahwah, N.J.: Lawrence Erlbaum Associates.

Cloitre, M. (2004). Aristotle revisited: The case of recovered memories. Clinical Psychology: Science and Practice, 11, 42-46.

Cloitre, M., Cancienne, J., Brodsky, B., Dulit, R., \& Perry, S. W. (1996). Memory performance among women with parental abuse histories: Enhanced directed forgetting or directed remembering? Journal of Abnormal Psychology, 105, 204-211.

Coleman, B. L., Stevens, M. J., \& Reeder, G. D. (2001). What makes recovered-memory testimony compelling to jurors? Law and Human Behavior, 25, 317-338.

Conway, A. R. A., \& Engle, R. W. (1994). Working memory and retrieval: A resource-dependent inhibition model. Journal of Experimental Psychology: General, 123, 354-373.

Conway, M. A. (2001). Repression revisited. Nature, 410, 319-320.

Crews, F. (1995). The memory wars: Freud's legacy in dispute. New York: New York Review of Books.

Crombag, H. F. M., Wagenaar, W. A., \& van Koppen, P. J. (1996). Crashing memories and the problem of "source monitoring". Applied Cognitive Psychology, 10, 95-104.

Crowne, D. P., \& Marlowe, D. A. (1960). A new scale of social desirability independent of psychopathology. Journal of Consulting Psychology, 24, 349-354.

Cunnien, A. J. (1997). Psychiatric and medical syndromes associated with deception. In R. Rogers (Ed.), Clinical assessment of malingering and deception (pp. 23-46). New York: Guilford.

Davis, P. J., \& Schwartz, G. E. (1987). Repression and the inaccessibility of affective memories. Journal of Personality and Social Psychology, 52, 155-162.

Deese, J. (1959). On the prediction of occurrence of particular verbal intrusions in immediate recall. Journal of Experimental Psychology, 58, 17-22.

DePrince, A. P., \& Freyd, J. J. (2004). Forgetting trauma stimuli. Psychological Science, 15, 488-492. 
Derakshan, N., \& Eysenck, M. W. (1997). Repression and repressors: Theoretical and experimental approaches. European Psychologist, 2, 235-246.

Derakshan, N., Myers, L. B., Hansen, J., \& O'Leary, M. (2004). Defensiveness and attempted suppression of negative material. European Journal of Personality, 18, 521-535.

DeViva, J. C., \& Bloem, W. D. (2003). Symptom exaggeration and compensation seeking among combat veterans with posttraumatic stress disorder. Journal of Traumatic Stress, 16, 503-507.

Drzavni zavod za statistiku [Croatian Bureau for Statistic] (1991). Popis stanovnistva iz 1991 [Population census from 1991]. Zagreb.

Edens, J. F., Otto, R. K., \& Dwyer, T. (1999). Utility of the Structured Inventory of Malingered Symptomatology in identifying persons motivated to malinger psychopathology. Journal of the American Academy of Psychiatry and the Law, 27, 387-396.

Ehlers, A., \& Clark, D. M. (2000). A cognitive model of posttraumatic stress disorder. Behaviour Research and Therapy, 38, 319-345

Eisen, M. L., \& Lynn, S. J. (2001). Dissociation, memory, and suggestibility in adults and children. Applied Cognitive Psychology, 15, S49-S73.

Erdelyi, M. H. (1990). Repression, reconstruction and defense: History and integration of the psychoanalytic and experimental frameworks. In J. Singer (Ed.), Repression and dissociation: Implications for personality theory, psychopathology and health (pp. 1-31). Chicago: University of Chicago Press.

Erdelyi, M. H. (in press). The unified theory of repression. Behavioral and Brain Sciences.

Eysenck, M. W. (1992). Anxiety: The cognitive perspective. Hove: Erlbaum.

First M. B., Spitzer, R. L., Gibbon M., \& Williams, J. B. W. (1996). Structured clinical interview for DSM-IV Axis I disorders. New York: Biometrics Research Department, New York State Psychiatric Institute.

Fischoff, B. (1977). Perceived informativeness of facts. Journal of Experimental Psychology: Human Perception and Performance, 3, 349-358.

Franklin, C. L., Repasky, S. A., Thompson, K. E., Shelton, S. A., \& Uddo, M. (2003). Assessment of response style in combat veterans seeking compensation for posttraumatic stress disorder. Journal of Traumatic Stress, 16, 251-255.

Frazier, P. A., Tix, A. P., \& Barron, K. E. (2004). Testing moderator and mediator effects in counseling psychology research. Journal of Counseling Psychology, 51, 115-134.

Frederickson, R. (1992). Repressed memories: A journey to recovery from sexual abuse. New York: Simon and Schuster.

Freud, S. (1957). Repression. In J. Strachy (Ed. \& Transl.), The standard edition of the complete psychological works of Sigmund Freud (Vol. 14, pp. 147-165). London: Hogarth Press. (Original work published 1915).

Freud, S. (1959). Inhibitions, symptoms, and anxiety. In A. Strachy, \& J. Strachy (Eds. \& Transl.), The standard edition of the complete psychological works of Sigmund Freud (Vol. 20). London: Hogarth Press. (Original work published 1926).

Freyd, J. J. (1996). Betrayal Trauma: The logic of forgetting childhood abuse. Cambridge, MA: Harvard University Press.

Freyd, J. J., \& Gleaves, D. F. (1996). "Remembering" words not presented in lists: Relevance to the current recovered/false memory controversy. Journal of Experimental Psychology: Learning, Memory, and Cognition, 22, 811-813

Friedman, N. P., \& Miyake, A. (2004). The relations among inhibition and interference control functions: A latent variable analysis. Journal of Experimental Psychology: General, 133, 101-135.

Frueh, B. C., Hamner, M. B., Cahill, S. P., Gold, P. B., \& Hamlin, K. L. (2000). Apparent symptom overreporting in combat veterans evaluated for PTSD. Clinical Psychology Review, 20, 853-885.

Furnham, A., \& Traynar, J. (1999). Repression and effective coping styles. European Journal of Personality, 13, 465-492. 
Garry, M., Manning, C. G., Loftus, E. F., \& Sherman, S. J. (1996). Imagination inflation: Imagining a childhood event inflates confidence that it occurred. Psychonomic Bulletin and Review, 3, 208-214.

Gast, U., Rodewald, F., Nickel V., \& Emerich, H. M. (2001). Prevalence of dissociative disorders among psychiatric inpatients in a German university clinic. Journal of Nervous and Mental Disease, 189, 249-257.

Geraerts, E., Arnold, M. M., Lindsay, D. S., Merckelbach, H., Jelicic, M., \& Hauer, B. (in press b). Forgetting of prior remembering in people reporting recovered memories of childhood sexual abuse. Psychological Science.

Geraerts, E., Elbers, N., \& van Heerden, J. (2005). Hallucinating consistency. Manuscript accepted pending revisions.

Geraerts, E., \& van Heerden, J. (2004). Verdringing: Een kritische kijk op de visie van Ramachandran [Repression: A critical view on Ramachandran's vision]. Nederlands Tijdschrift voor de Psychologie [Dutch Journal of Psychology], 59, 115-118.

Geraerts, E., Kozarić-Kovačić, D., Merckelbach, H., Peraica, T., Jelicic, M., \& Candel, I. (2006a). Assessing malingering in war veterans with war-related posttraumatic stress disorder. Manuscript submitted for publication.

Geraerts, E., Merckelbach, H., Jelicic, M., Smeets, E., \& van Heerden, J. (2006b). Dissociative symptoms and how they relate to fantasy proneness in women reporting repressed or recovered memories. Personality and Individual Differences, 40, 1143-1151.

Geraerts, E., Merckelbach, H., Jelicic, M., \& Smeets, E. (in press c). Long term consequences of suppression of intrusive anxious thoughts and repressive coping. Behaviour Research and Therapy.

Geraerts, E., Schooler, J., Merckelbach, H., \& Jelicic, M. (2006c). A corroborative investigation of continuous and discontinuous memories of childhood sexual abuse. Manuscript submitted for publication.

Geraerts, E., Smeets, E., Jelicic, M., van Heerden, J., \& Merckelbach, H. (2005). Fantasy proneness, but not self-reported trauma is related to DRM performance of women reporting recovered memories of childhood sexual abuse. Consciousness and Cognition, 14, 602-612.

Geraerts, E., Smeets, E., Jelicic, M., Merckelbach, H., \& van Heerden, J. (in press a). Retrieval inhibition of trauma-related words in women reporting repressed or recovered memories of childhood sexual abuse. Behaviour Research and Therapy.

Gershuny, B. S., \& Thayer, J. F. (1999). Relations among psychological trauma, dissociative phenomena, and trauma-related distress : A review and integration. Clinical Psychology Review, 19, 631-657.

Giesbrecht, T. (2006). Dissociation: A defensive maneuver? Dissertation, Maastricht University, Maastricht.

Giesbrecht, T., Merckelbach, H., Geraerts, E., \& Smeets, E. (2004). Dissociation in undergraduate students: Disruptions in executive functioning. Journal of Nervous and Mental Disease, 192, 567-569.

Ginsburg, N., \& Karpiuk, P. (1994). Random number generation: Analysis of the responses. Perceptual and Motor Skills, 79, 1059-1067.

Ginzburg, K., Solomon, Z., \& Bleich, A. (2002). Repressive coping style, acute stress disorder, and posttraumatic stress disorder after myocardial infarction. Psychosomatic Medicine, 64, 748-757.

Gold, P. B., \& Frueh, B. C. (1999). Compensation seeking and extreme exaggeration of psychopathology among combat veterans evaluated for posttraumatic stress disorder. Journal of Nervous and Mental Disease, 187, 680-684.

Goldsmith, M., Koriat, A., \& Weinberg-Eliezer, A. (2002). Strategic regulation of grain size memory reporting. Journal of Experimental Psychology: General, 131, 73-95.

Goldstein, E., \& Farmer, K. (1993). True stories of false memories. Boca Raton, FL: Upton Books.

Goodman, G. S., Ghetti, S., Quas, J. A., Edelstein, R. S., Alexander, K. W., Redlich, A. D., Cordon, I. M., \& Jones, D. P. (2003). A prospective study of memory for child sexual abuse: New findings relevant to the repressed-memory controversy. Psychological Science, 14, 113-118. 
Goodman, G. S., \& Paz-Alonso, P. M. (in press). Trauma and memory: Normal versus special memory mechanisms. In B. Uttl, N. Ohta, \& A. L. Siegenthaler (Eds.), Memory and emotions: Interdisciplinary perspectives. New York: Blackwell.

Grinker, R. R., \& Spiegel, J. P. (1943/1945). Men under stress. New York: McGraw-Hill.

Groot, de, A.D. (1969). Methodology: Foundations of inference and research in the behavioral sciences. Den Haag: Mouton.

Gudjonsson, G. H. (1997). Accusations by adults of childhood sexual abuse: A survey of the members of the British False Memory Society (BFMS). Applied Cognitive Psychology, 11, 3-18.

Guriel, J., \& Fremouw, W. (2003). Assessing Posttraumatic Stress Disorder: A critical review. Clinical Psychology Review, 23, 881-904.

Halligan, P. W, Bass, C., \& Oakley D. A. (2003). Malingering and illness deception. Oxford: Oxford University Press.

Harvey, A., \& Bryant, R. A. (1998). The role of valence in attempted thought suppression. Behaviour Research and Therapy, 36, 757-763.

Harvey, M. R., \& Herman, J. L. (1994). Amnesia, partial amnesia, and delayed recall among adult survivors of childhood trauma. Consciousness and Cognition, 3, 295-306.

Health Council of the Netherlands (2004). Disputed memories. The Hague: Health Council of the Netherlands; publication no. 2004/02.

Herbart, J. F. (1816/1881). A textbook in psychology: An attempt to found the science of psychology on experience, metaphysics, and mathematics. New York: Appleton.

Herman, J. L. (1992). Trauma and recovery. New York: Basic Books.

Hermans, D., \& de Houwer, J. (1994). Affective and subjective familiarity ratings of 740 Dutch words. Psychologica Belgica, 34, $115-139$.

Holmes, D. (1990). The evidence for repression: An examination of sixty years of research. In J. Singer (Ed.), Repression and dissociation: Implications for personality theory, psychopathology and health (pp. 85-102). Chicago: University of Chicago Press.

Holmes, E. A., Brewin, C. R., \& Hennessy, R. G. (2004). Trauma films, information processing, and intrusive memory development. Journal of Experimental Psychology: General, 133, 3-22.

Horne, R. L., Evans, F. J., \& Orne, M. T. (1982). Random number generation, psychopathology and therapeutic change. Archives of General Psychiatry, 39, 680-683.

Horowitz, M., Wilner, N., \& Alvarez, W. (1979). Impact of event scale: A measure of subjective stress. Psychosomatic Medicine, 41, 209-218.

Horselenberg, R. (2005). Pseudomemories and personality characteristics. Dissertation, Maastricht University, Maastricht.

Horselenberg, R., Merckelbach, H., Muris, P., Rassin, E., Sijsenaar, M., \& Spaan, V.(2000). Imagining fictitious childhood events: The role of individual differences in imagination inflation. Clinical Psychology and Psychotherapy, 7, 128-137.

Hyman, I. E. J., \& Billings, F. J. (1998). Individual differences and the creation of false childhood memories. Memory, 6, 1-20. Irwin, H. J. (2001). The relationship between dissociative tendencies and schizotypy: An artefact of childhood trauma? Journal of Clinical Psychology, 57, 331-342.

Jang, K. L., Paris, J., Zweig-Frank, H., \& Livesley, W. J. (1998). Twin study of dissociative experiences. Journal of Nervous and Mental Disease, 188, 26-30.

Jelicic, M., Geraerts, E., Merckelbach, H., \& Guerrieri, R. (2004). Acute stress enhances memory for emotional words, but impairs memory for neutral words. International Journal of Neuroscience, 114, 13431351 .

Jelicic, M., Hessels, A., \& Merckelbach, H. (2006). Detection of feigned psychosis with the structured inventory of malingered symptomatology (SIMS): A study of coached and uncoached simulators. Journal of Psychopathology and Behavioral Assessment, 28, 19-22. 
Jelicic, M., \& Merckelbach, H. (2004). Traumatic stress, brain changes, and memory deficits: A critical note. Journal of Nervous and Mental Disease, 192, 548-553.

Jelicic, M., Smeets, T., Peters, M., Candel, I., Horselenberg, R., \& Merckelbach, H. (in press). Assassination of a controversial politician: Remembering details from a non-existent film. Applied Cognitive Psychology.

Johnson, M. K., Hashtroudi, S., \& Lindsay, D. S. (1993). Source monitoring. Psychological Bulletin, 114, 3-28.

Jones, E., Vermaas, R. H., McCartney, H., Beech, C., Palmer, I., Hymans, K., \& Wessely, S. (2003). Flashbacks and post-traumatic stress disorder: The genesis of a 20th-century diagnosis. British Journal of Psychiatry, 182, 158-163.

Joseph, S. (2000). Psychometric evaluation of Horowitz's impact of event scale: A review. Journal of Traumatic Stress, 13, 101-113.

Joslyn, S., Loftus, E. F., McNoughton, A., \& Powers, J. (2001). Memory for memory. Memory \& Cognition, 29, 789-797.

Kardiner, A., \& Spiegel, H. (1941/1947). War, stress and neurotic illness (2nd ed.). New York: Hoeber.

Kaufmann, G., Drevland, G. C. B., Wessel, E., Overskeid, G., \& Magnussen, S. (2003). The importance of being earnest: Displayed emotions and witness credibility. Applied Cognitive Psychology, 17, 21-34.

Kendler, K. S., Kuhn, J. W., \& Prescott, C. A. (2004). Childhood sexual abuse, stressful life events and risk for major depression in women. Psychological Medicine, 34, 1475-1482.

Kihlstrom, J. F. (1996). The trauma-memory argument and recovered memory therapy. In K. Pezdek, \& W. P. Banks (Eds.), The recovered memory/false memory debate (pp. 297-311). San Diego: Academic Press.

Kihlstrom, J. F. (2002). No need for repression. Trends in Cognitive Sciences, 6, 502.

Kihlstrom, J. F. (2004). An unbalanced balancing act: Blocked, recovered, and false memories in the laboratory and clinic. Clinical Psychology: Science and Practice, 11, 34-41.

Kihlstrom, J. F. (in press). Trauma and memory revisited. In B. Uttl, N. Ohta, \& A. L. Siegenthaler (Eds.), Memory and emotions: Interdisciplinary perspectives. New York: Blackwell.

Kihlstrom, J. F., Glisky, M. L., \& Angiulo, M. J. (1994). Dissociative tendencies and dissociative disorders. Journal of Abnormal Psychology, 103, $117-124$.

Kihlstrom, J. F., \& Schacter, D. L. (2000). Functional amnesia. In F. Boller, \& J. Grafman (Eds.), Handbook of Neuropsychology, 2nd edition: Vol. 2 (pp. 409-427). Amsterdam: Elsevier Science.

Klotz Flitter, J. M., Elhai, J. D., \& Gold, S. N. (2003). MMPI-2 F Scale elevations in adult victims of child sexual abuse. Journal of Traumatic Stress, 16, 269-274.

Kozarić-Kovačić, D., Folnegovic-Smalc, V., \& Skrinjaric, J. (1993). Systematic raping of women in Croatia and Bosnia and Herzegovina: Preliminary psychiatric report. Croatian Medical Journal, 34, 86-87.

Kozarić-Kovačić, D., Folnegovic-Smalc, V., Skrinjaric, J., Szajnberg, M. N., \& Marusic, A. (1995). Rape, torture and traumatization of Bosnian and Croatian women: Psychological sequelae. American Journal of Orthopsychiatry, 65, 428-433.

Kozarić-Kovačić, D., Kocijan-Hercigonja, D., \& Jambrosic, A. (2001). Psychiatric help to psychotraumatized persons during and after the war in Croatia. Croatian Medical Journal, 43, 221-228.

Kuch, K., \& Cox, B. J. (1992). Symptoms of PTSD in 124 survivors of the Holocaust. American Journal of Psychiatry, 149, 337-340.

Kuyken, W., \& Brewin, C. R. (1995). Autobiographical memory functioning in depression and reports of early abuse. Journal of Abnormal Psychology, 104, 585-591.

Laney, C., \& Loftus, E. F. (2005). Traumatic memories are not necessarily accurate memories. Canadian Journal of Psychiatry, 50, 823-828.

Lauteslager, M., Schaap, T., \& Schievels, D. (1986). Schriftelijke woordassociatienormen voor 549 Nederlandse zelfstandige naamwoorden [Written word association norms for 549 Dutch words]. Lisse: Swets \& Zeitlinger. 
Lawrence, T., Edwards, C., Barraclough, N., Church, S., \& Hetherington, F. (1995). Modelling childhood causes of paranormal belief and experience: Childhood trauma and childhood fantasy. Personality and Individual Differences, 19, 209-215.

Lewis, J. L., Simcox, A. M., \& Berry, D. T. R. (2002). Screening for feigned psychiatric symptoms in a forensic sample by using the MMPI-2 and the structured inventory of malingered Symptomatology. Psychological Assessment, 14, 170-176.

Lief, H. I., \& Fetkewicz, J. (1995). Retractors of false memories: The evolution of pseudomemories. The Journal of Psychiatry and Law, 23, 411-436.

Lilienfeld, S. O., \& Loftus, E. F. (1998). Repressed memories and World War II: Some cautionary notes. Professional Psychology: Research \& Practice, 29, 471-475.

Lindsay, D. S. (1994). Contextualizing and clarifying criticisms of memory work in psychotherapy. Consciousness and Cognition, 3, 426-437.

Lindsay, D. S., \& Read, J. D. (1994). Psychotherapy and memories of childhood sexual abuse: A cognitive perspective. Applied Cognitive Psychology, 8, 281-338.

Lindsay, D. S., \& Read, J. D. (1995). "Memory work" and recovered memories of childhood sexual abuse: Scientific evidence and public, professional, and personal issues. Psychology, Public Policy, and Law, 1, 846-908.

Lindsay, D. S., \& Read, J. D. (2001). The recovered memories controversy: Where do we go from here? In G. M. Davies \& T. Dalgleish (Eds.), Recovered memories: Seeking the middle ground (pp. 71-93). Chichester, UK: John Wiley \& Sons.

Loftus, E. F. (1993). The reality of repressed memories. American Psychologist, 48, 51 8-537.

Loftus, E. F. (1997a). Repressed memory accusations: Devastated families and devastated patients. Applied Cognitive Psychology, $11,25-30$

Loftus, E. F. (1997b). Dispatch from the (un)civil memory wars. In J. D. Read, \& D.S. Lindsay (Eds.), Recollections of trauma: Scientific evidence and clinical practice (pp. 171-198). New York: Plenum.

Loftus, E. F. (2003). Make-believe memories. American Psychologist, 58, 867-873.

Loftus, E. F., Garry, M., \& Feldman, M. (1994). Forgetting sexual trauma: What does it mean when $38 \%$ forget? Journal of Consulting and Clinical Psychology, 62, $1177-1181$.

Loftus, E. F., Joslyn, S., \& Polage, D. (1998). Repression: A mistaken impression? Development and Psychopathology, 10, 781-792.

Loftus, E. F., \& Ketcham, K. (1994). The myth of repressed memory. New York: St. Martin's Press.

Loon van - Vervoorn, W. A., \& Bekkum van, I. J. (1991). Woordassociatie lexicon [Word association lexicon]. Lisse: Swets \& Zeitlinger.

Mack, J. E. (1994). Abduction: Human encounters with aliens (rev. ed.). New York: Ballantine.

Macklin, M. L., Metzger, L. J., Litz, B. T., McNally, R. J., Lasko, N. B., Orr, S. P., \& Pitman, R. K. (1998). Lower precombat intelligence is a risk factor for posttraumatic stress disorder. Journal of Consulting and Clinical Psychology, 66, 323-326.

Maechler, S. (2001). The Wilkomirski affair: A study in biographical truth. New York: Schocken Books.

Markowitz, L. J., \& Borton, J. L. (2002). Suppression of negative self-referent and neutral thoughts: A preliminary investigation. Behavioural and Cognitive Psychotherapy, 30, 271-277.

Mazzoni, G. A. L., Loftus, E. F., Seitz, A., \& Lynn, S. J. (1999). Changing beliefs and memories through dream interpretation. Applied Cognitive Psychology, 13, 125-144.

McNally, R. J. (2001). The cognitive psychology of repressed and recovered memories of childhood sexual abuse: Clinical implications. Psychiatric Annals, 31, 509-514.

McNally, R. J. (2003a). Remembering trauma. Cambridge, MA: Belknap Press/Harvard University Press.

McNally, R. J. (2003b). Recovering memories of trauma: A view from the laboratory. Current Directions in Psychological Science, 12, 32-35.

McNally, R. J. (2004). The science and folklore of traumatic amnesia. Clinical Psychology: Science and Practice, 11, 29-33. 
McNally, R. J. (2005a). Debunking myths about trauma and memory. Canadian Journal of Psychiatry, 50, 817-822.

McNally, R. J. (2005b). Troubles in traumatology. Canadian Journal of Psychiatry, 50, 815-816.

McNally, R. J., Clancy, S. A., \& Barrett, H. M. (2004a). Forgetting trauma? In D. Reisberg and P. Hertel (Eds.), Memory and Emotion (pp. 129-154). Oxford: Oxford University Press.

McNally, R. J., Clancy, S. A., Barrett, H. M., \& Parker, H. A. (2004b). Inhibiting retrieval of trauma cues in adults reporting histories of childhood sexual abuse. Cognition \& Emotion, 18, 479-493.

McNally, R. J., Clancy, S. A., Barrett, H. M., \& Parker, H. A. (2005). Reality monitoring in adults reporting repressed, recovered, or continuous memories of childhood sexual abuse. Journal of Abnormal Psychology, 114, 147-152.

McNally, R. J., Clancy, S. A., \& Schacter, D. L. (2001). Directed forgetting of trauma cues in adults reporting repressed or recovered memories of childhood sexual abuse. Journal of Abnormal Psychology, $110,151-156$.

McNally, R. J., Clancy, S. A., Schacter, D. L., \& Pitman, R. K. (2000a). Personality profiles, dissociation, and absorption in women reporting repressed, recovered, or continuous memories of childhood sexual abuse. Journal of Consulting and Clinical Psychology, 68, 1033-1037.

McNally, R. J., Clancy, S. A., Schacter, D. L., \& Pitman, R. K. (2000b). Cognitive processing of trauma cues in adults reporting repressed, recovered, or continuous memories of childhood sexual abuse. Journal of Abnormal Psychology, 109, 355-359.

McNally, R. J., Metzger, L. J., Lasko, N. B., Clancy, S. A., \& Pitman, R. K. (1998). Directed forgetting of trauma cues in adult survivors of childhood sexual abuse with and without post-traumatic stress disorder. Journal of Abnormal Psychology, 107, 596-601.

McNally, R. J., Perlman, C. A., Ristuccia, C. S., \& Clancy, S. A. (in press). Clinical characteristics of adults reporting repressed, recovered, or continuous memories of childhood sexual abuse. Journal of Consulting and Clinical Psychology.

McNally, R. J., \& Ricciardi, J. N. (1996). Suppression of negative and neutral thoughts. Behavioural and Cognitive Psychotherapy, 24, 17-25.

McNally, R. J., Ristuccia, C. S., \& Perlman, C. A. (2005). Forgetting trauma cues in adults reporting continuous or recovered memories of childhood sexual abuse. Psychological Science, 16, 336-340.

McNally, R. J., \& Shin, L. M. (1995). Association of intelligence with severity of posttraumatic stress disorder symptoms in Vietnam combat veterans. American Journal of Psychiatry, 152, 936-938.

Melchert, T. P. (1999). Relations among childhood memory, a history of abuse, dissociation, and repression. Journal of Interpersonal Violence, 14, $1172-1192$.

Melchert, T. P., \& Parker, R. L. (1997). Different forms of childhood abuse and memory. Child Abuse and Neglect, 21, 125-135.

Mendolia, M., Moore, J., \& Tesser, A. (1996). Dispositional and situational determinants of repression. Journal of Personality and Social Psychology, 70, 856-867.

Merckelbach, H. (2004). Telling a good story: Fantasy proneness and the quality of fabricated memories. Personality and Individual Differences, 37, 1371-1382.

Merckelbach, H., à Campo, J., Hardy, S., \& Giesbrecht, T. (2005). Dissociation and fantasy proneness in psychiatric patients: A preliminary study. Comprehensive Psychiatry, 46, 181-185.

Merckelbach, H., Dekkers, T., Wessel, I., \& Roefs, A. (2003a). Amnesia, flashbacks, nightmares, and dissociation in aging concentration camp survivors. Behaviour Research and Therapy, 41, 351360 .

Merckelbach, H., Dekkers, T., Wessel, I., \& Roefs, A. (2003b). Dissociative symptoms and amnesia in Dutch concentration camp survivors. Comprehensive Psychiatry, 44, 65-69.

Merckelbach, H., Horselenberg, R., \& Muris, P. (2001). The Creative Experiences Questionnaire (CEQ): A brief self-report measure of fantasy proneness. Personality and Individual Differences, 31, 987-996. 
Merckelbach, H., Horselenberg, R., \& Schmidt, H. (2002). Modeling the connection between self-reported trauma and dissociation in a student sample. Personality and Individual Differences, 32, 695-705.

Merckelbach, H., \& Jelicic, M. (2004). Dissociative symptoms are related to endorsement of vague trauma items. Comprehensive Psychiatry, 45, 70-75.

Merckelbach, H., \& Muris, P. (2001). The causal link between self-reported trauma and dissociation: A critical review. Behaviour Research and Therapy, 39, 245-254.

Merckelbach, H., Muris, P., van den Hout, M., \& de Jong, P. (1991). Rebound effects of thought suppression: Instruction-dependent? Behavioural Psychotherapy, 19, 225-238.

Merckelbach, H., Muris, P., \& Rassin, E. (1999). Fantasy proneness and cognitive failures as correlates of dissociative experiences. Personality and Individual Differences, 26, 961-967.

Merckelbach, H., Smeets, T., Geraerts, E., Jelicic, M., Bouwen, A., \& Smeets, E. (2006). I haven't thought about this for years! Dating recent recalls of vivid memories. Applied Cognitive Psychology, 20, 33-42.

Merckelbach, H., \& Smith, G. L. (2003). Diagnostic accuracy of the Structured Inventory of Malingered Symptomatology (SIMS) in detecting instructed malingering. Archives of Clinical Neuropsychology, $18,145-152$.

Morel, K. R. (1998). Development and preliminary validation of a forced-choice test of response bias for posttraumatic stress disorder. Journal of Personality Assessment, 70, 299-314.

Moulds, M. L., \& Bryant, R. A. (2002). Directed forgetting in acute stress disorder. Journal of Abnormal Psychology, $111,175-179$.

Myers, L. B. (2000a). Identifying repressors: A methodological issue for health psychology. Psychology and Health, 15, 205-214

Myers, L. B. (2000b). Deceiving others or deceiving themselves? The Psychologist, 13, 400-403.

Myers, L. B., \& Brewin, C. R. (1994). Recall of early experience and the repressive coping style. Journal of Abnormal Psychology, 103, 288-292.

Myers, L. B., Brewin, C. R., \& Power, M. J. (1992). Repression and autobiographical memory. In M. A. Conway, D. C. Rubin, H. Spinnler, \& W. Wagenaar (Eds.), Theoretical perspectives on autobiographical memory (pp. 375-390). Dordrecht, The Netherlands: Kluwer Academic Press.

Myers, L. B., Brewin, C. R., \& Power, M. J. (1998). Repressive coping and the directed forgetting of emotional material. Journal of Abnormal Psychology, 107, 141-148.

Myers, L. B., \& Derakshan, N. (2004a). To forget or not to forget: What repressors forget and when do they forget? Cognition \& Emotion, 18, 495-511.

Myers, L. B., \& Derakshan, N. (2004b). Do childhood memories colour social judgements of today? The case of repressors. European Journal of Personality, 18, 321-330.

Nadel, L., \& Jacobs, W. J. (1998). Traumatic memory is special. Current Directions in Psychological Science, 7, 154-156.

Neisser, U., \& Harsch, N. (1992) Phantom flashbulbs: False recollections of hearing the news about Challenger. In E. Winograd, \& U. Neisser (Eds.), Affect and consistency in recall: Studies of 'flashbulb' memories (pp. 9-31). Cambridge: Cambridge University Press.

Ornstein, P. A., Ceci, S. J., \& Loftus, E. F. (1998a). Comment on Alpert, Brown, and Courtois (1998): The science of memory and the practice of psychotherapy. Psychology, Public Policy, and Law, 4, 9961010 .

Ornstein, P. A., Ceci, S. J., \& Loftus, E. F. (1998b). Adult recollections of childhood abuse: Cognitive and developmental perspectives. Psychology, Public Policy, and Law, 4, 1025-1051.

Ornstein, P. A., Ceci, S. J., \& Loftus, E. F. (1998c). More on the repressed memory debate: A reply to Alpert, Brown, and Courtois (1998). Psychology, Public Policy, and Law, 4, 1068-1078.

Öst, J., Costall, A., \& Bull, R. (2001). False confessions and false memories: A model for understanding retractors' experiences. Journal of Forensic Psychiatry, 12, 549-579.

Öst, J., Costall, A., \& Bull, R. (2002). A perfect symmetry? A study of retractors' experiences of making and then repudiating claims of early sexual abuse. Psychology, Crime and Law, 8, 155-181. 
Padilla-Walker, L. M., \& Poole, D. A. (2002). Memory for previous recall: A comparison of free and cued recall. Applied Cognitive Psychology, 16, 515-524.

Palyo, S. A., \& Beck, J. G. (2005). Is the concept of repression useful for understanding chronic PTSD? Behaviour Research and Therapy, 43, 55-68.

Parks, T. E. (1999). On one aspect of the evidence for recovered memories. American Journal of Psychology, $112,365-370$.

Pendergrast, M. (1998). Response to Karon and Widener (1997). Professional Psychology: Research and Practice, 29, 479-481.

Pesta, B. J., Murphy, M. D., \& Sanders, R. E. (2001). Are emotionally charged lures immune to false memory? Journal of Experimental Psychology: Learning, Memory, and Cognition, 27, 328-338.

Peters, M. J. V., Horselenberg, R., Jelicic, M., \& Merckelbach, H. (in press). The false fame illusion in people with memories about a previous life. Consciousness and Cognition.

Peters, M. J. V., Jelicic, M., Haas, N., \& Merckelbach, H. (in press). Mild executive dysfunctions in undergraduates are related to recollecting words never presented. International Journal of Neuroscience.

Pezdek, K., \& Lam, S. (in press). What research paradigms have cognitive psychologists used to study "False memory", and what are the implications of these choices? Consciousness and Cognition.

Piaget, J. (1973). The affective unconscious and the cognitive conscious. Journal of the American Psychoanalytic Association, 21, 249-261.

Platt, R. D., Lacey, S. C., lobst, A. D., \& Finkelman, D. (1998). Absorption, dissociation, fantasy proneness as predictors of memory distortion in autobiographical and laboratory-generated memories. Applied Cognitive Psychology, 12, S77-S89.

Polusny, M. A., \& Follette, V. M. (1996). Remembering childhood sexual abuse: A national survey of psychologists' clinical practices, beliefs, and personal experiences. Research and Practice, 27, 4152.

Poole, D. A., Lindsay, D. S., Memon, A., \& Bull, R. (1995). Psychotherapy and the recovery of memories of childhood sexual abuse: U.S. and British practitioner's opinions, practices, and experiences. Journal of Consulting and Clinical Psychology, 63, 426-437.

Pope, H. G., Jr., Barry, S., Bodkin, A., \& Hudson, J. I. (2006). Tracking scientific interest in the dissociative disorders: A study of scientific publication output 1984-2003. Psychotherapy and Psychosomatics, 75, 19-24.

Pope, H. G., Jr., Oliva, P. S., \& Hudson, J. I. (1999). Repressed memories: The scientific status. In D. L. Faigman, D. H. Kaye, M. J. Saks, \& J. Sanders (Eds.), Modern scientific evidence: The law and science of expert testimony. vol. 1 (pp. 115-155). St. Paul: West Publishing.

Porter, S., \& Birt, A. R. (2001). Is traumatic memory special? A comparison of traumatic memory characteristics with memory for other emotional life experiences. Applied Cognitive Psychology, 15, S101-S117.

Porter, S., Birt, A. R., Yuille, J. C., \& Lehman, D. R. (2000). Negotiating false memories: Interviewer and rememberer characteristics relate to memory distortion. Psychological Science, 11, 507-510.

Proust, M. (1913). Du côté de chez Swann (Vol. 1). Paris : Bernard Grasset.

Proust, M. (1923). Swann's Way (Vol. 1). (C. K. S. Moncrieff, Trans.). New York: Henry Holt \& Co.

Rachman, S. J. (1994). The overprediction of fear. A review. Behaviour Research and Therapy, 32, 683-690.

Ramachandran, V. S. (1995). Anosognosia in parietal lobe syndrome. Consciousness and Cognition, 4, 2251 .

Ramachandran, V. S., \& Blakeslee, S. (1999). Phantoms in the brain. London: Fourth Estate.

Rassin, E., Merckelbach, H., \& Muris, P. (2002). Paradoxical and less paradoxical effects of thought suppression: A critical review. Clinical Psychology Review, 20, 973-995.

Rauschenberger, S. L., \& Lynn, S. J. (1995). Fantasy proneness, DSM-III-R axis I psychopathology, and dissociation. Journal of Abnormal Psychology, 104, 373-380. 
Read, J. D., \& Lindsay, D. S. (2000). Amnesia for summer camps and high school graduation: Memory work increases reports of prior periods of remembering less. Journal of Traumatic Stress, 13, 129-147.

Rind, B., Tromovitch, P., \& Bauserman, R. (1998). A meta-analytic examination of assumed properties of child sexual abuse using college samples. Psychological Bulletin, 124, 22-53.

Roediger, H. L. III, \& Bergman, E. T. (1998). The controversy over recovered memories. Psychology, Public Policy, and Law, 4, 1091-1109.

Roediger, H. L. III, \& McDermott, K. B. (1995). Creating false memories: Remembering words not presented in lists. Journal of Experimental Psychology: Learning, Memory, and Cognition, 21, 803-814.

Roediger, H. L. III, Watson, J. M., McDermott, K. B., \& Gallo, D.A. (2001). Factors that determine false recall: A multiple regression analysis. Psychonomic Bulletin \& Review, 8, 385-407.

Rogers, R., Hinds, J. D., \& Sewell, K. W. (1996). Feigning psychopathology among adolescent offenders: Validation of the SIRS, MMPI-A, and SIMS. Journal of Personality Assessment, 67, 244-257.

Rosen, G. M. (2004). Malingering and the PTSD data base. In G. M. Rosen (Ed.), Posttraumatic stress disorder: Issues and controversies (pp. 85-99). Chichester: John Wiley \& Sons.

Rosen, G. M. (in press). DSM's cautionary guideline to rule out malingering can protect the PTSD data base. Journal of Anxiety Disorders.

Rosen, V. M., \& Engle, R. W. (1998). Working memory and suppression. Journal of Memory and Language, 39, 418-436.

Rubin, D. C., Schrauf, R. W., \& Greenberg, D. L. (2004). Stability in autobiographical memories. Memory, 12, 715-721.

Sabor Republike Hrvatske [Parliament of the Republic of Croatia] (1997). Zakon o pravima hrvatskih branitelja iz Domovinskog rata i clanova njihovih obitelji [Law about the protection of Croatian war veterans and their families]. Zagreb: Narodne novine.

Schacter, D. L. (1995). Memory wars. Scientific American, 272, 135-139.

Schacter, D. L. (1996). Searching for memory: The brain, the mind, and the past. New York: Basic Books.

Schacter, D. L. (1999). The seven sins of memory: Insights from psychology and cognitive neuroscience. American Psychologist, 54, 182-203.

Schelach, L., \& Nachson, I. (2001). Memory of Auschwitz survivors. Applied Cognitive Psychology, 15, 119 132.

Schooler, J. W. (1994). Seeking the core: The issues and evidence surrounding recovered accounts of sexual trauma. Consciousness and Cognition, 3, 452-469.

Schooler, J. W. (1999). Seeking the core: The issues and evidence surrounding recovered accounts of sexual trauma. In L. M. Williams (Ed.), Trauma and memory (pp. 203-216). Thousand Oaks, CA: Sage Publications.

Schooler, J. W. (2001). Discovering memories of abuse in the light of meta-awareness. In J. J. Freyd \& A. P. DePrince (Eds.), Trauma and cognitive science: $A$ meeting of minds, science, and human experience (pp. 105-136). New York: Haworth.

Schooler, J. W., Ambadar, Z., \& Bendiksen, M. A. (1997a). A cognitive corroborative case study approach for investigating discovered memories of sexual abuse. In J. D. Read, \& D. S. Lindsay (Eds.), Recollections of trauma: Scientific research and clinical practices (pp. 379-388). New York: Plenum.

Schooler, J. W., Bendiksen, M. A., \& Ambadar, Z. (1997b). Taking the middle line: Can we accommodate both fabricated and recovered memories of sexual abuse? In M. Conway (Ed.), False and recovered memories (pp. 251-292). Oxford: Oxford University Press.

Schwarz, N., Park, D. C., Knäuper, B., \& Sudman, S. (1998). Cognition, aging, and self-reports. Hove, UK: Psychology Press.

Scott, S. (2001). The politics and experience of ritual abuse: Beyond disbelief. Buckingham, UK: Open University Press.

Searle, J. (1992). The rediscovery of the mind. Cambridge, MA: MIT Press. 
Shobe, K. K., \& Kihlstrom, J. F. (1997). Is traumatic memory special? Current Directions in Psychological Science, 6, 70-74.

Shobe, K. K., \& Schooler, J. W. (2001). Discovering fact and fiction: Case-based analyses of authentic and fabricated memories of abuse. In G. M. Davies \& T. Dalgleish (Eds.), Recovered memories: Seeking the middle ground (pp. 95-151). Chichester: John Wiley \& Sons.

Smeets, T., Jelicic, M., Peters, M., Candel, I., Horselenberg, R., \& Merckelbach, H. (in press). "Of course I remember seeing that film" - How ambiguous questions generate crashing memories. Applied Cognitive Psychology.

Smeets, T., Merckelbach, H., Horselenberg, R., \& Jelicic, M. (2005). Trying to recollect past events: Confidence, beliefs, and memories. Clinical Psychology Review, 25, 917-934.

Smith, G. P. (1997). Assessment of malingering with self-report instruments. In R. Rogers (Ed.), Clinical assessment of malingering and deception (pp. 351-370). New York: Guilford.

Smith, G. P., \& Burger, G. K. (1997). Detection of malingering: Validation of the Structured Inventory of Malingered Symptomatology (SIMS). Journal of the Academy of Psychiatry and Law, 25, 183-189.

Sobel, M. E. (1982). Asymptotic evidence intervals for indirect effect in structural equation models. In S. Leinhart (Ed.), Sociological models (pp. 290-312). San Francisco: Jossey-Bass.

Sparr, L. F., \& Bremner, J. D. (2005). Post-traumatic stress disorder and memory: Prescient medicolegal testimony at the international war crimes tribunal? Journal of the American Academy of Psychiatry and Law, 33, 71-78.

Spielberger, C., Gorsuch, R., Lushene, R., Vagg, P., \& Jacobs, G. (1983). Manual for the state-trait anxiety inventory. Palo Alto, CA: Consulting Psychologists Press.

Talarico, J. M., \& Rubin, D. C. (2003). Confidence, not consistency, characterizes flashbulb memories. Psychological Science, 14, 455-461.

Taub, S. (1996). The legal treatment of recovered memories of child sexual abuse. Journal of Legal Medicine, $17,183-214$.

Taylor, J. A. (1953). A personality scale of manifest anxiety. Journal of Abnormal and Social Psychology, 48 , $285-290$.

Terr, L. C. (1983). Chowchilla revisited: The effects of psychic trauma four years after a school-bus kidnapping. American Journal of Psychiatry, 140, 1543-1550.

Terr, L. C. (1994). Unchained memories: True stories of traumatic memories, lost and found. New York: Basic Books.

Thompson, J., Morton, J., \& Fraser, L. (1997). Memories for the Marchioness. Memory, 5, 61 5-638.

Tomarken, A. J., \& Keener, A. D. (1998). Frontal brain asymmetry and depression: A self-regulatory perspective. Cognition \& Emotion, 12, 387-420.

van der Kolk, B. A. (1994). The body keeps the score: Memory and the evolving psychobiology of posttraumatic stress. Harvard Review of Psychiatry, 1, 253-265.

van der Kolk, B. A. (1996). Trauma and memory. In B. A. van der Kolk, A. C. McFarlane, \& L. Weisaeth (Eds.), Traumatic stress: The effects of overwhelming experience on mind, body, and society (pp. 279302). New York: Guilford.

van der Kolk, B. A. (1997). The psychobiology of posttraumatic stress disorder. Journal of Clinical Psychiatry, 58, 16-24.

van der Kolk, B. A., \& Fisler, R. (1995). Dissociation and the fragmentary nature of traumatic memories: Overview and exploratory study. Journal of Traumatic Stress, 8, 505-525.

Van IJzendoorn, M. H., \& Schuengel, C. (1996). The measurement of dissociation in normal and clinical populations: Meta-analytic validation of the Dissociative Experience Scale (DES). Clinical Psychology Review, 16, 365-382.

VanOyen Witvliet, C. (1997). Traumatic intrusive imagery as an emotional memory phenomenon: A review of research and explanatory information processing theories. Clinical Psychology Review, 17, 509536 . 
Vrij, A., \& Fisher, A. (1997). The role of displays of emotions and ethnicity in judgements of rape victims. International Review of Victimology, 4, 255-265.

Wade, K., Garry, M., Read, J. D., \& Lindsay, D. S. (2002). A picture is worth a thousand lies. Using false photographs to create false childhood memories. Psychonomic Bulletin and Review, 9, 597-603.

Wagenaar, W. A., \& Crombag, H. (2005). The popular policeman and other cases. Amsterdam: Amsterdam University Press.

Wagenaar, W. A., \& Groeneweg, J. (1990). The memory of concentration camp survivors. Applied Cognitive Psychology, 4, 77-87.

Wechsler, D. (1997). Administration and scoring manual for the Wechsler Adult Intelligence Scale (3rd ed.). San Antonio, TX: The Psychological Corporation.

Wegner, D. M. (1994). Ironic processes of mental control. Psychological Review, 101, 34-52.

Wegner, D. M., Schneider, D. J., Carter, S. R. III, \& White, T. L. (1987). Paradoxical effects of thought suppression. Journal of Personality and Social Psychology, 53, 5-13.

Weinberger, D. A. (1990). The construct validity of the repressive coping style. In J. Singer (Ed.), Repression and dissociation: Implications for personality theory, psychopathology and health (pp. 405-434). Chicago: University of Chicago Press.

Weinberger, D. A., Schwartz, G. E., \& Davidson, R. J. (1979). Low-anxious, high-anxious, and repressive coping styles: Psychometric patterns and behavioral and physiological responses to stress. Journal of Abnormal Psychology, 88, 369-380.

Wessel, I. (1997). Attentional narrowing as a model for partial amnesia. Dissertation, Maastricht University, Maastricht.

Wessel, I., \& Merckelbach, H. (2006). Forgetting "murder" is harder than forgetting "circle": List-wise directed forgetting of emotional words. Cognition and Emotion, 20, 129-137.

Wessel, I., Merckelbach, H., \& Dekkers, T. (2002). Autobiographical memory specificity, intrusive memory, and general memory skills in Dutch-Indonesian survivors of the World War II era. Journal of Traumatic Stress, 15, 227-234.

Widows, M. R., \& Smith, G. P. (2005). Professional manual: Structured inventory of malingered symptomatology. Lutz: Psychological Assessment Resources.

Wilkomirski, B. (1996). Fragments. London: Picador.

Williams, L. M. (1994). Recall of childhood trauma: A prospective study of women's memories of child sexual abuse. Journal of Consulting and Clinical Psychology, 62, 1167-1176.

Wilson, S. C., \& Barber, T. X. (1983). Fantasy-prone personality: Implications for understanding imagery, hypnosis, and parapsychological phenomena. In A. A. Sheikh (Ed.), Imagery: Current theory, research, and application (pp. 340-387). New York: Wiley.

Winograd, E., Peluso, J. P., \& Glover, T. A. (1998). Individual differences in susceptibility to memory illusions. Applied Cognitive Psychology, 12, S5- S27.

Wright, D. B., \& Osborne, J. E. (2005). Dissociation, cognitive failures, and working memory. American Journal of Psychology, 118, 103-113.

Yehuda, R., Elkin, A., Binder-Brynes, K., Kahana, B., Southwick, S. M., Schmeidler, J., \& Giller, E. L. (1996). Dissociation in aging Holocaust survivors. American Journal of Psychiatry, 153, 935-940.

Yuille, J. C., \& Cutshall, J. L. (1986). A case study of eyewitness memory of a crime. Journal of Applied Psychology, 71, 291-301.

Zoellner, L. A., \& Bittenger, J. N. (2004). On the uniqueness of trauma memories in PTSD. In G. M. Rosen (Ed.), Posttraumatic stress disorder: Issues and controversies (pp. 147-162). New York: John Wiley \& Sons.

Zoellner, L. A., Foa, E. B., Brigidi, B. D., \& Przeworski, A. (2000). Are trauma victims susceptible to false memories? Journal of Abnormal Psychology, 109, 517-524. 



\section{AUTHOR AFFILIATIONS}

Michelle M. Arnold

Department of Psychology, University of Southampton, United Kingdom

Ingrid Candel

Department of Experimental Psychology, Maastricht University, The Netherlands

Petra Habets

Department of Psychiatry and Neuropsychology, Maastricht University, The Netherlands

Beatrijs Hauer

Department of Experimental Psychology, Maastricht University, The Netherlands

Jaap van Heerden

Department of Neurocognition, Maastricht University, The Netherlands

Marko Jelicic

Department of Experimental Psychology, Maastricht University, The Netherlands

Dragica Kozarić-Kovačić

Department of Psychiatry, National Center for Psychotrauma, Dubrava University Hospital, Zagreb, Croatia

D. Stephen Lindsay

Department of Psychology, University of Victoria, Canada

Harald Merckelbach

Department of Experimental Psychology, Maastricht University, The Netherlands 


\section{AUTHOR AFFILIATIONS}

\section{Tina Peraica}

Department of Psychiatry, National Center for Psychotrauma, Dubrava University Hospital, Zagreb, Croatia

Jonathan Schooler

Department of Psychology, University of British Colombia, Canada

Elke Smeets

Department of Experimental Psychology, Maastricht University, The Netherlands 


\section{CURRICULUM VITAE}

Elke Geraerts was born on 13 January, 1982, in Bilzen, Belgium. In June 2000 she graduated from secondary school (Heilig-Hart College, Lanaken). In September of that year, she started studying Psychology at Maastricht University. During this time she also worked as a teaching assistant and she chaired the student council of the faculty. In December 2003 she graduated with a specialization in Biological Psychology (cum laude). In January 2004 she started working as a PhD student at the Faculty of Psychology, Maastricht University. From February 2006, she is a PostDoc at the Department of Experimental Psychology, Maastricht University. In 2006 and 2007, she is also a Postdoctoral Fellow at Harvard University. 



\section{LIST OF PUBLICATIONS}

\section{PAPERS IN PRESS}

Geraerts, E., Arnold, M. M., Lindsay, D. S., Merckelbach, H., Jelicic, M., \& Hauer, B. (in press). Forgetting of prior remembering in people reporting recovered memories of childhood sexual abuse. Psychological Science.

Geraerts, E., Jelicic, M., \& Merckelbach, H. (in press). Symptom overreporting and recovered memories of childhood sexual abuse. Law and Human Behavior.

Geraerts, E., Kozarić-Kovačić, D., Merckelbach, H., Peraica, T., Jelicic, M., \& Candel, I. (in press). Traumatic memories in war veterans: Not so special after all. Consciousness and Cognition.

Geraerts, E., Merckelbach, H., Jelicic, M., \& Habets, P. (in press). Suppression of intrusive thoughts and working memory capacity in repressive coping. American Journal of Psychology.

Geraerts, E., Merckelbach, H., Jelicic, M., \& Smeets, E. (in press). Long term consequences of suppression of intrusive thoughts and repressive coping. Behaviour Research and Therapy.

Geraerts, E., Smeets, E., Jelicic, M., Merckelbach, H., \& van Heerden, J. (in press). Retrieval inhibition of trauma-related words in women reporting repressed or recovered memories of childhood sexual abuse. Behaviour Research and Therapy.

Jelicic, M., Merckelbach, H., Candel, I., \& Geraerts, E. (in press). Detection of feigned cognitive dysfunction using special malinger tests: A simulation study in naïve and coached malingerers. International Journal of Neuroscience.

\section{6}

Geraerts, E., Merckelbach, H., Jelicic, M., Smeets, E., \& van Heerden, J. (2006). Dissociative symptoms and how they relate to fantasy proneness in 


\section{LIST OF PUBLICATIONS}

women reporting repressed or recovered memories. Personality and Individual Differences, 40, 1143-1151.

Merckelbach, H., Smeets, T., Geraerts, E., Jelicic, M., Bouwen, A., \& Smeets, E. (2006). I haven't thought about this for years! Dating recent recalls of vivid memories. Applied Cognitive Psychology, 20, 33-42.

\section{5}

Geraerts, E., Smeets, E., Jelicic, M., van Heerden, J., \& Merckelbach, H. (2005). Fantasy proneness, but not self-reported trauma is related to DRM performance of women reporting recovered memories of childhood sexual abuse. Consciousness and Cognition, 14, 602-612.

\section{4}

Blokland A., Geraerts, E., \& Been, M. (2004). A detailed analysis of rat's spatial memory in a probe trial of a Morris task. Behavioural Brain Research, 154, 71-75.

Giesbrecht, T., Merckelbach, H., Geraerts, E., \& Smeets, E. (2004). Disruptions in executive functioning and dissociation in undergraduate students. Journal of Nervous and Mental Disease, 8, 567-569.

Jelicic, M., Geraerts, E., Merckelbach, H., \& Guerrieri, R. (2004). Acute stress enhances memory for emotional words, but impairs memory for neutral words. International Journal of Neuroscience, 1 14, 1343-1351.

\section{PAPERS SUBMITTED FOR PUBLICATION}

Geraerts, E., Elbers, N., \&. van Heerden, J. (accepted pending revision). Hallucinating consistency.

Geraerts, J., Kozarić-Kovačić, D., Merckelbach, H., Peraica, T., Jelicic, M., \& Candel, I. (2006). Assessing malingering in war veterans with warrelated posttraumatic stress disorder. Manuscript submitted for publication.

Geraerts, E., Schooler, J., Merckelbach, H., \& Jelicic, M. (2006). A corroborative investigation of continuous and discontinuous memories of childhood sexual abuse. Manuscript submitted for publication.

Giesbrecht, T., Geraerts, E., \& Merckelbach, H. (accepted pending revision). Dissociation, memory commission errors, and heightened autonomic reactivity. 
Hauer, B. J. A., Wessel, I., Geraerts, E., Merckelbach, H., \& Dalgleish, T. (2006). Autobiographical memory specificity in adults reporting childhood sexual abuse. Manuscript submitted for publication.

Smeets, T., Geraerts, E., Jelicic, M., Nicolson, N., \& Merckelbach, H. (2006). The awakening rise and diurnal pattern of cortisol and delayed recall of childhood sexual abuse memories. Manuscript submitted for publication.

\section{CHAPTERS}

Geraerts, E., \& Brennen, T. (2006). Investigating cognitive abnormalities in posttraumatic stress disorder. In M. Roy (Ed.), Novel approaches to the diagnosis and treatment of posttraumatic stress disorder (pp. 31 - 40). Amsterdam: IOS Press (NATO Science Series).

\section{NATIONAL JOURNALS}

Geraerts, E., \& van Heerden, J. (2004). Verdringing: Een kritische kijk op de visie van Ramachandran [Repression: A critical view on Ramachandran's vision]. Nederlands Tijdschrift voor de Psychologie [Dutch Journal of Psychology], 59,115-118.

Geraerts, E., Jelicic, M., Merckelbach, H., \& Guerrieri, R. (2004). Het effect van acute stress op neutraal en emotioneel geheugen [The effect of acute stress on neutral and emotional memory]. Neuropraxis, 8, 54-59. 